\title{
DISCLAIMER
}

This report was prepared as

Government. Neither the United Stales Government not any agencycy of the Unitod States bility for the accuracy, carrity, express or implied, or assumes any thereof, nor any of theit process disclosed, or representeteness, or usefulness of any information appiability or responsience herein to any specific comts that its use would nol infringe prion, apparatus, product, or manufacturer, of othecilic commercial product, process, or servivately owned rights. Refermendation, or favoring by does not necesearily constitute or imply irade name, tradematk. and opinions of United States Govetnment or any agency thereor necessarily state or teflect those of the

\section{Analyses in Support of \\ the Laboratory Microfusion Facility \\ and ICF Commercial Reactor Designs}

\author{
Final Report
}

Subcontract No. 2208703

Wayne R. Meier and Michael J. Monsler

W. J. Schafer Associates, Inc.

December 28, 1988 


\section{CONTENTS}

Overview

Laboratory Microfusion Facility (LMF) Studies

A. Carbon-Carpet First Wall for the LMF 6

Neutronic Analysis of the LMF 14

Effects of Target $\rho R$ on Neutron Activation 21

Neutron Heating in Materials Close to the Target 25

An Experiment to Test the Carbon Carpet First Wall Concept 32

Gas Protection from Tar:el Shrapnel 36

Gas Protection Against Debris Ions 39

Gas-Breakdown Limit on Gas Protection to First Walls 41

Concepts for the Final Optical System of the LMF 44

Conclusions and Bibliography for Optics Protection Work 72

The Analytic Hierarchy Process for Decision: Making 75

A Carbon-Fiber Brush-Like First Wall for the LMF 94

Commercial ICF Reactor Studies

New Heavy-Ion-Beam Target Gain Curves for the SAFIRE Code 109

Parametric Economic Studies for HYLIFE:

Implications for a New' Molten Salt Reactor $\quad 119$

Review of HYLIFE Fluid Dynamics 137

Preliminary Neutronics Considerations for HYLIFE-II 


\section{OVERVIEW}

Our work on this contract was divided into two major calegories; two thirds of the total effort was in support of the Laboratory Microfusion Facility (LMF), and one third of the effort was in support of Inertial Confinement Fusion (ICF) commercial reactors. This final seport includes copies of the formal reports, memoranda, and viewgraph presentations that were completed under this contract. The contents are summarized below beginning with the LMF work.

\section{LMF STUDIES:}

\section{A Carbon-Carpet First Wall for the LMF}

This is our final report on the first wall concept we invented for the LMF. We describe a passive, room-temperature first wall that conceptually solves the problem of survival under intense $x$-ray and ion loadings from ICF targets. The carbon-carpet first wall concept uses a clever configuration to overcome the limitations of maierial properties, and to reduce the mass loss per shot and the impulse delivered to the wall by more than an order of magnitude. The configuration provides an enormous surface area, within a small ( 3 in radius) chamber, for absorbing the $x$-rays and condensing the vapor generated by ablation. It does this in a way that minimizes the amount of ejected vapor, and thus, the net reaction force transmitted to the wall. The carbon that is vaporized protects the carpet from ionic target debris. Dverall, we conclude that the carbon carpet first wal] is an attractive option for the LMF. Further work on the chamber configuration, including the design of the neutron shield and the vacuum vessel wall, is needed.

\section{Neutronics Analysis of the LMF}

This paper, which was written for the Eighth Topical Meeting On the Technology of Fusion Energy, discusses a variety of neutronic and safety issues that have been addressed by the neutronics study group of the LMF design team. The main focus is on activarion analyses and the resulting radiological hazards in and around the target chamber. Sodium-24, which is produced by high energy neutron reactions with $\mathrm{Al}$, is a primary contributor to the radiation hazard for chambers with Al first walls. 


\section{Effects of Target $p R$ on Neutron Activation}

This memo reports the results of neutronics studies on the effects of the target $\rho R$ on neutron activation of the first wall. For a constant yield, the production of activation products that are a major concern decreases with increasing target $\rho R$. However, when we consider the anticipated increase in neutron yield with increasing $\rho R$, we find that the net effect is an increase in activation with increasing $p R$.

\section{Neutron Heating in Materials Close to the Target}

This memo reports the results of neutronic calculations to determine the neutron heating of materials that are placed very close to a high yield target. We examined carbon, silicon, copper, iron, and aluminum. The calculated minimum inner radius to avojd melting, just due to neutron heating, ranges from $13 \mathrm{~cm}$ for $\mathrm{SiC}$ to $21 \mathrm{~cm}$ for Al,

\section{An Experiment to Test the Carbon Carpet First Wall Concept}

This memo provides our initial thinking an experiment to test the carbon carpet first wall concepts. The primary questions that such an experiment should address are 1) does the carbon carpet reduce the impulse and pressure transmitted to the support structure, and 2) is the damage rate to the carbon filaments and fibers acreplably low?

\section{Gas Protection from Target Shrapnel}

This memo addresses the question of whether the gas that is used to protect the final optics from $x$-rays and ions can also protect the optics from the shrapnel that may be generated from targets and diagnostics in high yield experiments. Simple drag calculations indicate that the gas will be effective only for particle sizes less than $6.5 \mu \mathrm{m}$ in diameter. Since some larger particles are expected, a solid debris shield is recommended.

\section{Gas Protection Against Debris Ions}

This memo develops an equation for determining the amount of gas needed to stop energetic target ions. The stopping power equation is scaled for data on the ranges of various ions in air and is given as a function of the mass number of the stopping gas, the 
ion energy, and the mass number of the ion. As an example, we calculate that 4.2 tormeters of argon is required to stop $200 \mathrm{keV}$ gold ions.

\section{Gas-Breakdown Limit on Gas Protection to First Walls}

This memo addresses the question of whether or not the first wall could be protect by filling the chamber with gas while avoiding laser-induced breakdown near the target. We conclude this is not a viable first wall protection scheme.

\section{Concepts for the Final Optical System of the LMF}

This viewgraph presentation to the LMF design team describes our ideas on the final optical system for the LMF. It provides and overview of the problems that must be addressed in the design of the final optical system, including protection from $x$-ray and debris damage and concems about activation and maintenance. Several alternative design approaches and options are discussed.

\section{Conclusions and Bibliography for the Optics Protection Work}

Major conclusions from the optics protection work and a bibliography are given in this section.

\section{The Analytic Hierarchy Process for Decision Making}

This is a copy of a presentation made to the LMF study group on the A.HP for decision making. The AHP provide a systematic approach to choosing between several alternatives when the relative comparisons are not necessarily quantitative. The process could be used to help choose between several LMF first wall concepts.

\section{A Carbon-Fiber Brush-Like First Wall for the LMF}

This is the presentation that was given at the Eighth Topical Meeting on the Technology of Fusion Energy at Salt Lake City. The presentation summarized the complete paper which was written for the meeting (see above). 


\section{COMMERCIAL ICF REACTOR STUDIES:}

\section{New Heavy-Ion-Beam Target Gain Curves for the SAFIRE Code}

Algorithms for heavy-ion-beam target gain curves developed iy LLNL were incorporated in the SAFIRE code, which is used for ICF economic studies. This repor documents the modifications to the code, instructs users on how 10 use the new gain curves, and provides an example to compare with previously reported results.

\section{Parametric Economic Studies for HYLIFE:}

\section{Implications for a New Molten Salt Reactor}

One of the primary objectives of the HYLIFE-II reactor design study is to develop a concept that is more attractive than HYLIFE from an economic perspective. As a point of comparison, economic studies were carried out for the HYLIFE reactor to investigate the effects of various system parameters and design variables on the estimated cost of electricity. The implications for HYLIFE-II are discussed. For HYLIFE-II $t o$ be significantly less expensive than HYLIFE, the FLiBe hardware (pumps, pipes, heat exchangers, etc.) has to be much less expensive, and/or the total flow rate must be much smaller, and/or the intermediate loop must be very cheap or eliminated. A chamber pulse rate of a few $\mathrm{Hz}$ should be adequate. Lower driver costs and higher target gains would benefit HYLIFE as well as HYLIFE-II.

\section{Review of HYLIFE Fluid Dynamics}

This is a viewgraph presentation that was prepared for the ICF reactor studies groun. We are investigating the possibility of modifying the HYLIFE reactor to use molten salt instead of lithium as the blanket material and primary coolant. This presentation provides an overview of the fluid dynamics of HYLIFE.

\section{Preliminary Neutronics Considerations for HYLIFE-II}

This presentation reported the results of neutronics calculations done for the molten salt version of HYLIFE, tentatively known as HYLIFE-II. We calculated the thickness of FLiBe required to provide adequate tritium treeding and neutron damage protection for the first structural wall. We found that about $50 \mathrm{~cm}$ of FLiBe is need to get a tritium 
breeding ratio greater than one if all the breeding is done in the inner blanket. Only $30 \mathrm{~cm}$ of $\mathrm{FiBe}$ is needed to reduce the displacement damage rate to and acceptable level for a 30 year wall life. The blanket thickness could be reduced to $40 \mathrm{~cm}$ if FLiBe is added to the reflector region for added tritum breeding. 


\title{
A CARBON+CARPET FIRST WALL FOR THE
}

\section{LABORATORY MICROFUSION FACILITY}

\author{
M. J. Monsler and W. R. Meier \\ W. J. Schafer Associares, Inc. \\ 6140 Stoneridge Mall Rd. \\ Pieassinton, CA 94566 \\ 415-463-1108
}

\begin{abstract}
A first wall concept for the Latoratory Microfusion Facility (LMF) that uses carbon fibers in a brish- or carper-like configuration is described. This material and geometric configuration provide an extrencly effective way of absorbiog the intense burst of soft $\mathrm{x}$ tay radiation from the fusion energy pulse without damaging the underlying smocurt. The 2-cm-long carboa fibers are pointed at the target so that the $x$ rays illuminate the sides of the fibers at a glancing angle. We describe how the carpet-like configuration reduces the impulse due to the blow-off of material vaporized by the x-yays. Resulting stresses in the suppont structure ane low enough for the chamber radius to be brought in to $3 \mathrm{~m}$, which is much smaller than a chamber with an unprotected first wall. We conclude that this is a viable and attracbive concept for the LMF first wall.
\end{abstract}

\section{INTRODUCTION}

The ICF Laboratory Microfusion Facility (LMF) will be used to develop high gain targets, explore weapons physics, and conduct experiments relevant to the military and energy applications of ICF!' W.J. Schafer Associates is assisting the Laser Program at Lawrence Livenmore National Laboratory (LINL) in the design of the experimental chamber for the LMF.

Of all the products of the fusion microexplosion the $x$-rays are the most difficult to handle. To design a chamber with an inner radius of approximately $s$ meters the first wall must withstand a fluence of 50 $100 \mathrm{~J} / \mathrm{cm}^{2}\left(12-24 \mathrm{cal} / \mathrm{cm}^{2}\right)$ and ineensities up to $10^{10} \mathrm{~W} / \mathrm{cm}^{2}$ of $\mathrm{x}$-rays. At such high intensities, even the best carbon-carbon or ceramic tiles would fail due to the enormous stress wayes that are driven into the material in reaction to the fast vaporization during the 10 ns pulse of $x$-rays. To survive, a tile wall would have to stand back $15-20 \mathrm{~m}$. In order to build a smaller chamber, the first structural wall must be protected in some way.
Other groups propose to solve this problem by one of two ways. Firsh, one can employ a sacrificial inner layer of posous material on the first wall, which is isefficient at generating and transmitting $x$-ray driven shocks. Spraying a porous teflon coating on the wall, or refrigerating the wall to $-200^{\circ} \mathrm{C}$ and coating it with a layer of water frost, are two ideas proposed. ${ }^{2}$ These schemes require the active establishment of a new inner wall layer on every shot by spraying or tefrigeration.

The second strategy is to sumound the target with a sacrificial $x$-ray shield, which explodes and convers $x$-ray energy intc particulate kinetic energy, ${ }^{3}$ ICF proponents bave long pointed out that one of the beaucies of ICF was that you can get $1000 \mathrm{MJ}$ out per shot, with only the blast of a chenry bomb. It is very unlike the blast of its energy equivalem, a quartet-ton of TNT. To solve the $x$-ray problem then by increasing the blast seems to remove this advantage. Access to the cryogenic target by 50 to 100 final optics and tens of diagnostics would be needlessly restricted by an $x$-ray shroud. In addition, the optics and diagnostics would unnecessarily be subjected to the blast loading.

In contrast to the above approaches, we sought a passive, room temperature first wall that didn't require active maintenance, didn't have blast effects like a chemical explosion, and didn't restrict target mounting, alignment, diagnostics or illumination. We propose using carbon fibers in a brush- or carpet-like configuration, called the Carbon Carpet Furst Wall (CCFW), as a solution to the first wall problem. In this paper, we describe the CCFW concept and how it works to reduce both the peak suesses in materials and the impulse on the underlying support structure. Our passive, room temperature CCFW successfully dẹals with the $x$-rays and ions and allows the chamber radius to be reduced to $3 \mathrm{~m}$. 


\section{CARBON.CARPET FIRST WALL DESIGN}

The CCFW sufface is illustraled in Fig. 1. The approximately 2-cni-long carbon fibers are oriented radially so that the $x$-rays illuminate the sides of the fibers at a glancing (80 to $90^{\circ}$ from nomal) angle. With this confjguration, the surface area over which the $x$-rays deposit their energy is increased by more than a factor of 15 compared to a solid at the same radius. This scheme also creates an effective $x$-ray absorption zone of $2 \mathrm{~cm}$ rather than $2 \mu \mathrm{m}$. The surface area available for condensing the vaporized carbon is increased by a tactor of 40 or more. In one configuration that we are examining, the cotal condensing surface area is over $6000 \mathrm{~m}^{2}$, larger than the area of a foolball field. Each fiber making up the carbon carpel is $0.6 \mathrm{~mm}$ in diameter, and is in turm made up of 12,000 5- $\mu \mathrm{m}$ diameter filamenis. The fibers are flexible and resilient, not britle. The CCFW material is brush-like in that the fibers must be stift enough to maintain their radial orientation and open enough in allow the $x$-rays to irradiate the sides of the fibers. On the other hand. it is carpet-like in that the liber packing density is grcat enough that the suppor plate is not inadiated by the $x$-rays. We think the rigbt construction is somewhere between a siff, deep-pile carpet and a soft-bristle, dense-packed brush.

The carbon carpet type of material we propose for the first wall surface has in fact already beeo manufacnured. It is made the same way as commercial bousebold carpet, with muldi-filament carbon fibers feeding the loom. For our application a carbon cloth backing is probably the besl choice. We envision that the carton carpet would be attached to panels of aluminum plate or perhaps a Kevlar composite armor plate. We are investigating various arrangements of carbon-carpet coated amos plates within the chamber to protect against $x$-rays, ions and even quite energetic shrapoch One possibility is to consiruct an aluminum suppon frame in the shape of an icosahedron (20-sided polybedmo) with the triangular faces being $4 \mathrm{~m}$ on eact edge. Each face could then be subdivided into 16 equilateral triangles that are $1 \mathrm{~m}$ on a side. The inser radius to the closest point would be $3 \mathrm{~m}$. As shown later, this is an acceptable radius from the viewpoint of stresses that musi be handled by a carpet suppon plate. The total flat-plate surface area of this geomerric configuration is about $140 \mathrm{~m}^{2}$, and as previously stated, the lotal carbon fiber surface area is over $6000 \mathrm{~m}^{2}$.

The remainder of this paper is concemed with the analysis of the response of the carbon-cirpet surface to the $x$-ray energy deposition. Other aspects of a complete chamber design, such as mounting the CCFW panels, design of the neuton shield, vacuum pumping and vacuum vessel design, etc., and analyses

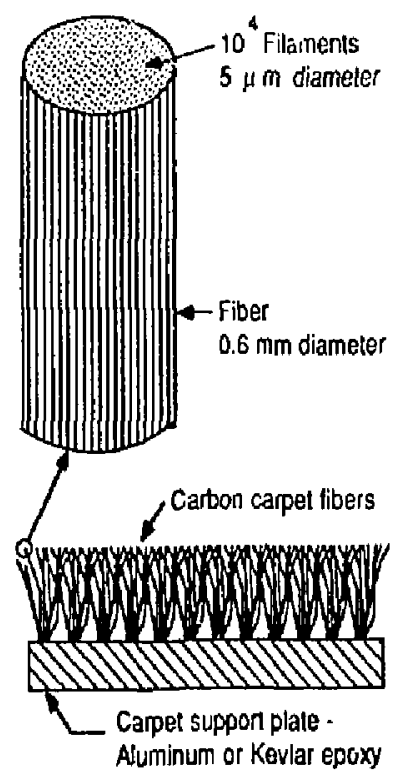

Fig. 1 The carbon-carpet first wall is made carbon fibers, woven into a carpeh, and cut to a length of $2 \mathrm{~cm}$. Each fiber consists of 12,000 5- $\mu \mathrm{m}$-diameter filaments. The fiber are grouped in tufts giving an overall packing faction of $32 \%$.

of remaining technical issues such as decontamination of the carbon carpel are outside the scope of this paper and will be the subject of future work. We do point out, however, that by using a CCFW attached to a Kevlar support plate we can etiminate the need for an aluminum wall in the high energy neutron flux. This significantly reduces the activation of $\mathrm{A}]$ to ${ }^{24} \mathrm{Na}$, which is currently the dominate contributor to short tetrm radiological hazard within the chamber. It is also a factor determining the shielding requirement to protect the oulside of the chamber, where workers may be within a day of the shot. The CCFW ofters the opportunity to bujild a truly low activation chamber, which is extremely imponant to operational safety and low operating cost, in addicion to the low capital cost of a smaller charmber.

\section{CCFW DYNAMICS}

The impulse delivered to the structural wall from the absorption of high intensity $x$-rays is due to the reaction to rapid vaporization of the wall material. There is no impulse if the energy can be conducted into the wall rapidly enough by themal conduction to avoid vaporization. The impulse generation process can be thought of in two complimentary ways, as the 
integral over time of the vapor pressure pushing on the wall, or equivalenlly, as the product of the ablated mass and the characteristic velocity of escape. Both are approximations to the actual deficition

$$
I_{m}=\int_{0}^{\infty}\left(P+\rho u^{2}\right) A d t .
$$

where $I_{m}=$ impulse, $P=$ pressure, $\rho=$ mass density, $u=$ velocity $A=$ wall surface area, and $I=$ Lime. The carbon carper protects the wall from damage in the following ways 1) by absorbing the $x$-rays and reflected laser light over ten times the surface area on fibers having an incidence angle of $\theta=85^{\circ}$ to the $x$ ray flux, 2) by reducing the wall pressure by spreading the plasma out over a very large region (the $\mathrm{H}=\mathbf{2} \mathrm{ctn}$ carpet depth) compared to an absorption depth of $2 \mu \mathrm{m}, 3)$ by spreading out the interaction ime from the 10 ns $x$-ray pulse-width to the $8 \mu$ s residence time of the plasma in the carpet, and 4) by condensing carbon aloms back onto the huge surface area of fibers before the vapar escapes from the carpet. The carbon carpet also protects itself and the supporing subsructure from energetic target debris. The debris front arrives so late that is absorbed in the inrushing carbon vapot and never reaches the carpet. The debris simply beats the vapor which then radiates to the carpet and causes more vaporization on a longer timescale.

Although the x-ray intensity on the fibers is an order of magnitude less than on a normal flat wall because of the $85^{\circ}$ angle of incidence, the local peak ccmpressive and thermal stresses can still exceed the ultimate stress on some fibers. For this reason we favor using carbon fibers which are each constructed of $12,0005 \mu \mathrm{m}$ filaments. Even if some surface filaments break, the integrity of the fiber is not affecled, and in no case is the structural integrity of the wall, or even the function of the carpet, compromised. In fact, many feel that because the tiny filaments are not much thicker than the x-ray absorption depth, any stress wave that forms would be quickly relieved from the sides, making the character of the energy addition much closer to that of volumetric heating.

It is easy to understand how the carpet reduces the pressure felt by the wall to safe values far below the material stength, by increasing the plasma volume and lengthening out the vapor residence time on the wall. Compare Cases A and B of Fig. 2. In case A the pulse lasts from the time vaporization commences until the end of the $x$-ray pulse; in case $B$ the pressure isa't felt until the plasma fills the carpet, and it lasts unil the pressure is relieved by the rarefaction wave which propagales in from the end of the carpet

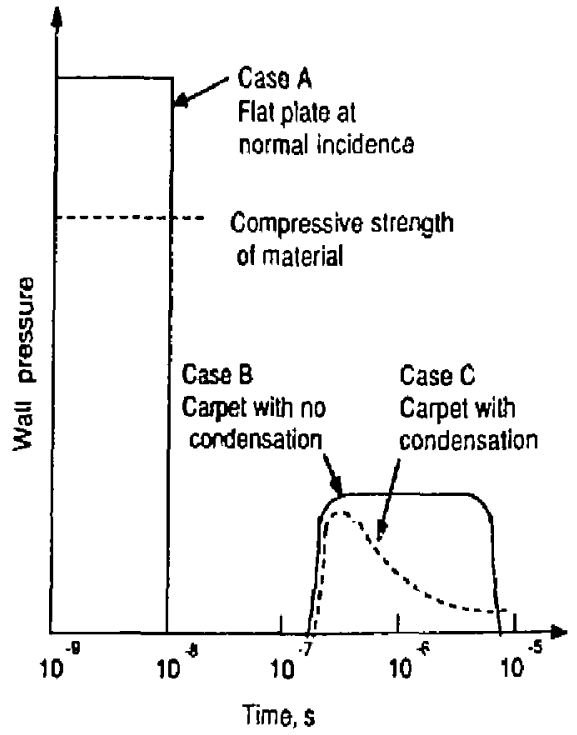

Fig. 2 The impulse is the area under the pressuretime curve. A flat piate experiences a peak pressures exceeding the material compressive stength. Without condensation, the impulse detivered to a caspet is the same as a flat plate, but the peak pressure is far lower. With condensation, the impulse can also be substartially less.

However helpful this time strecching may be, the tolal impulse would be the same were it not for the additional effects of themal conduction and condensation. These two effects are the source of impulse reduction. The residence time of the plasma in the cappet $(-8 \mu \mathrm{s})$ is long esough, and the condensing area large enough ( 40 times wall area) that more than $90 \%$ of the vaporized mass can condense out on the fibers. All the vapor energy conducted into the fibers and all the vapor mass lost to condensation are unavailable to contribute to the momentum generation of inwardly directed gas. When a flat plase is irradiated by a 10 ns pulse there is no time for these mitigating processes, However, in the CCFW the interaction time is 800 times longer, allowing conduction and condensation to reduce the ejected momentum by a substantial amount. This is shown schematically by the area under the $\mathrm{P}(\mathrm{t})$ curve in Case $\mathrm{C}$ of Fig. 2

With this overall understanding, we can examine the impulse generation process in more detail. Instead of using an actual or projected ICF $x$-ray spectrum, we calculate a simpler fictional case using $200 \mathrm{MJ}$ of monochromatic I keV $x$-rays, which impinge on first 
walls located from 1 to $15 \mathrm{~m}$ from the source. The ions are of no consequence to us. They arrive so late that they are totally absorbed by the insushing carbon vapor that results from the $x$-ray deposition. The ions further bear the gas, which radiates away the encrgy to the walls by thermal radiation over a sufficiently long timescale that is oot a hazard to the wall. Absorbing the $10 \mathrm{GW} / \mathrm{cm}^{2}$ of $\mathrm{x}$-rays is the problem.

The best way to understand the heating, vaporization, and condensation processes is to calculate and exrmine the relative timescales of the problem. which are shown in Fig. 3. The first imporant time duration is the $x$-ray pulse width, $\tau_{x y}$ which is $10 \mathrm{~ns}$. Next is the time to begin vaporization, $I_{b y}$. By balanoing the $x$-ray flux with the thermal conduction tate, we calculate that the time necessary to initiate vaporization varies from $10^{10} \mathrm{~s}$ at $5 \mathrm{~m}$ to $4 \times 10^{-9} \mathrm{~s}$ gy $15 \mathrm{~m}$. The time duration of the vaporization process is the difference berween the $x$-ray pulse duration and the time to begin vaporization,

$$
\tau_{v \Phi}=\zeta_{x}-t_{t w} .
$$

Next we calculate the lime it lakes for the blowoff plasma itself to become opaque to the incoming $x$-ray radiation. The time to become opaque is importan because the vaporization due to $x$-ray absorption is siut off, and the vapor is heated, perhaps even to the point where it radiates away energy by thermal tadiation. (In the closed geometry of a spherical chamber, prompt thermal radiation will just cause more vaporization however.) In Fig, 3 we have ploted the time required for the yapor to bave a densiry-length product equal to twice the opaciny of the solid,

$$
L_{\text {Lt: }}=\left(2 \lambda_{x} \mathrm{P}_{4} \mathrm{H}_{4}\right) / \mathrm{I}_{\mathbf{x}}(\mathrm{R}) \text {. }
$$

whete $\lambda_{2}=2 \mu \mathrm{m}$ is the absorpion length of $x$-rays in solid carbon, $\rho_{\mathrm{c}}=2100 \mathrm{~kg} / \mathrm{m}^{3}$ is the density, $H_{1}=C_{\gamma} T_{4}+L_{2}=59.5 \mathrm{MJ} / \mathrm{kg}$ is the total energy required to vaporize cartroil, and $L_{x}$ is the intenzicy of $x$-rays. To first order, this time is independent of the irradiarion angle of the fiber.

The third line on the graph of Fig. 3 is the time for the vapor to fill the space between the fibers of the carper, $i_{\text {ifl }}$ approximately $2 \times 10^{-7} \mathrm{~s}$. This is really the : arliest time that the wall car feel any pressure. The pressure pulse lasts for a time equal to ine residence time of the yapor in the carpet.

$$
\tau_{\mathrm{wb}}=\mathrm{H} / \mathrm{v},
$$

where $H$ is the thickness of the carper $(2 \mathrm{~cm})$, and $v$ is the thermis velocity of the vaporized carton (2.5 $\left.110^{5} \mathrm{~cm} / \mathrm{s}\right)$. While the vapor is in the carpet, it

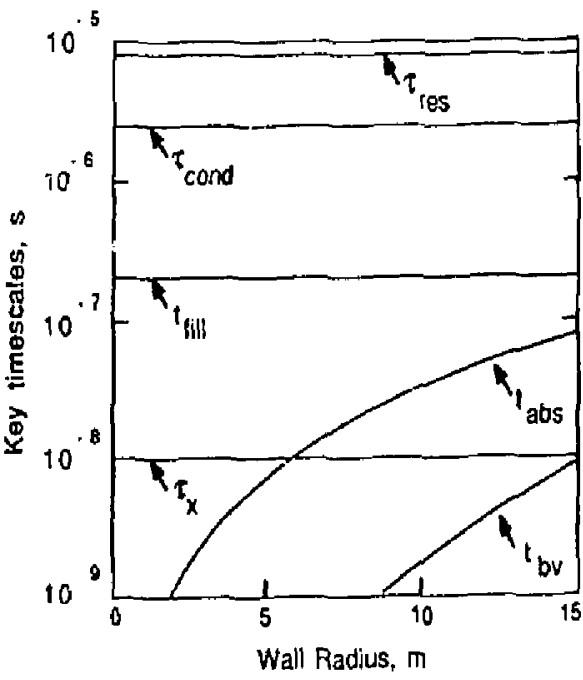

Fig. 3 The key timescales of the problem: $t_{t y}$ is the time to begin vapotization, $\tau$ is the $x$.ray pulse duration, $\mathrm{t}_{\mathrm{z}}$ is the time it cakes tor the vapor to besome absorbirg. $f_{\text {fing }}$ is the time for the vapor to fill the carpet, $t_{\text {cond }}$ is the characteristic condensation time, and $c_{\text {ro }}$ is the residence time of the vapor in the carpet

condenses out with a claracteristic time

$$
t_{\text {and }}=4 \mathrm{H}(1-\eta) /(\Omega S v) \text {. }
$$

where $\eta$ is the packing fraction of fibers $(0.32), \Omega$ is the condens,ng area ratio (44), $S$ is the sticking coefficient (0.2). The ratio of condensing surface area (of fibers) to the spherical first wall area is

$$
\mathbf{\Omega}=1+(4 \pi ; / d)
$$

where $d$ is the fiber djameter $(0.06 \mathrm{~cm})$. Using the base case values given in above in parentheses, gives a residence time $\tau_{\mathrm{T} z}$ of $8.0 \mu \mathrm{s}$ and a condersation time of $2.5 \mu \mathrm{s}$. Since the residence time is more than a factor of 3 longer than the condensation time, we expect substancial condensation even though we ase uncertain about many factors, particularly the value of the sticking coefficient

The initial mass ablated off is approximately

$$
m_{0}=\left(t_{x} / H_{p}\right) A \Omega t_{v i p},
$$

where all the symbols have been previously defined. The amount of mass left after condensation is

$$
m=m_{b} \exp \left(-r_{\text {re }} / i_{\text {sind }}\right) .
$$




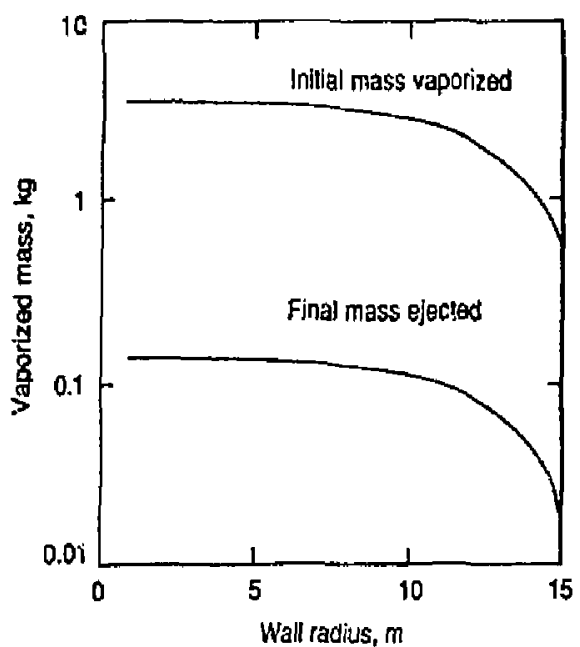

Fig, 4 Ine initial mass of carbon vapor vaporized by the $x$-rays and the final mass of ejected vanor. The difference is the mass condensed in the carpet.

The carbon atoms continue to condense out until a relief wave, propagating in from the inner surface of the carpet towards the wall, suddenly tums the thermalized plasma into a flow directed toward the eenter of the yacuum chamber. The pressure on the wall is thus shut off at time $\tau_{\mathrm{ret}}=$ Hov. As the relief wave passes. and the gas expands into ite vacuum, it is accelerated to a speed

$$
v_{e x}=\sqrt{2 E_{p} / m_{0}} \text {. }
$$

where $E_{p}$ is the energy in the blowoff plasma

We nave plotted the initial ablated mass and the final mass ejected from the CCFW in Fig. 4. Note that over 95\% of the vapor bas condensed out during the residence time of the vapor in the carpet We also expect that most of the carbon that initially blows into the center of the chamber $(-0.13 \mathrm{~kg})$ will eventually condense in the carpet, su.ber reducing the ne! mass loss per show. This is very favorable for the lifetime of the wall from the standpoint of erosion rate. If makes no difference if the condensed carbon takes the form of a uniform layer, or a snow-like soot deposit, or even diamond. On the next shot, the deposited carbon will again be recycled, and the majority of the material will stay in the carpet.

The final outward-diected impulse delivered to the wall is simply equal to the momentum of the inwardly directed vapor.

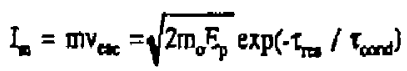

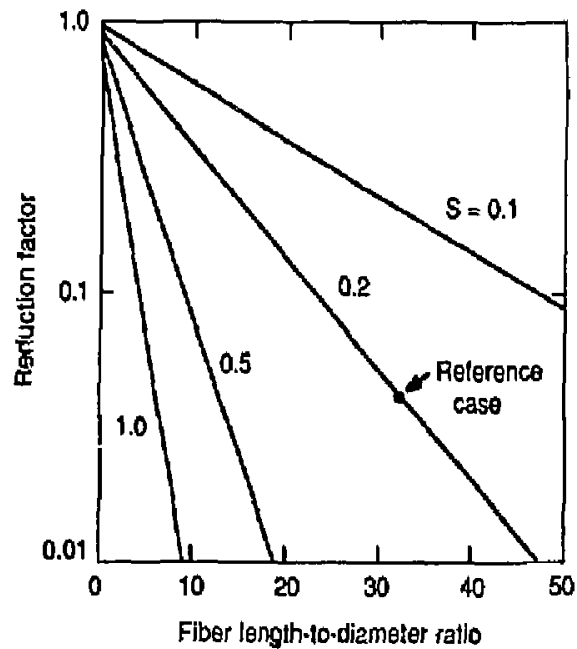

Fig. 5 The factor by which erosion is reduced by condensation, as a function of the length-10diameter ratio of the carbon fibers shown for sticking coefficients ranging from 0.1 to 1.0 .

The exponential reduction factor multiplies both the mass loss and the impulse. It is a function only of the carpet geometry and sticking coeflicient, since

$$
\frac{\tau_{\pi 4}}{t_{\text {ond }}}=\frac{\Omega S}{4(1-\pi)}=\frac{S}{(1-\eta)}\left[\frac{1}{4}+\frac{\eta H}{d}\right]
$$

The exponential reduction factor is plotted in Fig. $S$ for various sricking coefficients and fiber length-10diamser ratios with a fixed fiber packing fraction of 0.32. The reduction factor is the key performance parameies in the geometrical design of the cappet We see that one to two order of magninde reductions in erosion and impulse can be achieved with realistic length-10-diameter ratios. Using the parameters for sticking coefficient and carpe! dimensions given above, the ratio of residence time to condensation time is 3.2 , resulting in a :eduction of mass loss and impulse of 0.04 .

In Fig. 6, we graph the iropulse per unit area

$$
J(R)=I_{a} /\left(4 \pi R^{2}\right)
$$

as a function of wall madius for our example case of $200 \mathrm{MJ}$ of $\mathrm{x}$-rays, and for both the CCFW and a flat carbon plate at the same radius. At $R=3 \mathrm{~m}_{1}$ the impulse per unit area in the CCFW is about 4 Pa-s, corresponding to a wall pressure of 5 atmospheres for $8 \mu \mathrm{s}$. 


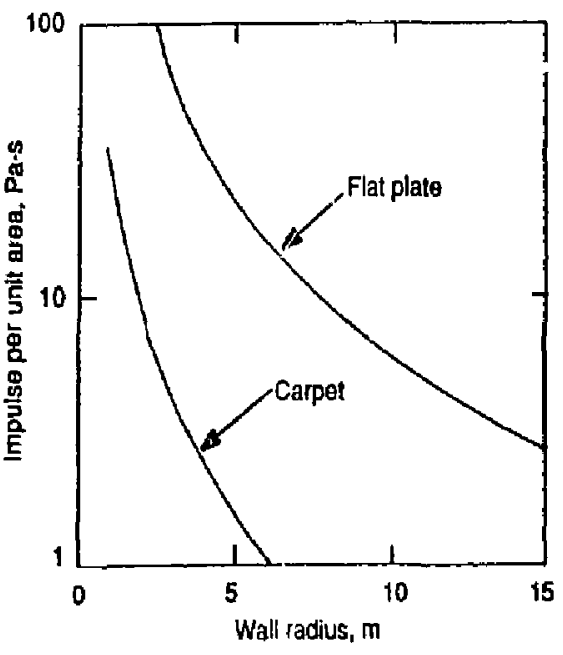

Fig. 6 A comparison of the impulse deiivered to the first wall by $x$-rays on a carbon flat plate and a carbon carpet surface.

\section{TRANSIENT STRESSES}

To calculate the resultant stress due to the impulse, we need a first strucnural wall model. The best way to withstand a trensient spherically symmerric losul is with a perfect spherical shell, the unit suesses of which are all in simple uniaxial tension thoop stress). Unfonunately this would be unacceptably idealistic since the model completely breaks down for a real sphese baving Jarge stress concentrations from the hundreds of holes that will be necessary for laser beams and diagnostics.

We believe that a more realistic model is that of a wall made of nat panels that are attached to a very rigid spherical space frame constructed inside a spherical vacuum vessel. The first wall would be tiled with these panels, which might have a characteristic size of $1 \mathrm{~m}$ across, and $1.0 \mathrm{~cm}$ thick. The carbon carpet would be altached to the inside surfaces. The panels could be square, rectangular or triangular, of either aluminum or a Kevlar-epoxy composite, and be either simply supponed or have clamped edges. As long as these panels have approximately the same size and strength as our example, the delails don't matter.

We shall model the first wall as $1 \mathrm{~m} \times 1 \mathrm{~m} x$ $0.01 \mathrm{~m}$ aluminum flat plates, havigg a yield stress of $33 \mathrm{kpsi}$, and a design strength of one-half the yield stress. These plates would have their largest bending stress at the edges, if they were clamped, or at the middle, if simply supported, but of essentially the same magnitude. This transient stress is given by

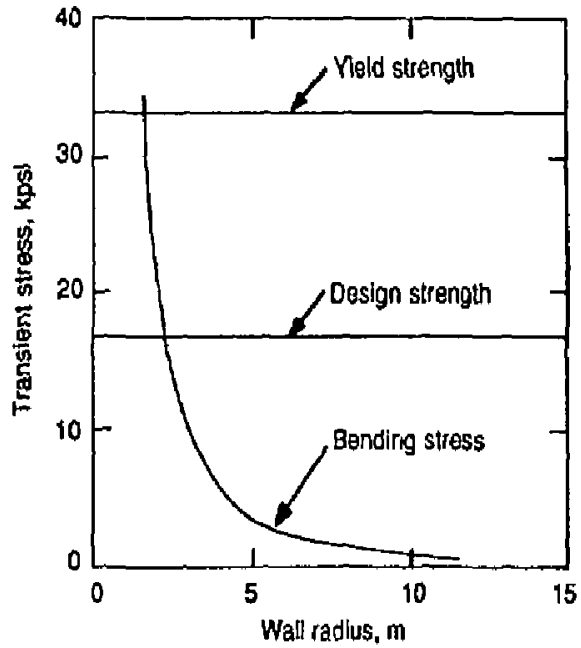

Fig. 7 Bending stress in an aluminum flat plate $1 \mathrm{~m}$ square and $1 \mathrm{~cm}$ thick doe to the impulsive loading of $200 \mathrm{hiJ}$ of $\mathrm{x}$-rays.

$$
\sigma_{\mathrm{p}}=2 \pi\left(b^{2} / 2 h^{2} K_{2}\right) f_{p} J(R)
$$

where $b=$ plate size, $b=$ plate thickness, $K_{2}$ is a sbape factor that equals 1,62 for a square plate; and $f_{p}=0.8 \mathrm{kHz}$ is the (lowest) vibrational frequency of the plate. For reference, the suress conversion factor is $6.9 \times 10^{6} \mathrm{~Pa} / \mathrm{kpsi}$. We have graphed this transient bending suress in Fig. 7, showing that it is below the design stress at all charnber radii greater than $2,31 \mathrm{~m}$. We find that the minimum radius scales as the square rool of the plate thickness; if we double the plate thicksess to $2.0 \mathrm{~cm}$, the chamber radius can be brought in to $1.63 \mathrm{~m}$, while a $0.5 \mathrm{~cm}$ thick plate would require a radius of $3.26 \mathrm{~m}$. We believe that, for the actual yield and target spectra of the LMF, an inner radius of approximately $3 \mathrm{~m}$ is achievable with a passive, room-temperature carbon-carpet first wall.

\section{ISSUES AND POTENTIAL SOLUTIONS}

One unresolved critical issue for the CCFW is its lifelime - how many shots will it last before it has to be replaced, as a function of the $x$-ray loading per shot? While experiments are needed to verify the lifetime properties of the carbon carpet, we expect that the carpet will have a reasonably long lifeume (hundreds of high yield shots; for several reasons. Some of the outermost filaments of exposed fibers (recall each fiber is a bundle of over 10,000 filaments) will be damaged on each stor due to vaporization and compressive themal and ablation induced stresses. We do nol, however, expect the stocks generated in the outer filaments to propagate 
very efficiently to the underlying filaments since the fiber itself is similar to a compressible, porous material, and energy will be dissipated in filament motion and friction. The underlying filaments are thus protected, and the integrity of the fiber as a whole should not be seriously degraded

In addition, condensation of vaporized carbon may reduce the damage to the outermost filaments on subsequeat shois and thus extend the fiber lifetime. The nature of the condensation needs to be addressed experimentally. What if filaments or fibers are fused together by condensate? The fused areas may be separated by the subsequent shots or the process might continue and reduce the total fiber surface area available for condensation. We don't expect fusing to oocur, because we expect the condensate to be more like soot than tar. LLNL will begin to investigate the survivability of various first wall concepts, including the CCFW, in experiments planned for Fall 1988.

Another issue that has been raised is thal tritum and radioactive larget debris might build up to an unacceptable level in the carbon carpet. The tritum build-up could be limited by adding a small amount $\left(0.01\right.$ tor) of $\mathrm{CO}_{2}$ to the chamber before each sbot. The microexplosion would dissociate the $\mathrm{CO}_{2}$, and the unbumed tritium would be pied up as $\mathrm{T}_{2} \mathrm{O}$ and pumped out of the chamber so that it does not build-up. Proper selection of target materials will minimize the activation load from target debris. It is estimated that activaled debris could accumulate for more than a couple of years before the design goal dose rate (100 mrem/hr 7 days after a high yield shot) would be exceeded

There is also some concern that vaporized carbon will contaminate the final optics. We don't expect this to be a significant problem. First of all, about $95 \%$ of the vaporized carbon condenses in the carpet before to it has a chance to escape into the center of the chamber. Of the $130 \mathrm{~g}$ of carbon that is ejected into the vacuum chamber most of it $(-98 \%$ or whatever the solid angle fraction of carpet coverage is) will expand back out into the carpet and have a high probability of condensing. The small fraction that expands out into the beam tubes should be stopped by gas that is puffed into the beam nubes or by the fast acting values that are designed to stop shrapnel. ${ }^{6}$ The thermal velocity of the vaporized carton $(2.5 \mathrm{~km} / \mathrm{s})$ is in the range of the shrapnel velocities that the values are being designed to handle (up to $10 \mathrm{~km} / \mathrm{s}$ ). If the optics can be protecied from shrapnel. they will be protected from carbon condensate.

\section{CONCLUSIONS}

We have described a passive, room-temperature first wall that conceptually solves the problem of survival under intense $x$-ray and ion loadings from ICF largets. The carbon-carper firs: y.all concept uses a clever configuration to overcome the limitations of material froperties, and to reduce the mass loss per shot and the impulse deliycred to the wall by more than an order of magnitude. The configuration provides an enormous surface area, within a small ( $3 \mathrm{~m}$ radjus) chamber, for absorbing the $x$-rays and condensing the vapor generated by ablation. If does this in a way that minimizes the amount of ejected vapor, and thus, the net seaction force transmitted to the wall. The carbon that is vaporized protects the carpet from i.snic larget debris. There is every indication that this concept will work as well on the hundredth shot as the firs shot, but experimental confirmation is needed.

The use of low activation material and the possibility of eliminating Al from the high energy neutron hux raduces the short term radiation bazard The CCFW does not require cryogenic cooling, does not need reestablishment oi iefiuroisinment between shots, and does not interfere with target alignment. mounting, irradiation and diagnostics. These factors should help minimize operation and maintenance costs. The use of commercially available materials in a compact chamber that itn be operated at room temperature should help minimize capi.il costs. Overall, the carbon carpet list wall is an attractive option for the LMF.

\section{ACK:NOWLEDGMENTS}

This work was supported by Lawrence Livermore National Laboratory; subcontract number 2208703 under Department of Energy contract W-7405-ENG48. We also acknowledge the useful technical discussions we had with David Johnson and lamy McNichols of McDonnell Douglas.

\section{REFERENCES}

1. D. SLAUGHTER, "Overview of the ICF Megajoule Experiment Chamber Design," UCRL-99627, (SepL 1988) also these proceedings

2. C. D. ORTH, "Frost as a First Wall for the Laboratory Microfusion Facility," UCRL-98450 (Sept. 1988) also these proceedings. 
3. J. H. PITTS, J. G. WOODWORTH, and M. TABAK, "Preventing Vaporization and Destructive Shock Waves in ICF Target-Chamber First Walls," UCRL.98440 (SepL 1988) also these proceedings.

4, R, J, ROARK and W. C. YOUNG, rymulas for Stress and Sirain, McGraw Hill Bo,k Co., New York, N.Y. (1982).

5. M. T. TOBNN, Private communication (Och 1988).

6. D. G. WILSON and J. G. WOODWORTH, "Fina] Optics Protection Designs for ICF Containment Chambers," UCRL-98649 (Sept. 1988) also these proceedings. 


\section{MEUTROHICS AMALYSIS OF THE LABDRATORY RICROFUSIOH FACILITY}

\author{
H. T. Tobin and H. S. Singh \\ Laurence LIvermore Hational Laboratory \\ P.0. Box 5508, L-49i \\ Livermore. a 94550 \\ (415) $423-1168$
}

H. R. Heter

H. J. Schafer Assoclates

6140 Stonerldgé Ma!l Roid, Sulte 385

Pleasanton, $\mathrm{Ca} 94566$

(4I5) $463-1108$

\section{ABSIRACT}

The radiological safty hazards of the experimental area (EA) for the proposed Inertial Confinement Fusion (iCF) Laboratory microfusion fac?!lty (LHF) have been examined. The EA includes those structures required to establish the proper pre-shot environment. polint the beans. contain the pellet yluld, and zeasure many different facets of the expert. ments. The radiation dose rates from neutron activation of representative target chamber aterlals, the laser beal tubes and the argon gas they contain, the alr surrousding the chamber, and the concrete walls of the experlmental ared are glven. Comblring ihese results $y$ th the allowable osse rates for workers, we show how radlological censideratlons affect access to the Inside of the target chamber and to the diagnostic platfora area located outside the chamber. Haste disposal and tritilum containment issues are summarized. Other neutronics issues, such as radiation damage to the final optics and neutron heating of materlals placed close to the target, are also addressed.

\section{INTRODUCTION}

The Laboratory Microfusion Facility will be designed to contain target fusion reaction yteids up to a nominat $1000 \mathrm{MJ}$. This corresponds to the production of $3.6 x$ 1020 0-T neutrons per shot peaked at 14.1 Mev. The radtological hazards, resulting fron this burst of high energy neutrons and from the surrounding materials they activate. present a significant challenge to the facllity designers. Heutrons must be moderated and absorbed, along with the secondary and decay gamma rays, in such a manner that the factlity meets the U.S. liepartment of Energy (DOE) radiological siting requi rements, tlip Internatlonal Comission on Radiologital Protection (ICRP) (and DOE) public dose IImts 2 the DOE occupational dose $11 \mathrm{mits}, 3$ and the more stringent LLHL as lou as reasonably achlevabie (ALARA) guldelines.4
The primary goal of the facllity is to conduct some 1400 target experlments over a flve-year period to dentonstrate $h$ igh gain in the laboratory. Projected ylelds for these experlments range from $10 \mathrm{MJ}$ to $-1000 \mathrm{MJ}$. After high galn has been achieyed, target ylalós above $100 \mathrm{~h}$ wlll be used to conduct weapons physics and vedpons effects experiments, High galn experiments are expected to be conducted once per week. Th/s vill extend the faclity lifetime to as much as 30 years.

He have set two dosign goals that ainimize the affect of radiatlon hazards on the operation of the factility. The first is that LWF workers will have access to the diagnosilc platforms outside the target chamber within 24 hours after a hlgh-jleld shot. This is required to retrleve data and set up for the next shot. Although it is possible that routine interfor chamber cperatlons 111 be done remotely, vorkers may occaslonally requlre access to the instide of the chamber for nonroutine operations and malntenance.

Therefore, the second design goal is that vorkers can safely onter the chamber for d short time 7 days after a high-yleld shot. As quantitatlue measures of these tro desian goals, we have established dase rate lifits of $2 \mathrm{mrem} / \mathrm{hr}$ outside the chamber 24 hours after a shot and 100 mren/hr inside the chamber 7 days after a shot.

Several conceptual designs are currently being proposed for the Uif target chaber. All the deslgns inciude an inner flrst vall (alumlnum, carbon, Kevlar epoxy, or fiberglass) that is protected from $x$ rays vith some other material (frozen nitrogen, a layer of lce or porous alumina, or a carbon (arpet), a neutron moderator and absorber (water or boraled graph(te), and an outer structural wal] (aluml num or steel). In this paper, ve describe the results for a representative target chamber that consists of an Inner 4-cm-thick aluminum wil, 2-m-thick reglon of water, and an outer 4-cm-thlck structural wall 
also made of alumlnum, and a concrete bullding as shown is $\mathrm{Flg}$. 1. While this may not be the design chosen for the LHF, it serves as a useful example for discussing radiological issues. and it serves as a point of comparison for the other concepts being proposed. Where possible, we polnt out the anticlpated Impact of design modifications.

Hote that al though aluminum is generally consldered a lou-activation materlal, the $2 \epsilon_{\mathrm{Na}}$ produced by $(n, a)$ reactions with

$27_{\mathrm{Al}}$ is particularly troublesone for the first fen days after a shot. The $24 \mathrm{Ha}$ nas a half life of 15 hours and Its decay yieios two high energy gammas (2.75 and $1.37 \mathrm{HeV}$ ).

Our analys is includes: effects of leakage neutrons (fron some 72 beam ports), materials icpurities, nuclide bulldup, and neutron scattering from concrete and beam tubes. Our estimate of the 24-hour dose rate at a

diagnostic platform Includes contributions from the activation of alr, con:rete, bean tubes, vacuum chanber, and Interior chamber materlals.

Two cruclai deslgn 1ssues are the post-shot tritlum recovery and radiation damage to final optics. We Include data concerning the amount of tritlated waste and discuss means of handling and disposing of it. We diso show that, at the projected radius of 25 aeters. nestron damage to the flnal uptlos (degradation of transmisston) ylll not "mpede LMF operations.

\section{GENERAL NEUTRONICS ISSUES}

The calculations performed for this paper wert done using the couputer codes TART, 5

FORIG, 6 and ORLIE, ${ }^{3}$ The neutron-photon transport code TART uses a Honte Carlo technlque to deteraline the spatially-and energy-dependent fluences of neutrons and photons. ORLIB combines the neutron spectra frow TART with our most current neutron cross section llbrary to produce one energy group. spatialiy averaged, neutron activation cross sections. This information is then used by the nuclide generat!on-depletion code FORIG.

Generally. TAPT bas aiso used to determine the dose rates near actluated surfaces using photon transport calculations and rater to simblate tissur. as tissue is 714 vater. Mitrogen, oxygen-like in absorbing decay radiation, is another 237 . Therefore vater is an adequate model for 942 of the body

The buildup of nuclides over time was considered in all the andlyses using the equation

$$
H=H_{0}\left[\left(1-e^{-\lambda t n}\right) /\left(1-e^{-\lambda t}\right)\right],
$$

where $k$ is the number of curles of a given nuclide after $n$ shots soaced $t$ time units apart. $N_{0}$ is the amount of the nuclide produced on a single shot, and $\lambda$ is the decay constant for the particular nuclide. The nuclide bulldup approaches secular equllibrium

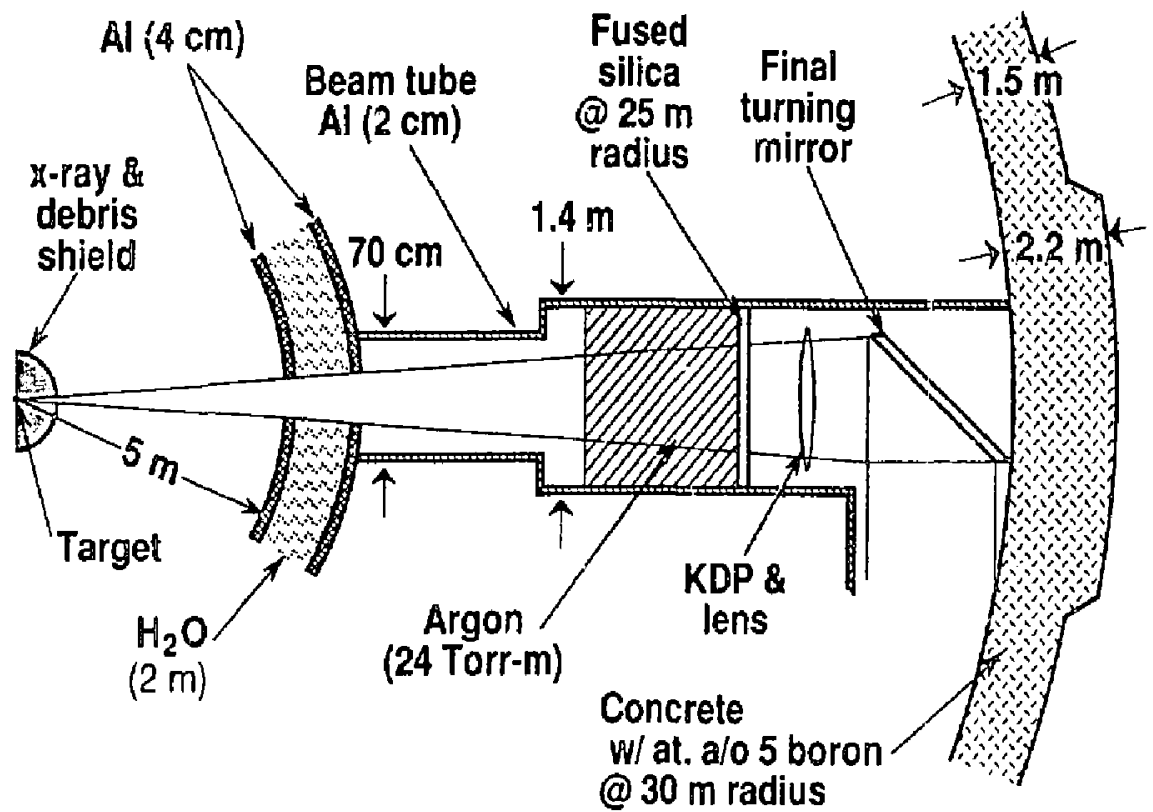

Fig. 1. Final optics protection and blological shield dimensions for activation analysts. 
(where the amount that decays between shots is equal to the amount produced in a singie shot). For example, at a shot rate of one per veek, the bulidup of $24 \mathrm{Ha}$ produced in Al after 500 shots 151,00043 times the quantity produced in the first shot. For $54 \mathrm{Mn}$, which is produced frcm fe and has a half-life of 31 ? days, the bulldup is 64.9 times the quantity produced in the first shot.

The or of the target (the density of the fuel reglon times its thickness) has a moderate effect on the activation of intertar-chamber and first mall materials since it changes the neutron energy spectrum due to sattering in the fuel. The greater the or of the fuel. the greater the neutron energy deposited in the fuel itself before the neutrons escape. A pr of $3 \mathrm{~g} / \mathrm{cm}^{2}$ atll be the average fuel density achleved in LMF although some targets may achteve a pr of $5 \mathrm{~g} / \mathrm{cm}^{2}$. The effect of the target's pr on miterlal activation is expected to be greatest for those neutron reactlons with thresholds (1.e., ginimum neutron enzrgy required to make the reaction energeticaliy possibles. For example, about 107 less $24 \mathrm{Na}$ is produced in an Al eirst wall for a pr of $5 \mathrm{giem}$ target than for a $p \mathrm{~T}$ of $3 \mathrm{~g} / \mathrm{cm}^{2}$ target. assuming the yieid is the same in both cases. Ifipllications of a range of $p$. yalues are beling consldered in the LMF distign.

\section{EXPERIMEMT AREA DESIGHS}

Tro issues domlnate the design of the EA: how to prevent or deal with the ray ablation of the first surface, and how to limlt activation levels after high-yleld shots to allow adequate accessibtlity.

The $x$ rays wlll be dealt with in one or zore of the following ways: with an $x-$ ray and debris shleld made of $15 \mathrm{~cm}$ of solid nitrogen or $0.25 \mathrm{~cm}$ of polyethylene at a radius of $20 \mathrm{cos}$ (Qef. B); yth a water frost lajer condensed on an diurinum first wall9; with a sacrificial ioyer at the flest wall made of alumina; wh a carbon-carpet Inner surface; or wh th pyranid-like carbon tiles.

Limlting activation leveis is done through careful maierlal selection (hlgh purtty, low activating) and by providing adequate shielding to maderate ind absorb the neutrons sufftcientiy to retard activation. The cholce of low-activating alunilum allows re-entry into the thamber at the 7-day point (100 mren/hr) For such a design, sufficient shielding must back this first Al wall to do two things: orevent activation of the second al wall outside the shleiding and attenuate the decay radlation from the first wall. This can be accomplished with 2 in of water. (see Fin 1.)

The 15-em-thick $x$-ray and debris shield ade of solic nitrogen provides not only a sink for soft $x$ rays and debris but also moderates and absorbs enough neutrons through $(n, y)$ captures to reduce the activation in an aluminum first wall by about $1 / 3$ from the case ith no debris shield. This reduces the time requtred for re-entry by hals a day. The carbon-14 and tritium production fram the nitrogen is insigniflcant.

Aluninum will be the material of choice over stainless steel for the frost condensing surface. Calculations using 3-mm-thick panels Indicate that 55304 would give an interlor chamber dose rate 25 times greater than $A 15083$ 6 days after 500 full-yleld shots (one-week spacing). This al 5083 dose rate (40 $\mathrm{mrem} / \mathrm{hr}$ ) could be cut in half if a low-activation Al With sinllar properties to Al 5083 were used. The constituents of this low-activation aluminum are listed in Table 1 (Ref. 11).

The frost concept currently includes the idea of using flberglass clocated behind the aluminum condensing surface) as the vacuum vessel and as the contaliner of the water used as the main neutron shleld. The cholce of flberglass rould result in an extremely low resldual level of activation. Access to both the outer wall and the interfor vould be much less inhibited than with any other scheme proposed thus far. Detalles analysis of the performance of fiberglass in a radiation field Is necessary. Hovever, epoxy phenolics can generally withstand about $10^{5}$ rad before experlencing signlficant reakening. 12 A $5-\mathrm{cm}$ ftrst all of flberglass sould recelve on the order of that dose furlng the LAF IIfetime.

Proponents of the carbon-carpet first wall concept have also proposed using a Kevlar epoxy first wall, thus ellainating most of the $A 1$ (except for some support structures) from the high energy fiux this too vould result in very low activation and good access to the interior of the chamber

\section{ACTIVATICN OF ARGON GAS USEO TO PROTECT FINAL OPTICS}

Final optics wust be protected from rays and deorls as well as shrapnei. Shown in Fig. 1 is

Table 1. Rluminum alloy th propertips sinllar to Al 5083 but ultr. lover impurity and activation levels. 11

$\begin{array}{ll}94.999 \text { tI } & \mathrm{Al} \\ 4.5 & \mathrm{Mg} \\ 0.5 & \text { Si } \\ 0.001 & \text { Fe }\end{array}$


a conceptual design of such a protection systen. 3 of Interrest for neutronics andlysis is the 24 Torr $m$ of argon intended to protect the fused-silica from soft $x$ rays. potential concern is the production of $41 \mathrm{Ar}$, both in the beam tube and in the surrounding amblent alr, by the leakage neutions. The concentration. of $4 l_{A r}$ in and out of the beam tubes were calculated. The 41 Ar concentration in a beam tube after a shot is at most $A \times 10^{-3} \mathrm{Cl} / \mathrm{m}^{3}$. Al though this exceeds the allowable concentration for continuous exposure to vorkers, the concentration decays co $4,5 \times 10^{-7} \mathrm{cl} / \mathrm{m}^{3}$. at the 24-nour re-antry polnt, about an order of oagnitude less than the al lowaile $11 \mathrm{mit}$. Likewise, the concentration in the amblent air of the target chamber (due to the actiyation of the argon in the air) is $5 \times 10^{-5} \mathrm{Cl}^{3} \mathrm{~m}^{3}$ after a shot and $6 \times 10^{-9} \mathrm{Cl}^{3} \mathrm{~m}^{3}$ at the 24-hour polnt.

\section{RCIVRTION OF BEAM TUBES}

The activation of the aluminum baam tubes is also a major concern that could prevent re-entry tnto the EA within 24 hours after a aximum yield shot. Estinided to be $2 \mathrm{~cm}$ thick, the tubes are modeled as cylindrical tubes encasing each final focusing optlc at the concrete all and extending to the discrete port for beam entry at the chamber outer vall. This destgn, a cylindrical instead of taperea. cone tube, uses the overlap around the actual bean hole as a shadow shleld that effectively protects the beam tube from direct-shine neutrons. The actual beam hole at the chamber outer uall may be uniy $50 \mathrm{~cm}$ in diameter. The tube olameter is $1.4 \mathrm{~m}$ at the final optic, changing to 0.7 at the second wall (see Fig. 1). The smaller radius is required at the chanber vall to provlde adequate spacing for all 36 bean tubes in the deslgnated solld angle of the sphere. Calculations indicate that the dose rate from the aluminum tube 24 hours after the flve hundredth 1000-N] shot is only 1.2 mrem/hr. A further step to minimlze beam tube activation rould be to line the interior of the tube $y_{1}$ th a thin layer $(1 \mathrm{~cm})$ of $\mathrm{CH}_{2}$. It is expected that those neutrons with a near grazlng incidence to the bean tube material will see an effective thickness of moderator that wll serve to further reduce neutrons to energles below the threshold for the $(n, \alpha)$ reaction in $A$ l that nets the troublesome nuclide, $24 \mathrm{Na}$. Fur ther work is required to estabilish the merit of this proposal and to see if normal Al 5083 could be used.

\section{heutron oAkage to FINAL OPIICS}

Final focuslag lenses should be made of a material that is resistant to radiation damage and produces insignificant residual radiation. The leading material of cholce is fusedsllica. He have conducted a study of the effects of 14-HeV neutrons in fused-sllica when exposed to fluences that are predlcted for the LMt final focusing lenses, wilch are currently set at $25 \mathrm{~m}$ fron the target. The experimental fivence uss $1.5 \times 10^{16}$ neutrons $/ \mathrm{cm}^{2}$. $\pm 20 \%$. This is equivalent to $\pi 3300$ full yfeld shots. Thls far exceeds the projected number of full-yleld shots for the LMF 11 fetime covering high-galn development (100 full-yleid shots). weapons physics experlments (1000 full-y (eid shots), and weapons effects. experiments (100 full-yield shots). Including moderate- and low-yleld shots, the equivalent number of llfetime full-yleld shots $\mathbf{1} 11$ be 1600 (Ref. 14$\rangle$.

In this more recent experiment, a sample of fused-sllica, $2.7 \mathrm{co}$ in diameter and $\rightarrow \mathrm{cm}$ thlck, was Irradlated using the Rotatling Target Heutron Source (RTHS II) facillty over a

two-reek perlod in May 1987. Spectrophotometry measurements made before and after the exposure Indicated a change in optical density primarily below $400 \mathrm{~nm}$ with the peak at $215 \mathrm{~nm}$. The basellne transmittance at los (1.05- $\mu \mathrm{m}$ vavelength $\mid$ ight $)$ and $20(0.53 \mu \mathrm{m})$ was not altered. However, there was some degradation at $3 \omega(0.33 \mu \mathrm{m})$ and substantial reduction III transmittance at $4 w(0.26 \mu \mathrm{m})$. An earlier stuóy showed no degradation in transrission at any wavelength for an experimental fluence level of $1.5 \times 10^{15}$ neutrons $/ \mathrm{cm}^{2}$. The final optical density messurements as a function of wavelength are given in Fig. 2 .

The neutron-Induced affects vere largely reversible. Annealing of the sample at $400^{\circ} \mathrm{C}$ for tro hours significantly recovered the transmlttance. An aoditional 4-hour annealifig had signlficantly less lupact, suggesting a much longer required time to completely reverse the effects. Gama spectrometry analysis indicated that there is a small amount of impurities in fused-stitica, namely. $2 n$, Hn, Ce. Ha, and $Y$. however, the resultant activation made no significant contribution to the residual radiation le'als.

The degradation in transmission it assumed to be due to atomic displacements by neutrons. Hovever, 5.5\% of the total dose (1 Mrad out of 18.7 Hrad) to the slilica is from secondary gamma radiation. There are indications that the gamal radlation threshold for damage is greater than 10 Hrad (Ref. 15). The degree to which electrontc collistons may be reducing transmission wlll be explored later then a sample will be exposed to a comparable gama dose and more spectrophotometry measurements are made.

\section{AIR ACTILATION}

The activation of the amblent alr In the concrete enclosed dome must not prevent access to the chamber at the 24-hour polnt for a full-yleld shot. Calculations indicate that, a 
day after a $1000 \mathrm{MJ}$ shot a 30-n-radlus dome will contaln $0.1 \mu \mathrm{Cl}$ of $4 \mathrm{I}_{\text {Ar produced frem }}$ the neutrons that get through the 2-n-tnick shield. The contribution from the direct shine neutrons that escape through the 2 to 37 open solid angle and scatter of the concrete is 60 口C of $41_{\mathrm{Ar}}$ at this same time. The Derived Afr Concentiation (the allowable concentration for someone to continually breathe and not recelve mora than $S$ rem in one year: is $3 \times 10^{-6} \mathrm{c}^{4} / \mathrm{m}^{3}$ and is an order of magnitude greater than the actual concentration at 24 hours.

\section{BIOLOGICAL SHIELD}

Personnel must be protected frem recelving encessive prompt doses of radiation from a inigh-yleid shot. as well as from the resldual radiation. Our results indlcate that a 1.5-n-thick concrete wall enclosing the eapertmen: 1 a: 2a ull resuce the prompt exposure frimidately outside the EA bullding to less than $1 \mathrm{mrem} / \mathrm{shot}$, or $50 \mathrm{mrem} / \mathrm{yr}$, if of the dlowdole annual dase. An additlonal $0.7 \mathrm{~m}$ of concrete $(2.2 \mathrm{~m}$ total) will be requlred ochlnd the final optics at the end of the beam ports (see fig. 1).

The activation of the concrete presents a source of residual radlation that might constrain access to the diagrostic ports at the 24-hour point. The 72 beam tubes constitute clear paths for unnoderated neutrons to create "hot spots" in the concrete wall. Assuming that the faner radius of the concrete is 30 meters, the dose at the 7-m dlagnostic ports at 24 hours is astimated to be about $10 \mathrm{mrem} / \mathrm{hr}$. The gueruhelming contribution to this dose rate is 24 Ha production from $(n, y)$ reactions wth $23 \mathrm{Na}$ in the concrete. The addition of boron to the concrete to suppress $t-15$ reaction wll be requtred, as well as some inelastle scattering shlelding in front of of inbedded in the concrete. Adding 5 at. $x$ boron to the concrete is estimated to reduce the activation by an order of magnitude. Further work is ahead to tallor the concrete shleld to the specifle LMF needs. He may alsc consider the use of "moblle shlelding" to shield the dagnostls platforms from the concrete.

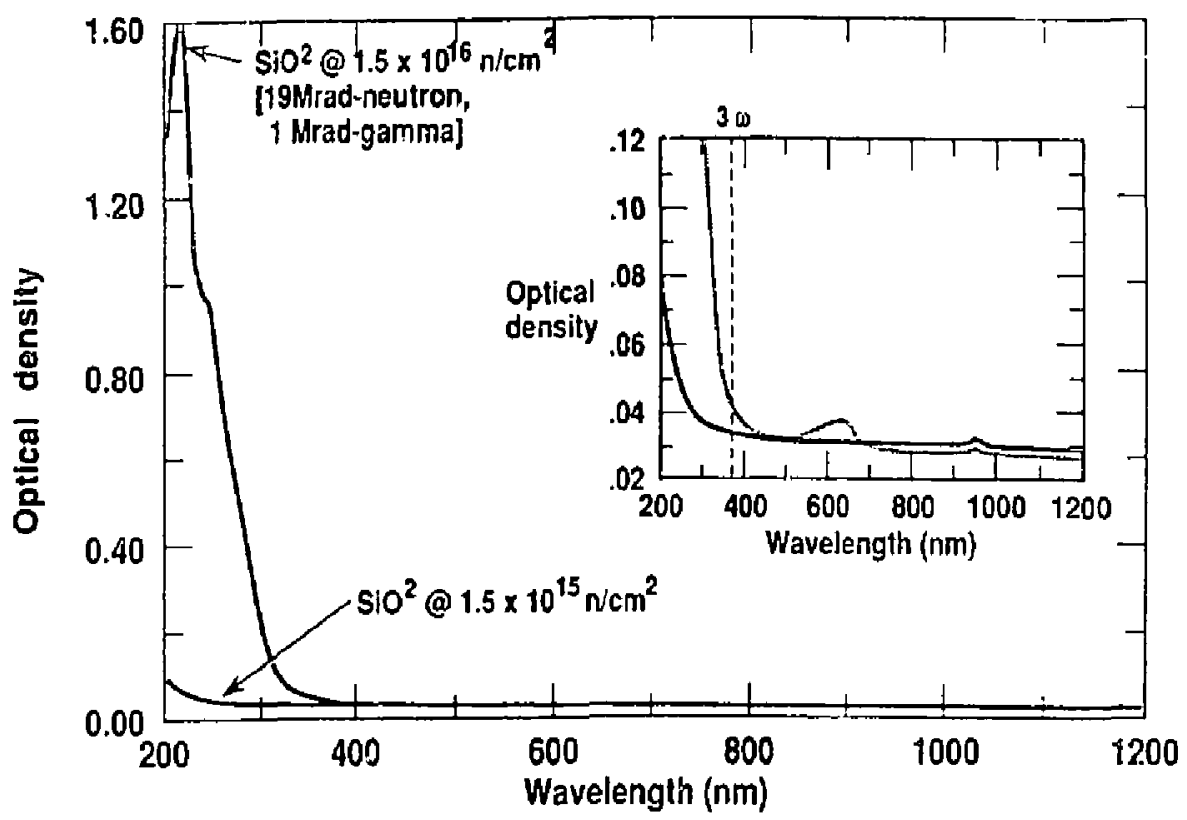

Final optics are set at $25 \mathrm{~m}$ from the iarget Transmission $(T)=10 \cdot D, D$ is optical densily

fig. 2. Heutrons and neutron-induced gamd rays cause lasignificant transalssion loss at ha in

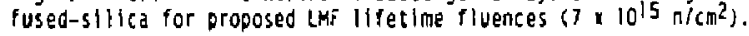




\section{MEUTRON MEAIING CLOSE TO THE TARGET}

He made a number of neutronics calculations to determine the neutron heating in materlals positioned close to the target. These alght incluoe target-support structures, shrouds, irradiation samples, and perhaps even diagnostics. Calculations were done for $\mathrm{Al}$. Fe, Cu, and SiC.

Our results stow that all the materidls vill melt, sublime, or diasjelate if placed vithin 10 to $20 \mathrm{~cm}$ of a $100 \mathrm{c}-\mathrm{i}_{1}$-yleld target. Carbon and sill con carbide have cemparable colntmum inner radil at wivit 13 cia, while the thiee metals consldered have mintars iadli closer to $20 \mathrm{~cm}$. Steel is slightly ietrit than Al and Cu. Even If we can protect macriosts from $x$ rays and debris, anything this ciuse to the target nust be considered sacrificlal since it 111 be destroyed by neutron heating. The innermost 10 to $20 \mathrm{~cm}$ of the target support structure, for example, ylll have to be replaced for every shot.

\section{IHTERIOR DOSE RATE}

The cumulative interior dose rate goal is <100 $\mathrm{mrem} / \mathrm{hr}$ about seven days after a full-yleid shot. The contributions to this cose rate come from the following: the target shroud and support mechanisa, the ablated and recondensed first wall, the remaining tritium (internal dose), the sacrificlal diagnostics. the first wall, and any materlals introduced into the chamber as part of an experiment (e.g., military applications). The tritium alli be rapldiv pumped from the chamber within alnutes, depending on the first vall constructlon. The target support components ylll be constructed frow composite materidis such as carbon-carbon or Kevlar to avold the activation problem here. Sacrificlal diagnostics ulli also be aade of nonactivating caterials. The first vall, if sollo nitrogen, vill not present any significant radiological hazard, nor alil polyethylene or frost. The carbon aill not have pers!stent activation products, as long as it is kept pure. A flrst wall. made of 4 con of lor actlvatiog Al (see Table 1) at a 5-m radius, will give $100 \mathrm{mrem} / \mathrm{hr}$ about seven days after five hundred $1000 \mathrm{MJ}$ shots spaced one week apart. when the solld nitrogen shield is used (and a value one-thiro higher when it is not). For a 3-0-radius first wali (2-ca thicks, $100 \mathrm{mrem} / \mathrm{hr}$ is attalned at 7.5 days after the five-hundredth 1000-HJ sho:. The longer tine is required oue to $1 / r^{2}$ effects and the less self-attenuation of decay gamaz rays in the thinner aluminum vali. Therefore, feel that a dose rate of $100 \mathrm{mrem} / \mathrm{hr}$ at about the seven-day point is attainable. This rate wlll allow liat ted personnel access into the chamber at thls the

\section{EXIERIOR DOSE RUIE}

Contributions to the exterior dose rate are: the flrst wall decay, the second wall decay, decay of Impuritles in the water that are activated, the concrete, and the bean tubes. As mentloned earlier, the dose rate f:om the first wall (5-a radius) outside the second wall (after 2 in of water) is $1 \mathrm{mren} / \mathrm{hr}$. The dose rate at this sase polnt from the activated concrete (due to "through-the-shleld" neutrons) is only $3 \mu \mathrm{rem} / \mathrm{hr}$. Hovever, the "hot spots" created by the direct shine (leakage) neutrons w11 contribute -1 arem/hr ror a 5 at. $z$ boron concentration in the concrete backing the final optics. Our water shield is not borated, both because a saturated solution of soracic acid in the water (the siaplest way to harate the water) does not introduce enough boron in the water to maxe a signtficant difference and iscause the boraclc acid or other boron conoounds rauld Introduce impuritties into the water, most notably sodfum. The contribution rron ictivated beam tubes to the overall dose rate it ine equator of the sphere is less than $0 .:$ mosinter. Since the goal is to limit the exterior rinss rate to $-2 \mathrm{nren} / \mathrm{hr}$, a conceptual deition al the features listed above can facitily achleve the goal dose rate.

\section{WASTE HAHDLIHG}

The expected trittum $[1 / 3 j: 4(\alpha 5 \mathrm{x} / / \mathrm{yr})$ and gaseous (2100 Cl/yr)) erflute"s ofll be any orders of magnltide below the has lnum permissible concentrations and bstal quatlties as glven in DOE 5480.11 . The des inn cbjective is to limit the facllity's controlid leleases to <100 cl/yr. This value has eas $1 /$, , wa by the ATHS II factlity, which had a somevice: higher trittun throughput. A typlcal hlg" ga!n target wlll contath io to $50 \mathrm{mg}$ of tritlitm. An estimated annual throughput then Is $25,000 \mathrm{Cl}$. for an aluminus first vall, the resioual tritlum diffusing from the adll after the chanber is pumped out wll mot present a personnel hazard. For a frost first uall, the Sulzer process for tritlum recovery would be used. 16 This can invalve cryogentc alstillation, coebined electrolysis catalytic exchange (CECE), water ilstlllation, electrolysis, gettering, gas storage, and flaxation. Here, the tritlum could be recycled as it is currently worth $\$ 20,000$ per gram. The Sulzer process increases the tritlum concentration in one strean uhlle greatly reducing (by up to six orders of magnltude) the concentration in the other stream. After 20 years operation, the total volume for the highly concentrated tritlated water could be only 300 hilers. Since this zater can be easfly doubly contained in certifled stalnless steel vessels, it presents no significant hazard. Any discharges wlll be many 
orders-of-magntlude below the pertinent standards. At concentrations $>1000 \mathrm{Cl}$ per contalner, the waste must be handled as Class 8 , wh the approprlate containers, etc. He estimate the total cost for vaste disposal for the first ten years of operation to be roughly $\mathbf{3 2 4}$. By keeping the site tritlum Inventory to $<30 \mathrm{~g}$ could ease siting requirements.

\section{CONCLUSIONS}

Facillty and experimental goals for the LMF can be achleved through careful design of the experimental area. Our calculations show that careful design and matertal selection can minimize activation and that surficlent shielding can be employed to protect materials prone to activation. For a chamber that uses an Al first vall. 24ka produced by $(n, a)$ reactions lth 27 A. is the des/gn-limiting radiological hazard. In the case ve examined, a 2 -m-thick water shield was needed to reduce the dose rate at the didgnostic platform at the za-hour point to an acceptable level. Reducing the dmount of al (or ellminating $(t)$ from the high energy flux tould reduce the shlelding requirements and allow earlier access to the inslde of the chamber. Interestingly, $24 \mathrm{Ha}$ produced by $(n, y)$ reactlons with $23 \mathrm{ka}$ in the concrete ualls of the experiment area aiso present sone difficulties. This radiation hazard can be reduced by adoling boron to the concrete. Neutron damage to final cptics appears to be wanageable and the effects of neutrons leaking through bean ports can be aftigated. The uaste produced oy the facllity. predominantly tritlim. can be safely and econoal cally managed.

\section{ACXHOHLEDGMEHT}

This work vas performed under the ausplces of the U.S. DOE by the Laurence Livermore Hationd Laboratory under contract Ho. H-7405-ENG-48.

\section{REFERERCES}

1. "General Design Criteria Manual," U.S. DOE, DOE Order 6430.1A (Dec. 7, 1987).

2. "Principles for Limiting Exposure of the Public to Natural Sources of Radiat'on." International Commssion of Radfologlcal Protection, Pub, 39, Ann. of ICRP (1983).

3. "Radiation ?rotection for Occupational Horkers," U.S. DOE, DOE Order 5480.11 (draft 4/5/BB; effective Jan. 1. 1989).

4. "LLill alaRA Progran," Kedith and Safety Manual Supplesient 33.011 , Lavrence Livermore Hational Laboratory (1986).
5. E. F, PLECHATY and J. R. KIHLINGER, "TARTHP: A Cowpled Heutron-Photon Honte Carlo Transport Code." UCRL-50400 Yol, 14. Larrence LIveraore Hational Laboratory (1976).

6. J. A. BLIHK, "FORIG: A Computer Code for Calculating Radlonutilide Generation and Oegletion in Fusion and Fission Reactors." UCRL-53633. Lawrence LIvermore National Laboratory (1985).

3. J. A. 8LIKK, R. E. DYE, and J. R. KIHLINGER, "ORLI8: A Coapiter Code that Produces One-Energy Group. TIme- and SpatiallyAveraged Heutron Cross Sections " UCRL-53262. Lawrence Livermore National Laboratory (1991).

8. J. H. PITTS et al. "Preventing Vaporization and Destructlve Shock Haves in ICF TargetChamber flrst Malls." these proceedings.

9. C. D. ORTh, "Frost as a First hall for tiue ICF Laboratory Hicrofuston Facllity, " these proceedings.

10. M. J. MONSLER and H. R. MEIER, "A CarbonFiber Brush-Like First Wall for the Laboratory Hicrofusion Faclility." these proceedings.

11. J. H. PltTS and P. R. LANDON, Lakrence Livermore Natlonal Laboratory, private cormunication (198B).

12. A. E. PROF 10, Radiation Shlelolag and Dos laetry. John wiley and Sons, Ine. Hev York, NY (1979).

13. D. G. MLLSON and 3. G. WOOCHORTH, "Final Opt I C Protection Designs for ICF Contalnment Chambers," these proceedings.

14. M. T. TOBIH, et al., "DOE Requirements for the IMF Experiment Area," Laser Pregram Annual Report 87. UCRL-50021-87. Latrence Livermore National Laboratory, to be published.

15. L. G. OESHAIER, L, E. GORRE and R. C PASiOR. "hater Free fused Sllica for Laser Hindows Hade by the Reactlve Atwosphere Fracess." in. Non-Cryst. Solids 89. $189(1986)$.

16. C. BOOCY, Sulzer Canada, Inc., Toronto Canada, private comnunication (June 1988). 
W. J. SGHAFER ASSOCIATES, INC - 6140 STONERIDGE MALL GOAD - SUITE J85 - PLEASANTON. CALIFOANIA 94566 * (415) 463.1109

March 24, 1988

SF-88-056

\section{MEM OR A N D M}

To: $\quad$ Mike Tobin, Mike Singh

From: Wayne Meier

Subject: Effect of Target $\rho R$ on Neutron Activation

As requested, I ran some TART calculations to determine the effect of the target $\rho \mathrm{R}$ on neutron activation in an aluminum first wall. The neutronics model consisted of a target at the center of a 5.0 -cm-thick aluminum chamber located at $5.0 \mathrm{~m}$. A 30 -cm-thick borated water shield surrounds the chamber wall. The target $\rho R$ was changed by changing the thickness of the source zone while leaving the material composition and density fixed. The three cases were run: $\rho R$ of 3,4 , and $5 \mathrm{~g} / \mathrm{cm}^{2}$.

The production of ${ }^{24} \mathrm{Na}$ via ${ }^{27} \mathrm{Al}(\mathrm{n}, \alpha)$ reactions and the production of ${ }^{\mathrm{N}} \mathrm{Mn}$ via ${ }^{35} \mathrm{Mn}(\mathrm{n}, 2 \mathrm{n})$ reactions are of primary irterest since the first dominates the short term hazard while the latter dominates the longer term (30 day) hazard. Both of these are threshold reactions, and we would therefore expect that increasing the target $p R$ would decrease the number of reactions since more high energy neutrons will be moderated in the compressed fuel region. The reaction rates as a function of $\rho R$ are tabulated below.

Burn zone $\rho R$

Reactions per source neutron

$$
{ }^{n} \mathrm{Al}(\mathrm{n}, \boldsymbol{\alpha})^{24} \mathrm{Na}
$$

2.710 E-2

$2.557 \mathrm{E}-2$

2.380 E-2
${ }^{s} \mathrm{Mn}(\mathrm{n}, 2 \mathrm{2n})^{\mathrm{s}} \mathrm{Mn}$

$2.922 \mathrm{E}-4$

2.660 E-4

$2.403 \mathrm{E}-4$ 
These results are plotted in Fig. 1 normalized to the respective value at a $p R$ of 3. The ${ }^{2 x} \mathrm{Na}$ production rate per source neution is reduced by $12 \%$ as the target $\rho R$ is increased from 3 to $5 \mathrm{~g} / \mathrm{cm}^{3}$. The " $\mathrm{Mn}$ production rate per source neutron is reduced by $18 \%$ over the same range of target $\mathrm{pR}$.

The above results are indicative of the effect of $p R$ on activation only if the target yield does not change with $\rho R$ (i.e., the source is constant). In reality, we expect the yield to scale as $\rho \mathrm{P} /(\rho \mathrm{R}+6)$. This relationsipip is also plotted in Fig. 1 . The yield at a $\rho R$ of 5 is $36 \%$ higher than at a $\rho R$ of 3 . The product of target yield and reactions per source neutron gives the result we want. The normalized ${ }^{20} \mathrm{Na}$ and ${ }^{5} \mathrm{Mn}$ production rates as a function of $\mathrm{pR}$ are plotted in Fig. 2. The ${ }^{2} \mathrm{Na}$ production rate increases by $20 \%$ as the target $\rho R$ is increased from 3 to 5 . The "Mn production rate increases by $12 \%$.

In summary, when we consider the combination of a reduction of activation per source neutron and an increase in the neutron yield with increasing target $\rho R$, we find that the net effect is an increase in production rate with increasing $\rho R$. 


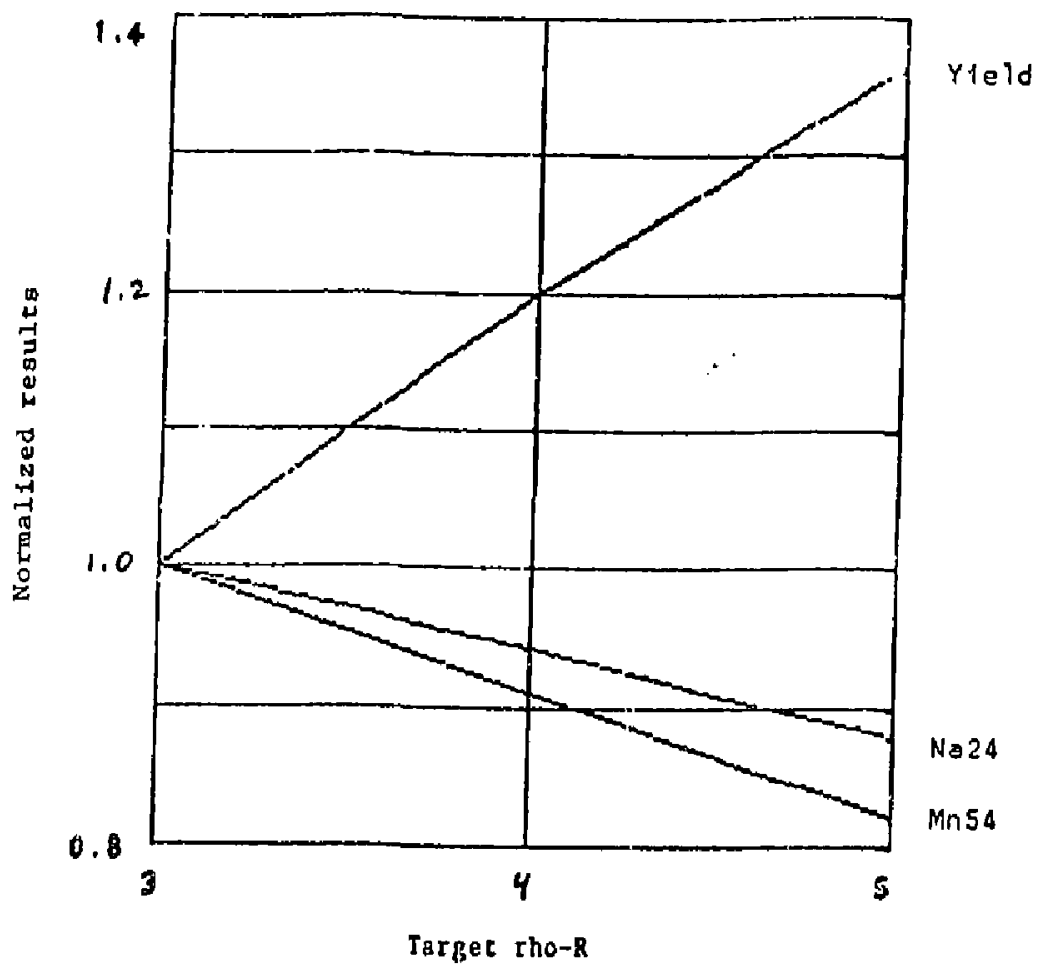

F1g. I Normalized target yfeld and normalized ${ }^{54} \mathrm{Mn}$ and ${ }^{24} \mathrm{Na}$ production rates per source neutron. 




Fig. 2 Normalized ${ }^{54} \mathrm{Mn}$ and ${ }^{24} \mathrm{Na}$ production rates when neutron source increases with target yfeld. 


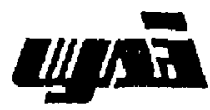

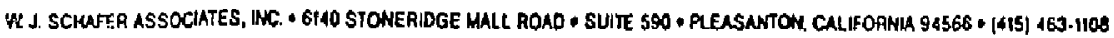

April 14, 1988

SF-88-083

\section{MEMORANDUM}

To: Charles Orth

Frow: Wayne Meier

Subject: Neutron Heating in Materials Close to the Target

At your request, I have ron a number of neutronics calculations to determine the neuron heating in materials positioned relatively close to the larget. These might include larget support structures, shrouds, irradiation samples, and perhaps even diagnostics.

\section{MODEL}

All of the calculations were done using TART. The reference case geometry consists of a sho- $\mathbb{R} S$ target at the center of a $1-\mathrm{cm}$-thick spherical shell of material with an inner radius of $10.0 \mathrm{~cm}$. The shell is divided into three, $1 / 3 \mathrm{~cm}$-thick zones, There is a vacuum between the target and the shell, and outside the shell is a leakage region (i.e, no backscatter). Calculations were done for $\mathrm{Al}, \mathrm{Fe}, \mathrm{Cu}, \mathrm{C}$, and $\mathrm{SiC}$. For aluminum, calculations were done with the inner radius of the shell at 5,10 and $15 \mathrm{~cm}$ in order 10 demonstrate the $1 / R^{2}$ scaling of the energy deposition per unit mass (J/kg). For the other material the inner radius was $10 \mathrm{~cm}$. Heating from neutrons and neutron induced gammas (i.e., from $(n, Y)$ reactions) was delermined Gamma transport was include in the calculations.

\section{TAKT RESULTS}

The results for the $\mathrm{A}$ shell at 5,10 and $15 \mathrm{~cm}$ are given in Table 1 . The energy deposition is given in $\mathrm{MeV}$ per source (14.1 MeV) neutron, while the energy density is given for a $1000 \mathrm{MJ}$ yield. Note that the energy deposition per $\mathrm{cm}$ of material is approximately constant at $0.15 \mathrm{MeV}$ per fusion neutron. As a result, the energy deposited per unit mass decreases as $I / R^{2}$, where $R$ is the radius to the middle of the shell. This is illustrated in Fig. 1. The variation in energy density across the 1-cm- 
thick shell is shown in Fig. 2 for the 10-cm shell. Extrapolating to the inner edge of the shell gives an energy density of about $2.5 \mathrm{E}+6 \mathrm{~J} / \mathrm{kg}$, which is $3 \%$ higher than the innermost zone and about $11 \%$ higher than the average for the entire shell. Results for the other materials are given in Table 2.

\section{MINTMUMM RADIUS}

While it is interesting to compare energy densities, the more important issue is determining the radius at which the material melts, sublimes or dissociates. Using the specific heat data in Table 3 and using the $1 / \mathbb{R}^{2}$ scaling, the minimum inner radius to prevent melting is given in Table 4. I have used the energy density for the innermost zone (i.e., the $1 / 3-\mathrm{cm}$ of the shell closest to the target) and assumed the injtial temperature is $293 \mathrm{~K}$. We simply solve the following for $\mathrm{R}_{\mathrm{mLr}}$;

$$
C_{p}^{*}\left(T_{L}-293\right)=E_{m l} *\left((10.167) /\left(R_{m b l}+0.167\right)\right)^{2} \text {. }
$$

$$
\text { where } \begin{aligned}
& C_{p}=\text { specific heat capacity }(\mathrm{J} / \mathrm{kg}-\mathrm{K}), \\
& T_{L}=\text { limiting temperature }(\mathrm{K}), \\
& E_{\text {ml }}=\text { energy density for innermost zone }(\mathrm{J} / \mathrm{kg}) \text {, and } \\
& R_{\min }=\text { minimum inner radius }(\mathrm{cm}) .
\end{aligned}
$$

\section{CONCLUSIONS}

As indicated in Table 4, all the materials will melt, sublime or dissociate if placed vrithin 10 to $20 \mathrm{~cm}$ of a $1000 \mathrm{MJ}$ target. Carbon and silicon carbide have comparable minimum inner radii at about $13 \mathrm{~cm}$, while the three metals considered have minimum radii closer $1020 \mathrm{~cm}$. Steel is slightly better than Al and Cu. Even if we can protect materials from $x$ rays and debris, anything this close to the target must be considered sacrificial since it will be destroyed by neutron heating. The las $101020 \mathrm{~cm}$ of the target support structure, for example, will ha're to be replaced for every shot. 
Table 1. Heating rales in Al shells with inner radii of 5, 10 and $15 \mathrm{~cm}$

Malerial - A

Yield $\mathrm{a} 1000 \mathrm{MJ}$

\begin{tabular}{cccccc}
$\begin{array}{c}\text { Zone } \\
\text { inner radius } \\
(\mathrm{cm})\end{array}$ & $\begin{array}{c}\text { Energy } \\
\text { deposition } \\
(\text { MeV/n) }\end{array}$ & $\begin{array}{c}\text { Slandard } \\
\text { deviation } \\
(\text { Mev/n) }\end{array}$ & $\begin{array}{c}\text { Standard } \\
\text { deviation } \\
(\%)\end{array}$ & $\begin{array}{c}\text { Mass .* } \\
(\mathrm{kg})\end{array}$ & $\begin{array}{c}\text { Energy } \\
\text { density } \\
(\mathrm{J} / \mathrm{kg})\end{array}$ \\
\hline & & & & & \\
5.000 & 0.04953 & $5.06 \mathrm{E}-04$ & 1.0 & 0.302 & $9.318 \mathrm{E}+06$ \\
5.333 & 0.04986 & $4.56 \mathrm{E}-04$ & 0.9 & 0.342 & $8.278 \mathrm{E}+06$ \\
5.667 & 0.04819 & $4.57 \mathrm{E} \cdot 04$ & 0.9 & 0.385 & $7.113 \mathrm{E}+06$ \\
& 0.14758 & & & 1.029 & $8.147 \mathrm{E}+06$
\end{tabular}

$\begin{array}{llllll}10.000 & 0.04986 & 7.67 \mathrm{E}-04 & 1.5 & 1.169 & 2.423 \mathrm{E}+06 \\ 10.333 & 0.05033 & 8.42 \mathrm{E}-04 & 1.7 & 1.247 & 2.293 \mathrm{E}+06 \\ 10.667 & 0.04860 & 6.05 \mathrm{E}-04 & 1.2 & 1.327 & 2.080 \mathrm{E}+06\end{array}$

Tolal

0.14879

$3.744 \quad 2.258 \mathrm{E}+06$

$\begin{array}{llllll}15.000 & 0.05144 & 9.22 E-04 & 1.8 & 2.602 & 1.123 E+06 \\ 15.339 & 0.05112 & 9.46 E-04 & 1.9 & 2.717 & 1.059 E+06 \\ 15.667 & 0.04896 & 6.70 E-04 & 1.4 & 2.835 & 9.811 E+05\end{array}$

Tolal

0.15152

$8.154 \quad 1.056 E+06$ 


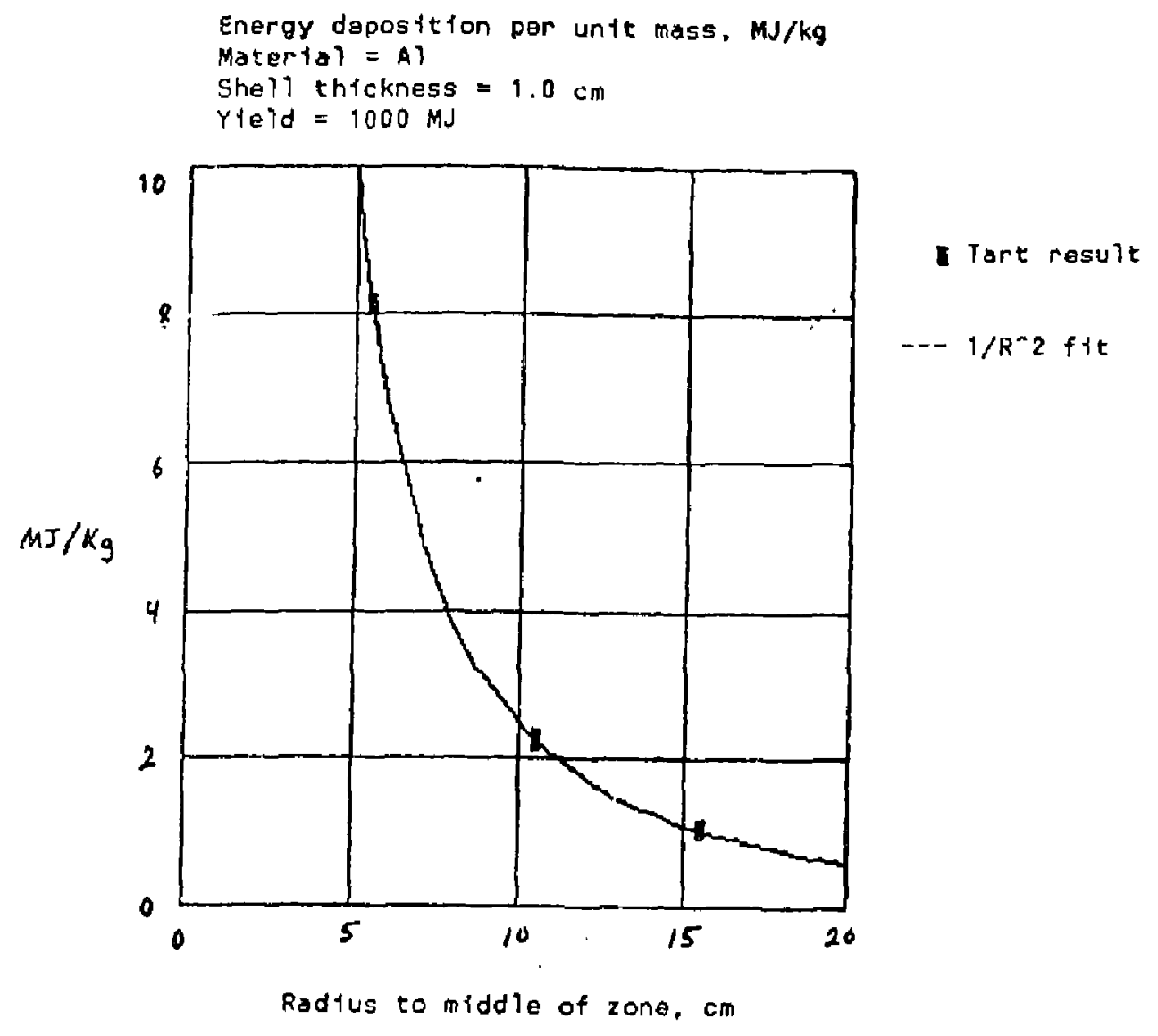

Fig. 1. Energy density in Al shell as a function of shell radius. Results are plotted at the middle of a 1-cm-thick shell, 
$M J / k g$ deposited in Al shell

Inner radlus $=10.0 \mathrm{~cm}$

Thtekness $=1.0 \mathrm{~cm}$

Yield $=1000 \mathrm{~mJ}$

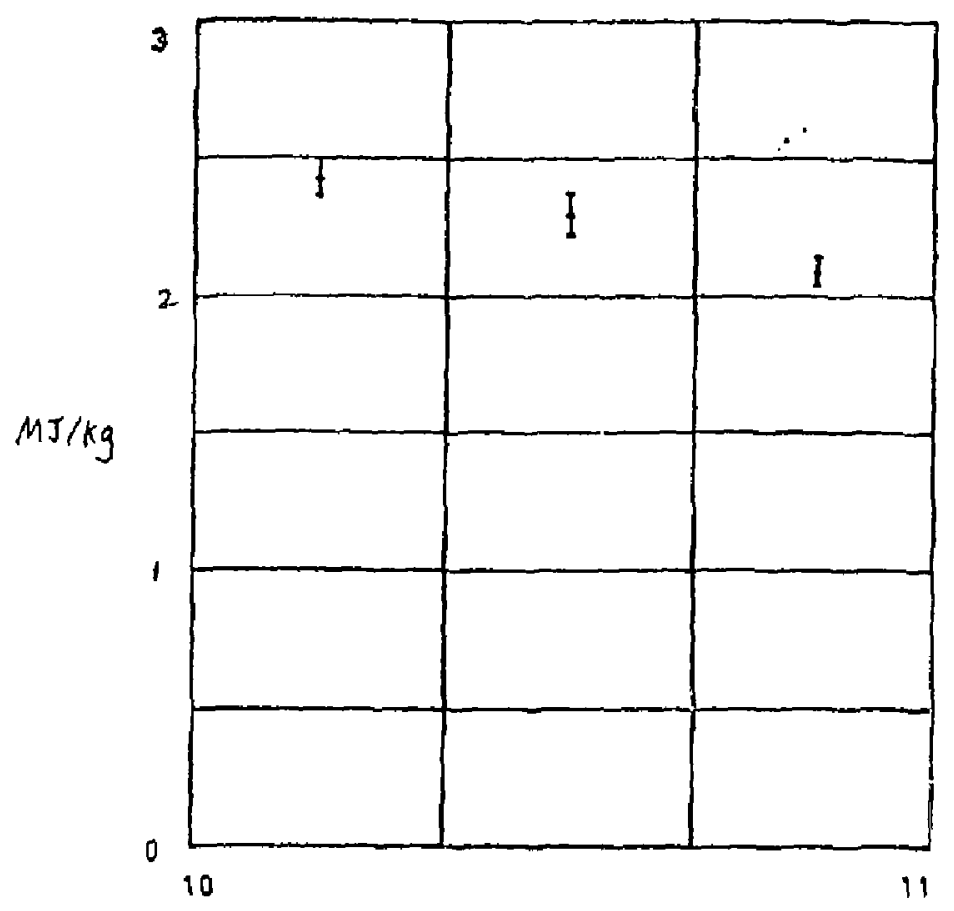

Radius, cm

Fig. 2. Yariation in energy density for an Al shell with inner radius of $10 \mathrm{~cm}$. Error bars are at $+/-2$ standard deviations. 
Table 2. Healing rates in $\mathrm{Fe}, \mathrm{Cu}, \mathrm{C}$ and $\mathrm{SIC}$ shells

Yield - $1000 \mathrm{MJ}$

Inner radius $=10 \mathrm{~cm}$

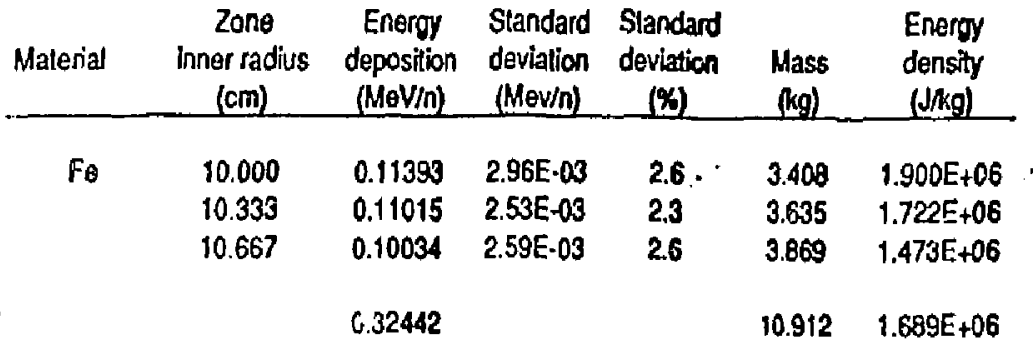

Cu

10.000
10.333
10.667

$0.10497 \quad 2.30 \mathrm{E}-03$

2.2

$3.880 \quad 1.537 \mathrm{E}+06$

10.333

$0.10372 \quad 2.08 E-03$

$2.0 \quad 4.138 \quad 1.424 E+06$

10.667 $0.09133 \quad 1.75 E-03$

1.9

$4.405 \quad i .178 E+06$

Total

0.30002

$12.423 \quad 1.372 E+06$

C

10.000
10.333
10.667

0.05687

4.82E-04

0.8

$0.736 \quad 4,390 E+06$

10.667

0.05634

$5.20 \mathrm{E}-04$

0.9

$0.785 \quad 4.077 \mathrm{E}+06$

$0.05470 \quad 3.73 E-04$

0.7

$0.836 \quad 3.719 E+06$

Total

0.16791

$2.357 \quad 4.048 E+06$

36

10.000
10.333
10.667

$0.08663 \quad 8.88 \mathrm{E}-04$

$0.08574 \quad 8.45 \mathrm{E}-04$

$0.08234 \quad 6.05 E-04$

1.0
1.0
0.7

$1.386 \quad 3.552 E+06$

$1.478 \quad 3.296 E+06$

0.25479

$4.437 \quad 3.262 E+06$ 
Table 3. Relevant physical properties (Ret. 1)

\begin{tabular}{|c|c|c|c|c|}
\hline Material & $\begin{array}{l}\text { Density } \\
\left(\mathrm{kg} / \mathrm{m}^{\prime}\right)\end{array}$ & $\begin{array}{l}\text { Snecific } \\
\text { Heat Cap. } \\
(\mathrm{J} / \mathrm{kg}-\mathrm{K})\end{array}$ & $\begin{array}{l}\text { Limiling } \\
\text { Temperature } \\
(\mathcal{K})\end{array}$ & Noles \\
\hline A & 2700 & 962 & 855 & (6061-T6 alloy) \\
\hline $\mathrm{Fe}$ & 7870 & 418 & 1783 & (AISIC1020 steel) \\
\hline $\mathrm{Cu}$ & 8960 & 385 & 1355 & \\
\hline C & 1700 & 690 & 3977 & (sublimes) \\
\hline $\mathrm{SiC}$ & 3200 & 837 & 3033 & (dissocia!es) \\
\hline
\end{tabular}

Ref. 1 Marks' Standard Handbook for Mechanical Engineers, McGraw Hill, NY, sth Ed., pgs. 6-11, 6-61, 6-176 (1978).

Table 4. Mínimum inner radii tor the five materials

\begin{tabular}{cc} 
Material & $\begin{array}{c}\text { Radius } \\
(\mathrm{cm})\end{array}$ \\
\hline $\mathrm{AJ}$ & 21.4 \\
$\mathrm{Fe}$ & 17.6 \\
$\mathrm{Cu}$ & 19.6 \\
$\mathrm{C}$ & 13.2 \\
$\mathrm{SiC}$ & 12.5
\end{tabular}




\section{패해}

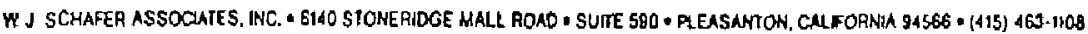

April 29, 1988

SF.88-095

To: Neil Frank, Dennis Slaughter

From: Michael Monsler

Subject: An experiment to test the carbon carpet first wall concept

\section{Issues and Qbjectives}

1) We know we're going to have vaporization and we can calculate the mass vaporized. Our model indicates it is the same as a flat plate. If we just want to verify vaporization dynamics, we could use a flat plate. Vaporization in itself is not a critical issue.

2) The seal purpose of the CCFW is to lengthen the duration of the impulse resulting from the $x$-ray deposition, without damaging the underlying structure. The magnitude of the impulse itself is not an issue, since it is the same for a flat plate or a carpet. Too bad, because the impulse (integral of pressure over time) is easily measured with a ballistic pendulum. We realiy need to measure either the pressure or the duration (1-10 $\mu \mathrm{sec}$; then, knowing the impulse, we can get the other.

3) We must obtain a realistic energy depositions, on both flat tile and brush-like samples. We must get the deposition length and tomescales right.

4) The key issue and concern is survivability of the fibers and the support plate. We now suspect failure is due to compressive thermal stress in the individual filaments. The simulation must be able to deterrine if filaments have failed. Are they ctushed by blow-off struss and or by thermal shock? The suppon plate has to be protected from direct exposure by proper design of the carpet. We have to show that the stress due to impulse on the support plate is acceptable.

Microscopic examination of the filaments after one pulse, and after 10 to 100 pulses, is desirable. So is a careful mass loss observation. It is desirable to distinguish between amounts of evaporation loss and of breakage. Does the damage extend beyond the furst outer layer of filaments in each fiber? Again a flat carbon sample should also be irradiated as a control.

5) We suspect that the brush will recondense the vaporized material quicker than a flat plate. A comparison of weight loss should give some indication of the effectuveness. What does the recondensed carbon look like. Again microscopic examination is critical, For multiple shots, we should look to see if recondensed carbon protects the fibers on subsequent shots. The interpulse time must be long enough to allow the sample to return to ambient temperature between shots. 
6) To reiterate, there are two key issues that an experiment must address.
a) Does the $\mathrm{CC}$ work as advertised by stretching out the duration of the impulse?
b) Is the total damage due to melting and breakage acceptable, such that the carpet does not have to be replaced very often?

\section{Energy Solarce}

1) What fluence do we need? A yield of $1000 \mathrm{MU}$ has $20 \%$ in $\mathrm{x}$-rays. At 5 meters radius we get a fluence of

$$
F=\frac{200 M J}{4 \pi(5 \mathrm{~m})^{2}}=60 \frac{\mathrm{J}}{\mathrm{cm}^{2}}
$$

Fluences of this order are needed to significantly exceed the vaporization threshold for carbon.

2) Spot size? A flat carbon surface has a blowoff layer that is 1 to $10 \mu \mathrm{m}$ thick, so a spot size of $10-100 \mu \mathrm{m}$ is adequate to achieve a one-dimensioned simulation. Our carbon brush surface is $1 \mathrm{~cm}$ deep, so to avoid the interference of edge effects we have to either have a $10 \mathrm{cr}$ spot size of put a $1 \mathrm{~cm}$ sample in a stoul cylindrical cup, so there will be no pressure relief from the edges.

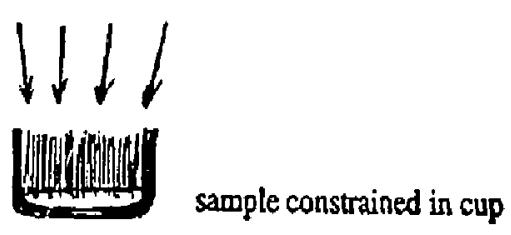

3) Background Pressure? A vacuum is needed, although not a very good one. The pressure of one atmosphere is well known to interfere with the experiment va laser suppc ted detonation waves, which must be avoided.

4) Wavelength and Pulselength? The key lengths and timescales in the $x$-ray deposition process are the mean free path of $1 \mathrm{keV} x$-ray in carbon $(l=2 \mu \mathrm{m})$ and the $\mathrm{x}$ ray pulse width (10ris).

Since the thermal diffusivity of carbon is about $\mathrm{K}=0.2 \mathrm{~cm} / \mathrm{sec}$, the thermal conduction time required to transfer heat for distances of the order of the deposition zone depth is

$$
t_{c}=\frac{\ell^{2}}{k}=\frac{\left(2.10^{-1} \mathrm{~cm}\right)^{2}}{0.2 \mathrm{~cm}^{2} / \mathrm{sec}}=200 \mathrm{nsec}
$$

Thus the $x$-ray pulse deposits energy in a time shor compased to the thermal conduction time, and so must the simulation. A laser or e-beam with a pulse width less than 100 nsec is ok.

The deposition depth must be realistic also. A laser of any wavelength is ok since energy will be deposited in depths less than $2 \mu \mathrm{m}$. An E-beam having an electron energy of $50 \mathrm{keV}$ or less would be required to get a high enough energy deposition at depths of $2 \mu \mathrm{m}$ or less. 


\section{Target Samples}

1) Both flat carbon samples and carbon carpet samples are required. It is desirable if they are close to the same kind of graphite. This may be impossible

2) Carbon fibers must be of the compound filament type (10,000 filament//5ber).

3) The cheapest way to prepare a few $\mathrm{cm}^{2}$ sample carpet is to hand weave one, exactly as they make wigs. Bundles of fibers are sewn to backing fabric as shown in Figure 2a. Bundles are sewn tightly enough together so they stand up, shoulder to shoulder, as in Figure $2 b$ they are then sheared off at an even height.

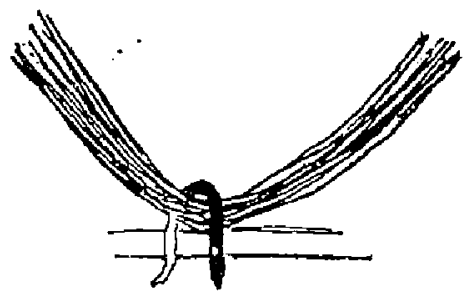

Figure 2a

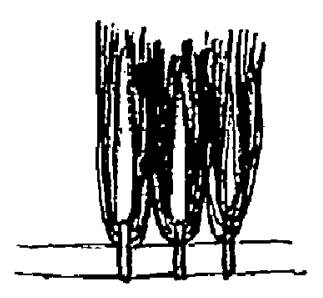

Figure $2 b$

The sample is the glued into the cylindricar cup in which it will be irradiated.

4) Some fibers should probably be inadiated separately at theta $=0^{\circ}$, i.e. sideways, and examined for damage mechanism.

IV. Data and Diagnostics

a) Measure mass loss per shot and after 10 and 100 shots from both carpet and flat plate. Try to distinguish between vaporization and breakage.

b) Measure impulse using a ballistic pendulum.

c) Measure either the pressure or the duration of the blowoff. We don'l know the best way to do this for timescales of $500 \mathrm{~ns}$ to $5 \mu \mathrm{sec}$. Would inserting a piezotiectric disk between the sample and pendulum give the desired $p=p(t)$ ?

d) Examine filaments microscopically to determine damage mechanism and recondensation morphology. Look for evidence of vaporization, melting, thermal shock. spallation, etc.

e) Observe gross changes in carpet - are fibers in iufts pushed aside, or smashed Dat, elc.

\section{Suggested Experiment}

A $100 \mathrm{~J}$ Nd: Glass or $\mathrm{CO}_{2}$ laser focused to a $1 \mathrm{~cm}^{2}$ spot size would be great. Tae pulse width must be $<100$ ns however, pulses of 1 usec to $1 \mathrm{~ms}$ are way 100 long. Wavelength is not critical. The sample should be mounted on a ballistic pendulum in a small vacuum chamber, as shown in Figure 3. 

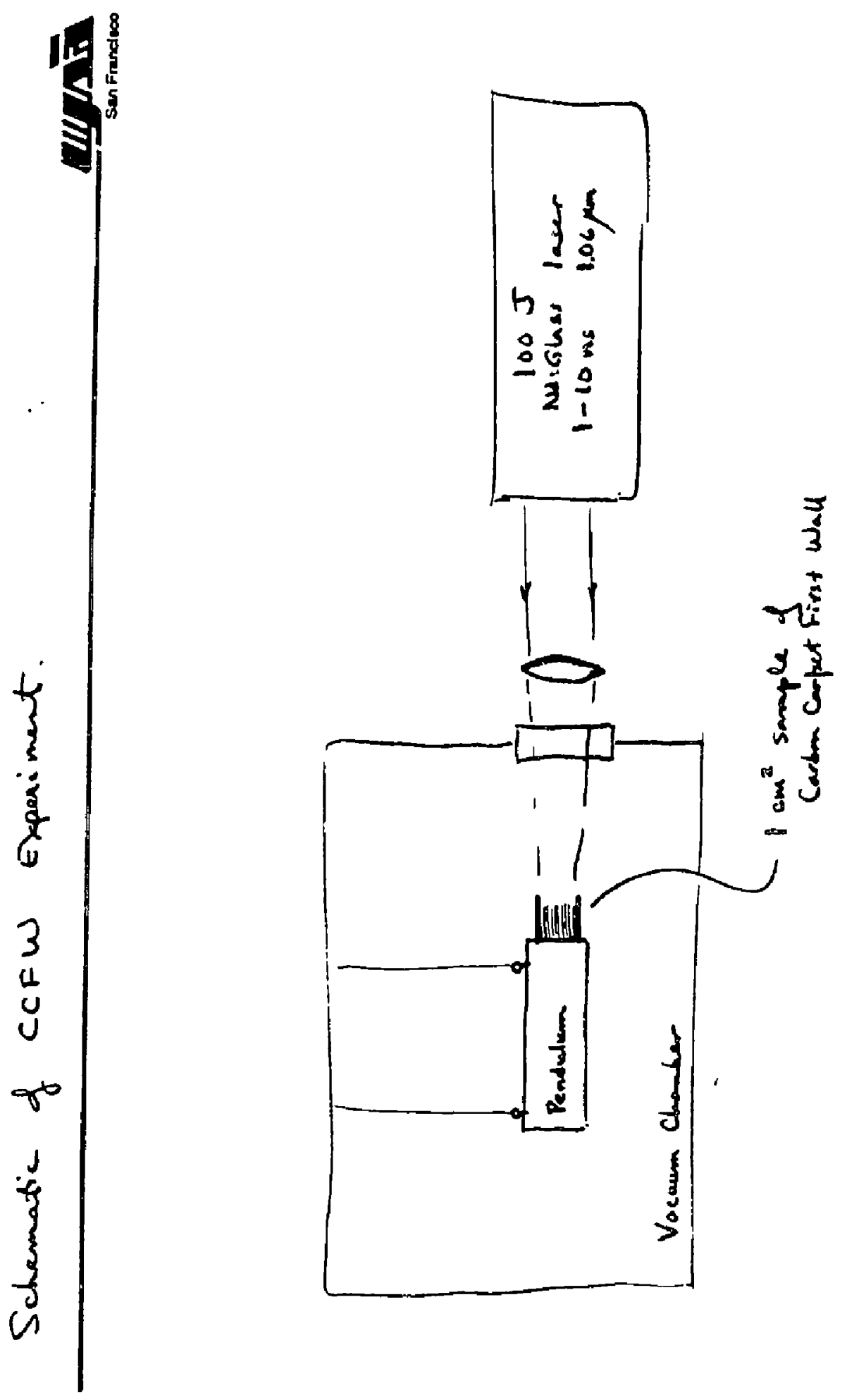


\section{III/}

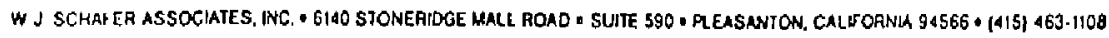
March 22, 1988

SF-88.055

To: $\quad$ Dave Nilson, John Woodworth, Charles Orh, Neil Frank

From: Michael Monsler

Subject: Gas Protecion from Target Shrapnel

\section{MEMORANDUM}

Can the gas protection that we envision usirg to stop $x$-rays and ions aiso stop such large debris as particulates having a diameter of micron to a millimeter? To answer this we shall do a simple drag calculation.

Assume a target of mass $M$ disassembles instead of vaporizes, such that $\mathrm{N}$ particles are formed, each of diameter $D_{p}$ and mass $m$. These particles start out with a total kinetic energy $\mathbb{E}$.

Then

$$
\begin{aligned}
& E=N\left(\frac{m v_{0}^{2}}{2}\right) \text {, and } \\
& M=N_{m}=N p_{p} \frac{\pi}{b} D_{p}^{3} \quad \text { where } \rho_{p}=\text { particle density }
\end{aligned}
$$

The initial velocity of each particle is:

$$
V_{t}=\sqrt{\frac{2 E}{M}}
$$

The particles decelerate by drag as follows:

$$
m \frac{d v}{d t}=-C_{0} A \frac{1}{2} p_{0} v^{2}
$$

We note that $P_{t}=$ gas density, and $C_{D}$ is the drag coefficient. Writing the particle mass $m$ and the frontal area $A$ in terms of the diameter $D_{p}$ gives the velocity decay as follows:

$$
\left.\frac{1}{V^{2}} \frac{d V}{d t}=-C_{D} / \frac{3}{4 D_{p}}\right) \frac{p_{s}}{p_{p}}
$$

The best way to integrate this is the calculate the stopping distance $\mathrm{L}$ as follows:

$$
L=\int_{0}^{t} v d t=-\frac{4 D_{p}}{3 C_{0}} \rho_{p} \int_{p_{V_{0}}} \int_{V_{0}}^{V_{f}} \frac{d v}{V}=\frac{4 D_{p} \rho_{\rho}}{3 C_{0} \rho_{s}} \ln \left(\frac{V_{p}}{V_{f}}\right)
$$


Let's rewrite this to appreciate the relationship between the stopping power of the gas, $\rho_{B} l$ in $g m s / \mathrm{cm}^{2}$, and the areal density of the particle, $\rho_{p} D_{p}$.

$$
p_{s} L=\left(p_{p} D_{p}\right)\left(\frac{4}{3 C_{0}}\right) \ln \left(V_{0} / v_{f}\right)
$$

To evaluate this equation, imagine a target of mass $M=1 \mathrm{gm}$ disassembies with a kinetic energy of $E=100 \mathrm{MJ}$. It's hard to imagine a larger : strergy than this because if this were to be a proper implosion, everything would vaporize and there would be no shrapnel. The initial velocity is then $Y_{0}=4.47 \times 10^{5} \mathrm{~cm} / \mathrm{sec}$. Assume we want to slow it down to $V_{f}=1 \mathrm{~cm} / \mathrm{sec}$. Then $\ln \left(V_{0} / V_{p}\right)=13$. Fortunattly the $\ln \left(V^{\circ} / N^{4}\right)$ logarithm is very insensitive to the assumptions. The drag coefficient for spheres at very high velocity varies from $C_{D}=0.5$ just after the iurbulent transition to $C_{D}=2$ for Newtonian hypersonic now. Let's simply take $C_{D}=1.0$ since we don't know the true unspherical shape of tie particle anyway. We then get

$$
\rho_{g} L=17.3 \rho_{p} D_{q}
$$

for the required stopping power of the gas. Note that if both sides of the equation are multiplied by the frontal area of the particle, we get a rule of thurob that says that to sop the paricle by aerodynamic drag, you need a mass of gas an order of magninude greater than the mass of the particle.

Tn stop the $x$-rays we have previously calculated that we would need a densitylength product of

$$
\left(\rho_{0} L\right)_{x \cdot m y}=1.4 \times 10^{-3} \mathrm{~g} / \mathrm{cm}^{2}
$$

This amount of gas protection will apparendy slop all gold particles $\left(\rho_{\mathrm{F}}=19.3 \mathrm{gm} / \mathrm{cm}^{3}\right)$ in the diameter range $O<D_{p}<6.5$ microns. Larger particles will sequire either more gas, or a solid debris shield.

We do not know the expected particulate diameter distribution, integrated over ime. The majority of particulates should be less than several microns, and the gas 
protection will filler these out. However, since it is probable that there will be a few occasional particles in the range of 10 microns 101 millimeter which the gas will not stop, it would seem wise to plan on using solid debris shields as well. 


\section{IIfin}

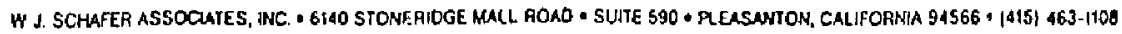

March 28, 1988

SF-88-057

To: Neil Frank, Dave Nilson, Charles Orth, Tohn Woodworth

From: Michael Monsier

Subject: Gas Protection Against Debris Ions

MEMORANDUM

Because there are so many physical processes occurring during the deceleration of a fast ion in a neutral gas, it is best to not stray too far from empirical data. I have not found data tables for gold ions slopping in argon gas, but there are data for other beavy ions in air from which we can scale.

We shall fit a scaling law to a few representative data points that span the atomic weight range. The data are for slopping in air rather than in solids. Unfonunately the data are at higher energy, but thal's all I have at the moment. In his book The Alomic Nucleus, R.D. Evans, discusses the stopping of both fission products and alpha particles in air at one atmosphere pressure. The data given in Table 1 that we shall scale from is taken from Evans, Chapter 22, "The Passage of Heavy Changed Particles through Matter".

$\begin{array}{lccc}\text { Atom } & \begin{array}{c}\text { Mass } \\ \text { Number }\end{array} & \begin{array}{c}\text { Energy } \\ \text { in MeV }\end{array} & \begin{array}{c}\text { Range } \\ \mathrm{cm}\end{array} \\ \mathrm{He} & 4 & 3.4 & 8.6 \\ \mathrm{Hr} & 97 & 95 & 2.5 \\ \mathrm{Se} & 138 & 67 & 1.9\end{array}$

Table 1. Range of some ions in one atmosphere air.

To scale to the situation of laser fusion debris ions, we shall take the simple approach of creating a range-energy scaling relation that fits the data of Table 1. This will be adequate for engineering estimates. 
A simple relationship for the range in one atmosphere air that fils the above data is:

$$
R_{0}=(1.9 \mathrm{~cm})\left(\frac{E}{67 \mathrm{MeV}}\right)^{0.2}\left(\frac{A_{i}}{138}\right)^{-0.6}
$$

where $\mathrm{E}$ is in $\mathrm{MeV}$ and the mass number of the ion is $\mathrm{A}_{\mathrm{i}}$. This holds in air of density $p_{0}=1.23 \times 10^{-3} \mathrm{gm} / \mathrm{cm}^{2}$ and an average mass number of $A_{0}=14.6$

How do we scale to other media than air, at other densities? Evans (p653) says that the quantity $(R \rho) \times d A$ is constant to within $+/-15 \%$ for heavy paricles whose range has not been shortened by multiple scattering in high $\mathrm{Z}$ materials. We therefore set

$$
\frac{\rho R}{\sqrt{A}}=\rho_{0} R_{0}
$$

and oblain for our stopping power in a gas

$$
p R=\left(2.34 \times 10^{-3} \frac{\mathrm{gm}}{\mathrm{cm}^{2}}\right)\left(\frac{A_{\mathrm{gq}}}{14.6}\right)^{0.5}\left(\frac{E_{\text {im }}}{67 \mathrm{MvV}}\right)^{0.2}\left(\frac{A_{\text {im }}}{138}\right)^{-0.6}
$$

Now let's relate this to ICF by the following example. Imagine a gold target of mass $2 \mathrm{gm}$, having an energy in debris ions of $200 \mathrm{MJ}$. The energy per particle would be $E=206 \mathrm{keV}$. Gold has a mass number of $A_{i}=197$. Argon has a mass number of $A=40$ and a standard density of $1.78 \times 10^{-3} \mathrm{gm} / \mathrm{cm}^{3}$.

The stopping power of the argon is then $\rho R=9.84 \times 10^{-4} \mathrm{gm} / \mathrm{cm}^{2}$, or 4.2 torr-meters at $273 \mathrm{~K}$. Using twice this much gas should assure the safety of the optics. 


\section{때소.}

W I SCHAFER ASSOCIATES, INC • 6140 STONERIDGE MALL ROAD - SUITE \$90 + PLEASARTOH, CALIFORNIA 94565 • (415) 469-1108

April 5, 1988

SF-88-066

\section{MEMORANDUM}

To: $\quad$ Neil Frank, Dave Nilson, Dennis Slaughter, John Woodworth

From: Michael Monsler

Subject: Gas-breakdown limit on gas protection to first walls.

How much gas can be added to the entire chamber to protect the first wall by absorbing the $x$-rays and debris? One limit on the gas pressure would be the occurrence of laser-induced gas breakdown near the target. During Nova operation it has been noted that a very small amount of air (in the millitorr range) in a leaky spanal filter will block the beam at the focal point. To estimate the breakdown limit, we have found an excellent paper with experimental data in the correct wavelength and pulselength range. The reference is "Laser-induced breakdown in $N_{2}$ and rare gases at 0.53 and 0.35 micrometers", by D.I. Rosen and G. Weyl, J. Phys. D: Appl. Phys. 20, (1987), $1264 \cdot 1276$.

Rosen and Weyl provide a graph of argon breakdown as a function of pressure at $\tau_{\mathrm{p}}=15 \mathrm{~ns}$ and a wavelength of 0.35 microns. Fitting their data, which is shown in the enclosed viewgraph, the breakdown threshold is

$$
I_{b d}=\left(3.5 \times 10^{11} \mathrm{w/ \textrm {cm } ^ { 2 }}\right)\left(\frac{p}{760 \text { torr }}\right)^{-0.85}\left(\frac{\tau_{p}}{15 \mathrm{ws}}\right)^{-0.6}
$$

Breakdown is defined as the appearance of a visible spark. At threshold, a yariation of a factor of two in laser power changes the probability of occurrence of a spark from less than 0.5 to more than 0.9 . The onset of average pulse energy attenuation greater than $5 \%$ correlated very well with the appearance of a spark. 
Using the above fit to experimental data, and assuming that a $10 \mathrm{~ns}$ shaped ICF pulse has most of its power in the last 5 ns, we expect an average intensity at the target on each of two sides of

$$
I=\frac{5 \mathrm{MJ}}{\pi(50 \mathrm{pmd} \times 30 \mathrm{~m})^{2} 5 \mathrm{~ns}}=\frac{10^{15} \mathrm{~W}}{\pi(0.15 \mathrm{~cm})^{2}}=1.4 \times 10^{16} \mathrm{15} / \mathrm{cm}^{2}
$$

We assumed that the beams add linearly; there will certainly be intensity spikes larger that this.

Setring the breakdown flux equal to the expected intensity, and setting $\tau_{p}=5 \mathrm{~ns}$, gives a maximum allowed pressure of argon in the chanber of

$$
p_{\text {max }}=6.4 \times 10^{-3} \text { torr }
$$

This amount of gas, distributed throughout a chamber of $R=5$ meters, will provide only 0.032 torr - meters of protection. The stoppir 3 power of argon for $1 \mathrm{keV}$ x-rays is such that 1.4 torr - meter of argon is needed to provide an attenuation of $\mathrm{e}^{-1}$ due to the photoeleitric effect. An amount of gas that will just cause breakdown near the targat is therefore very ineffective in protecting the wall. We plan on using at least 7 tors - meters to protect the optics.

One can operate somewhat above breakdown of course; most of the photons will probably still get on targei. It would be very risky to go too much above breakdownt, however, because of refractive effects in the plasmia. To get appreciable profection one would have 10 operate at pressures of 50 times the breakdown threshold - an unlikely prospect. I conclude that gas protection is not a viable first wall protection scheme for laser fusion. 


\section{Laser-induced breakdown in nitrogen and the rare gases at 0.53 and $0.35 \mu \mathrm{m}$}

D I Rosen and G Weyl

J. Privs. D: Appl. Phys. 20 (1987) 1264-12?6.

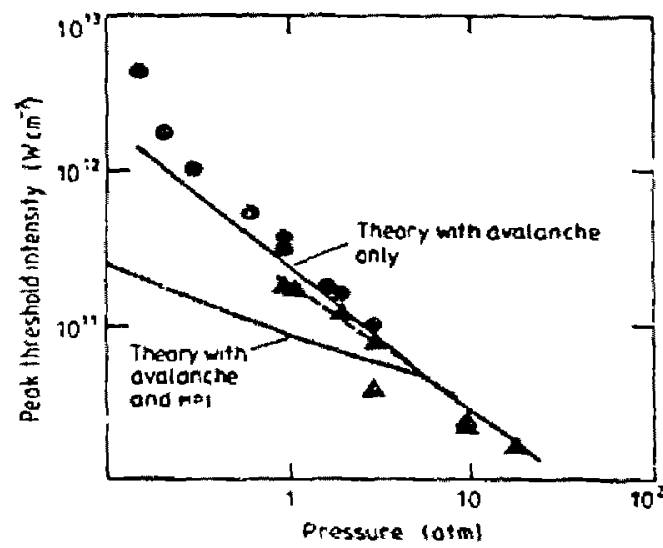

Figure 2. The breakdown threshold in argon at $\lambda=0.53 \mu \mathrm{m}: \theta$, f/10 optics, $t_{t}=6.5 \mathrm{um} ; \mathrm{A}$. $f / 30$ optics. $r_{1}=19.5 \mu \mathrm{m} ;-.-$ corrected (see text) measured thresholds of Buscher et al (1965) with $\tau_{p}=28 \mathrm{~ns}$ and $r_{1}=16 \mu \mathrm{m}$.

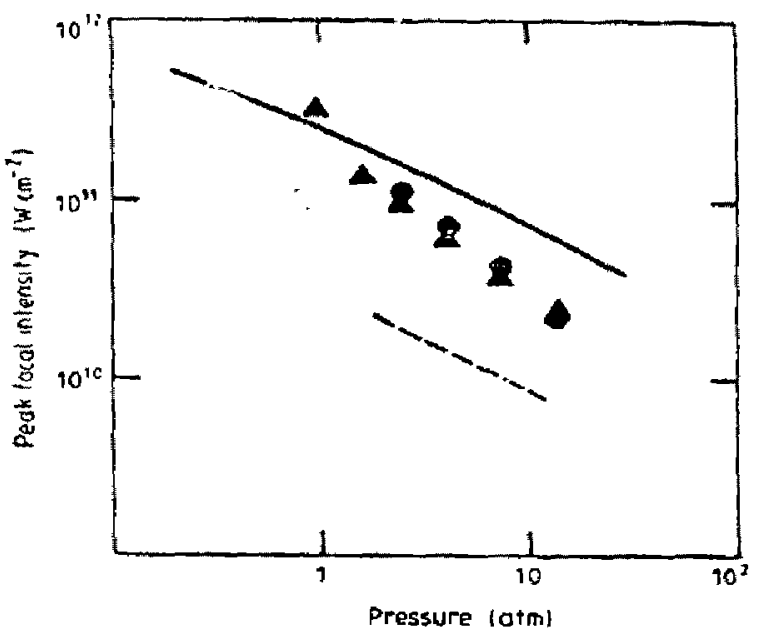

Flgure 3. The breakdown threshold in argon for $\lambda=0.35 \mathrm{um} ; 4$. $t / 14.6$ optics, $r_{r}=6.4 \mu \mathrm{m}: 6$. $f / 30$ optics, $r_{f}=7.7 \mathrm{um} ;$... corrected (see text) meastired thresholds of Buscher ef al (1965) with $\tau_{0}=20 \mathrm{~ns}$. 
Concepts for the Final Optical System of the Laboratory Microfusion Facility

\author{
M. J. Monsler \\ W. J. Schafer Associates, Inc. \\ February 16, 1988
}




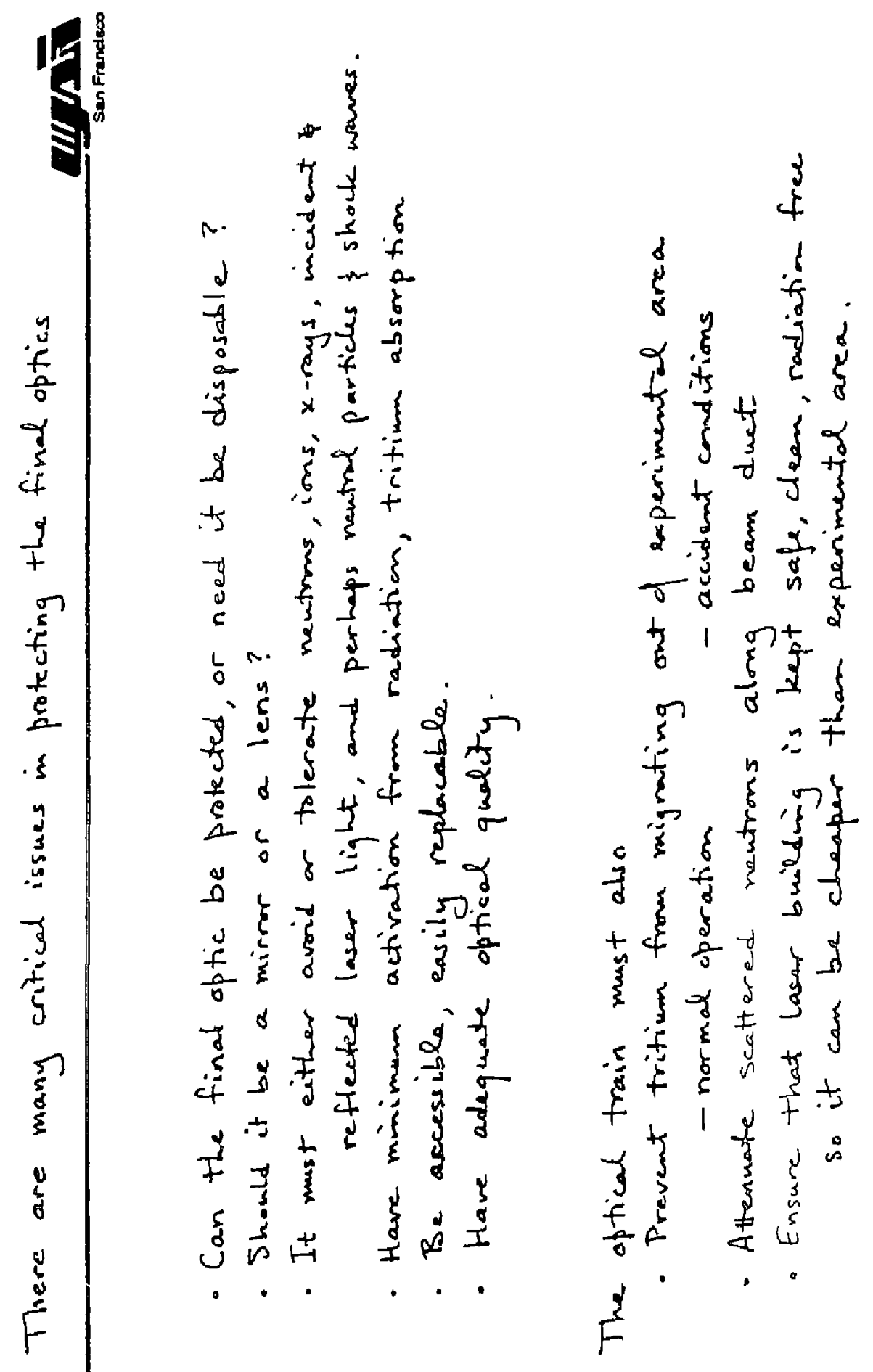




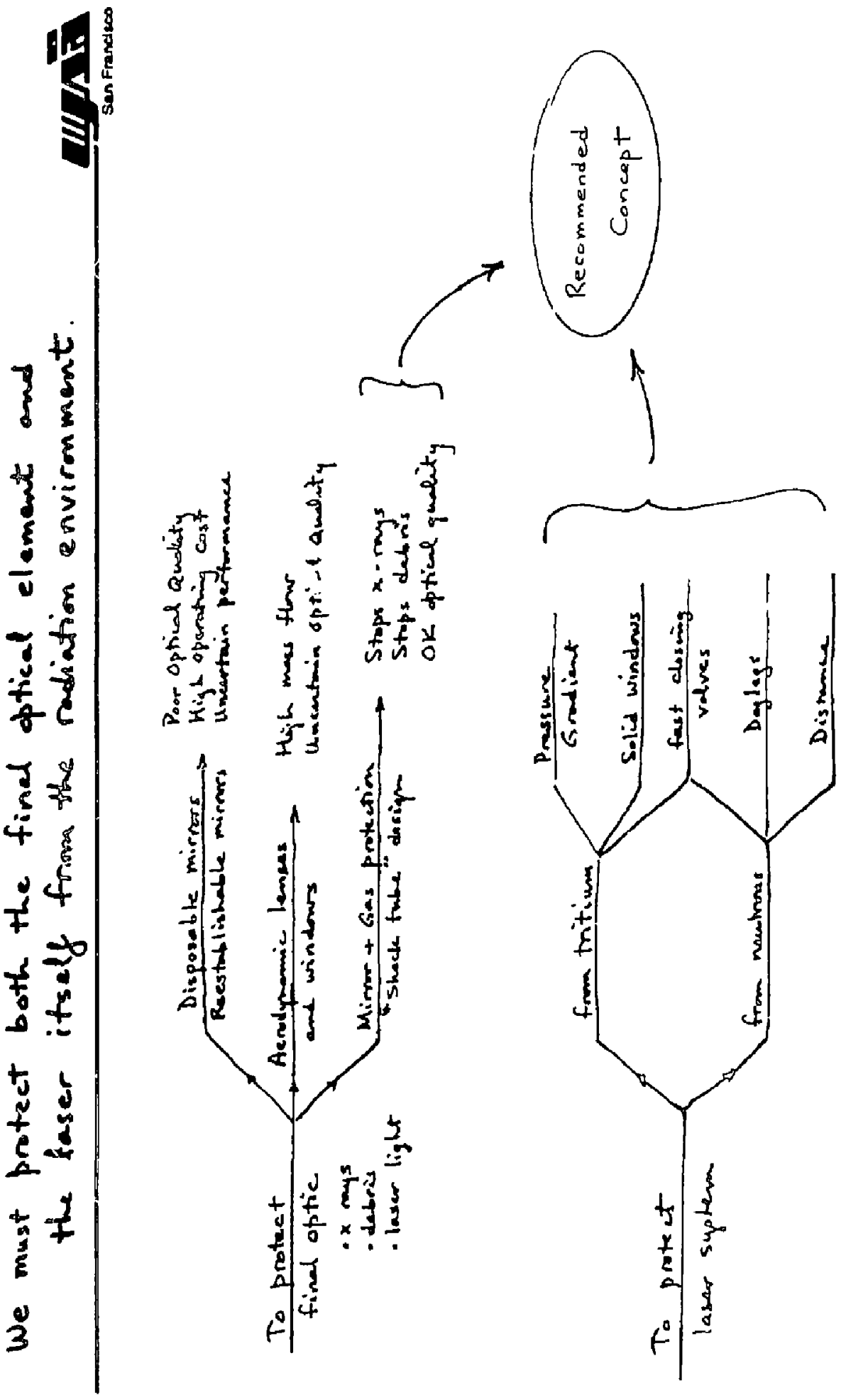




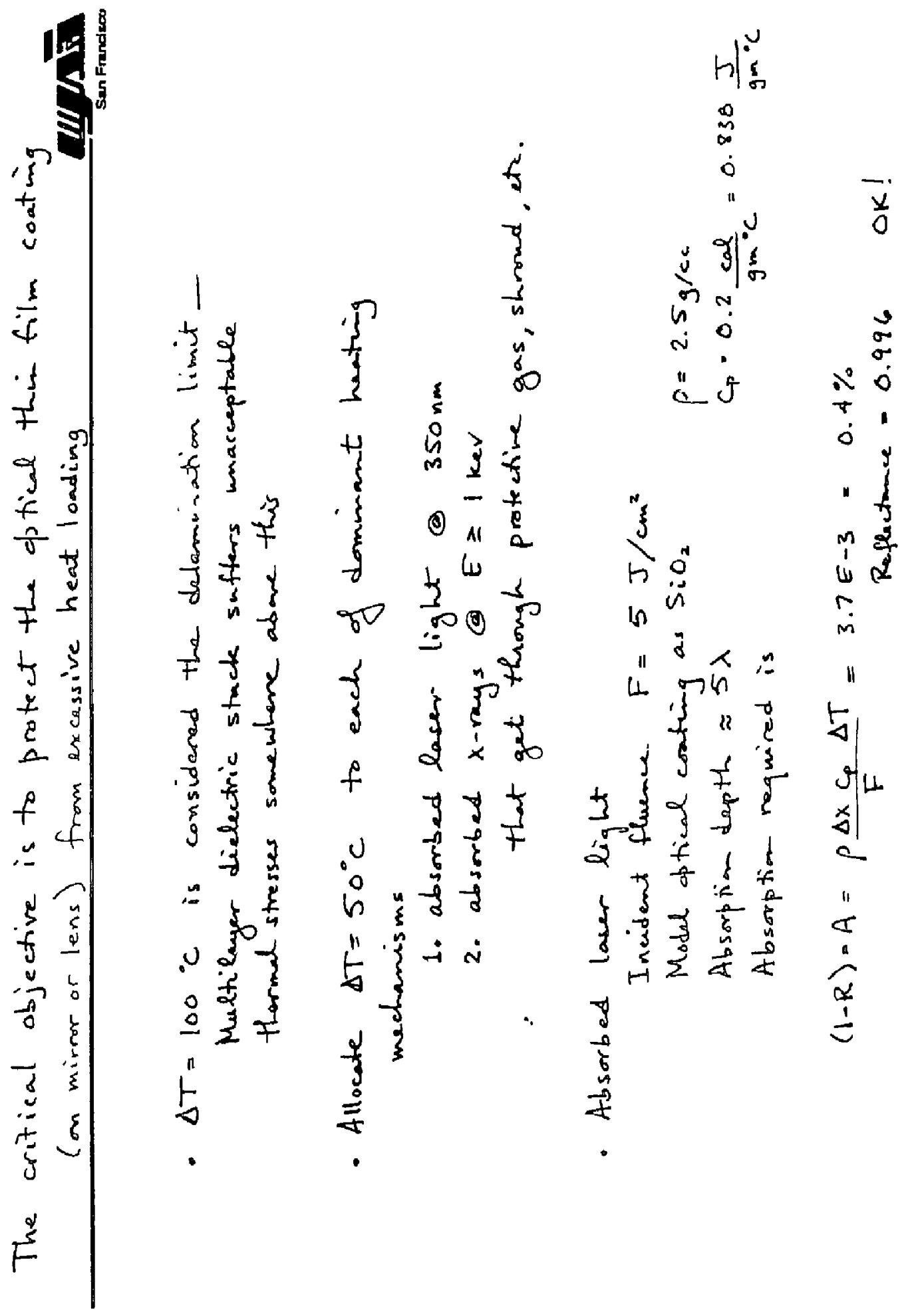




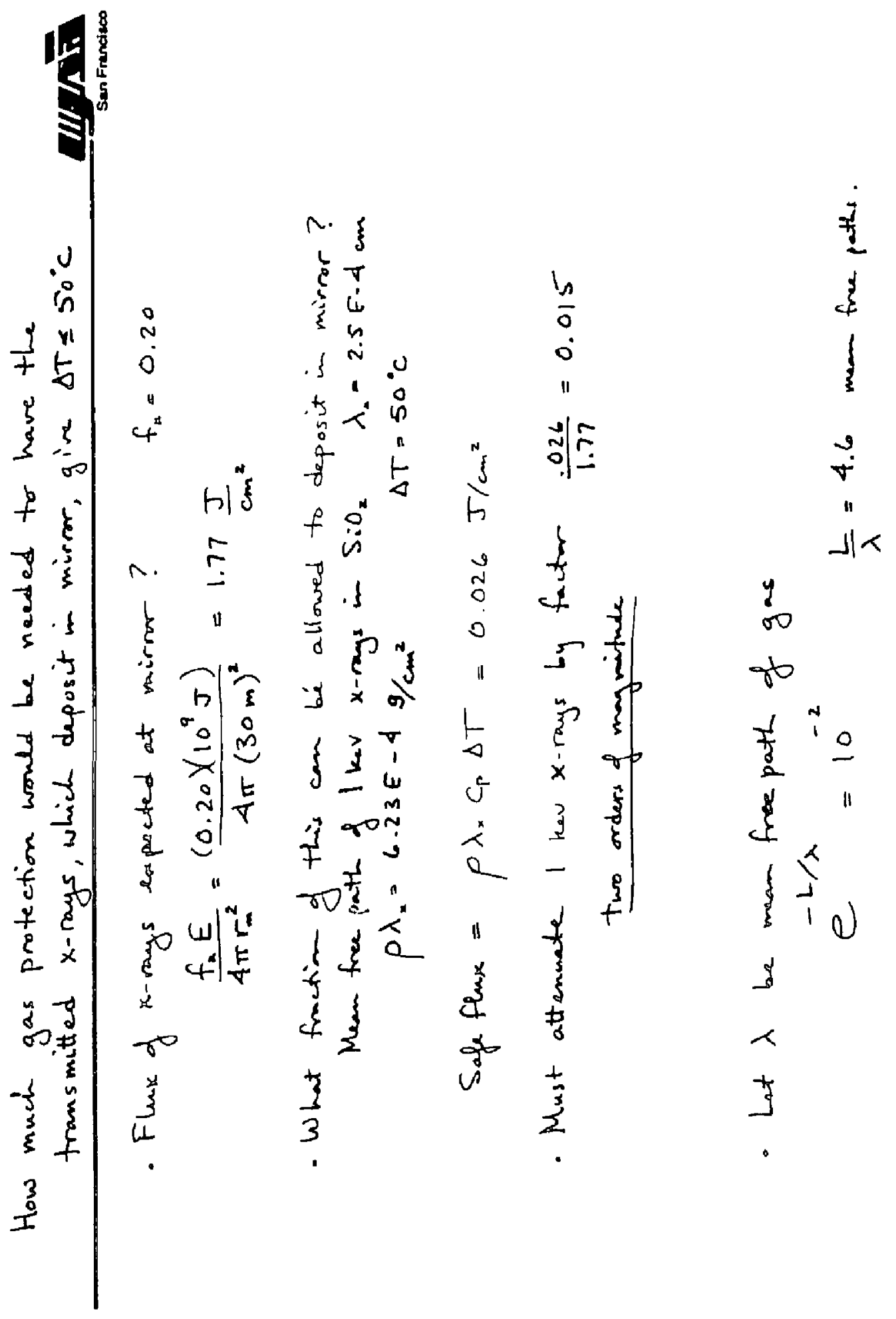




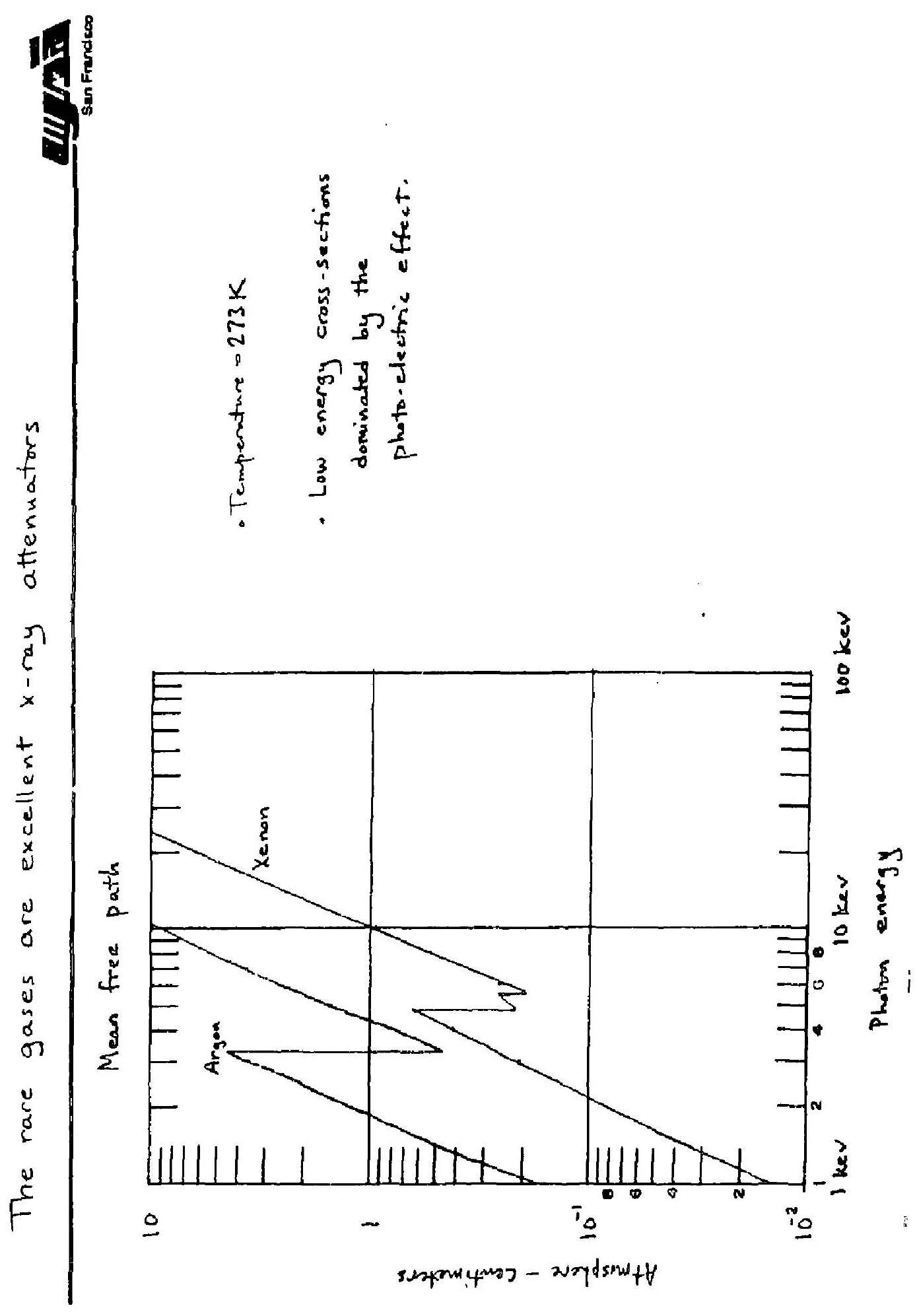




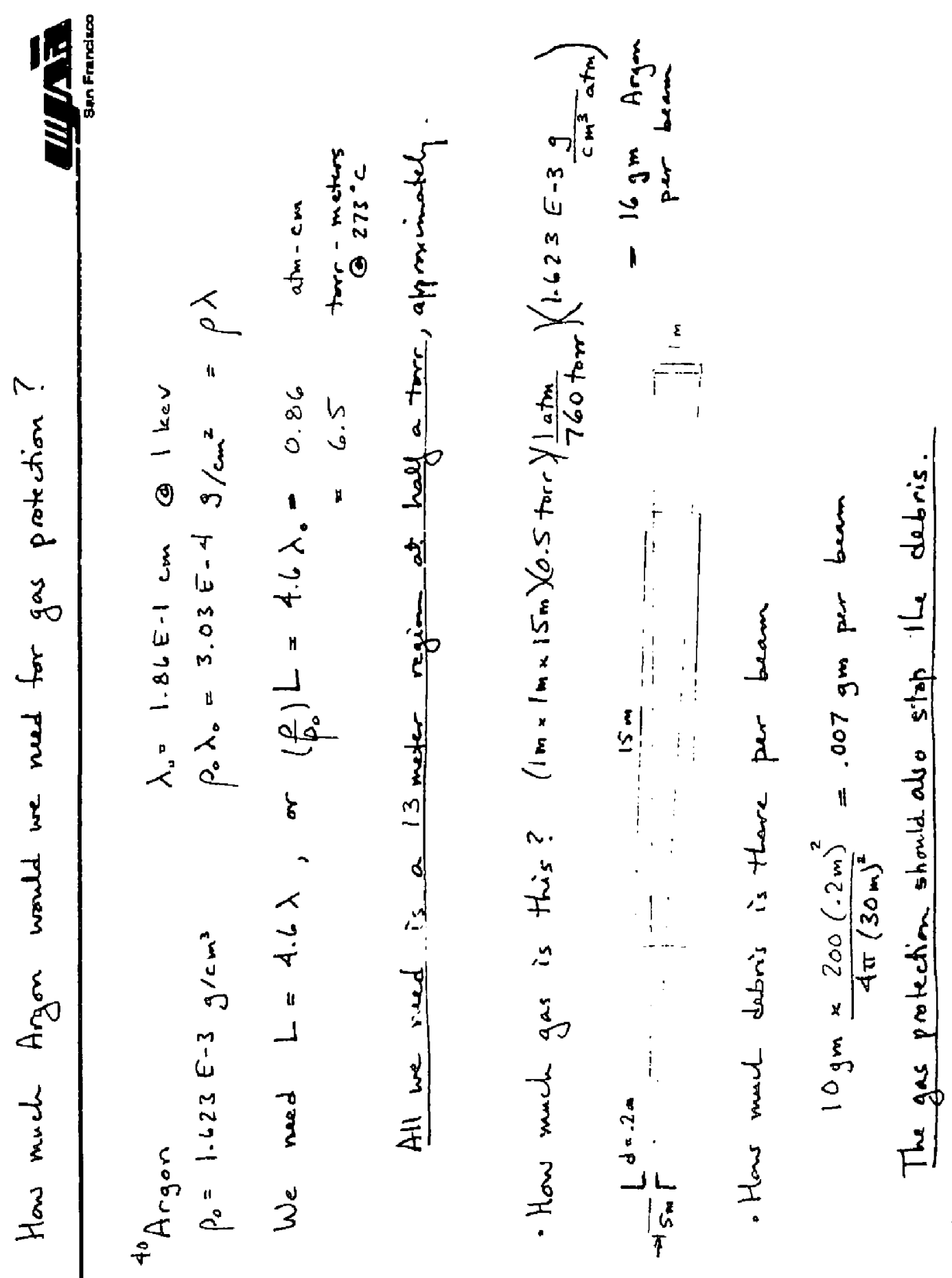



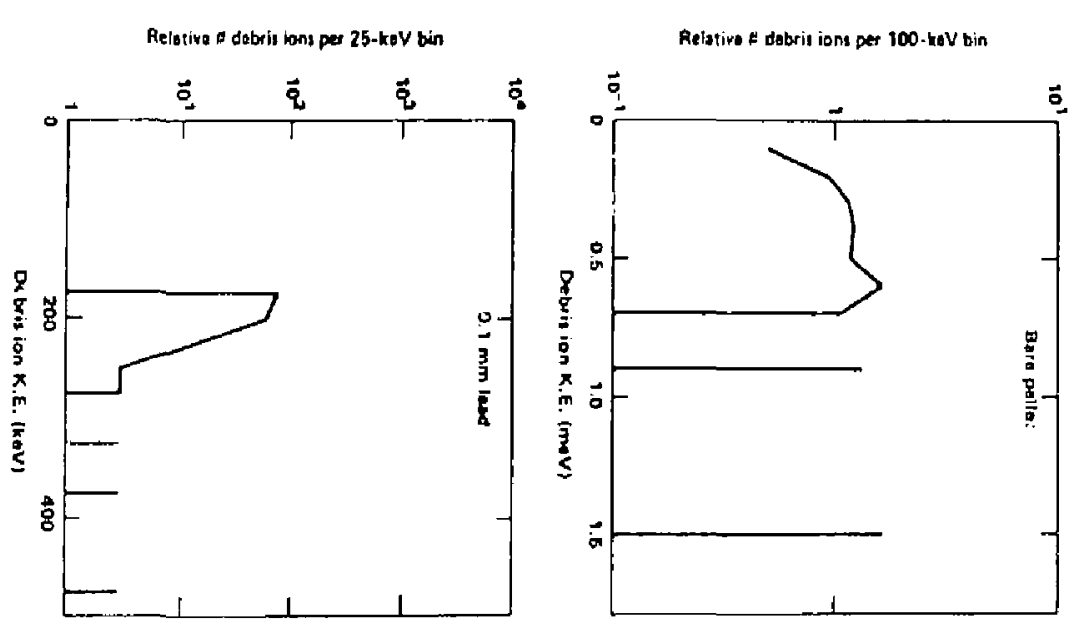

Relative Hebrin ions poe t5-kol bin
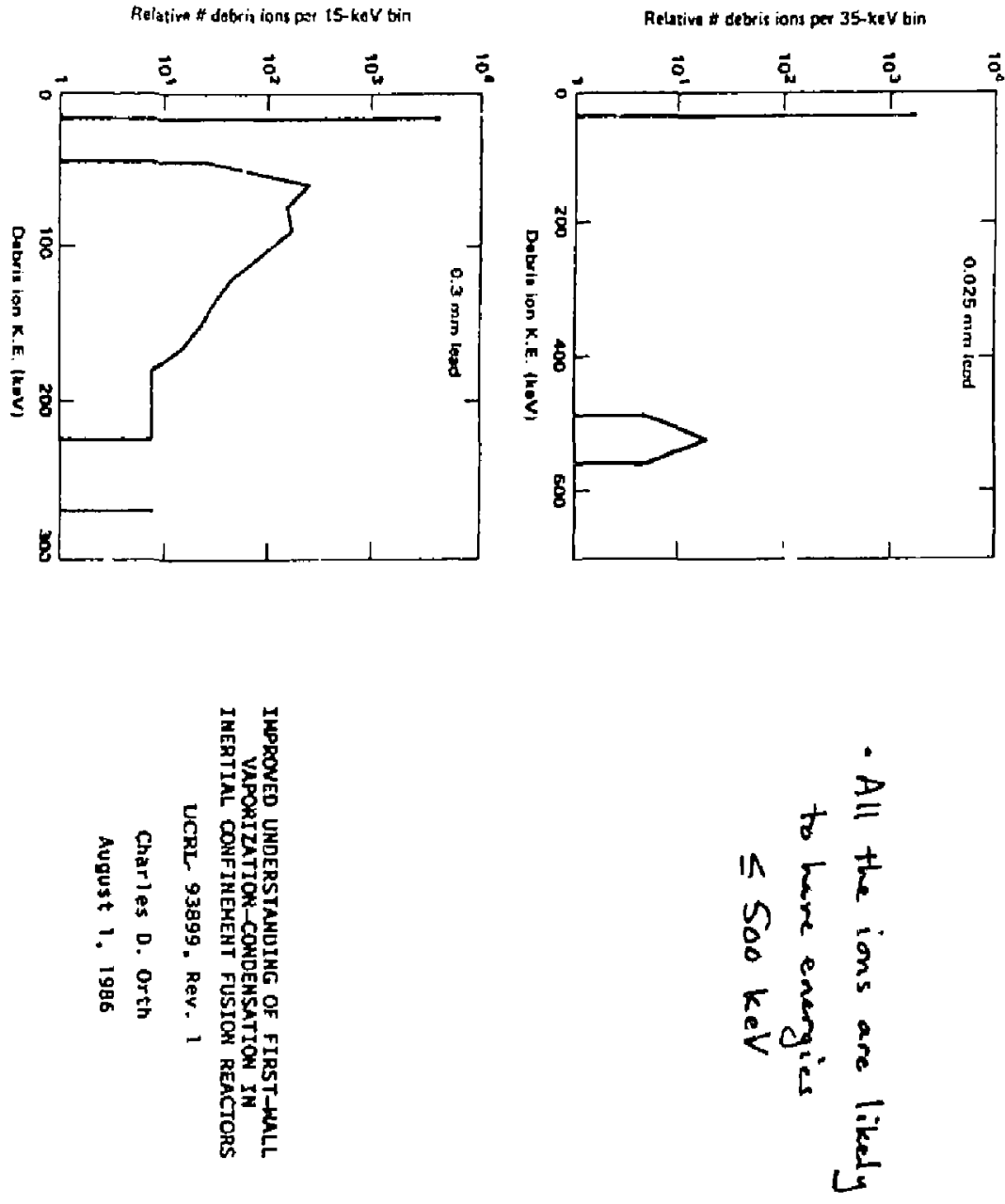

$\frac{\pi}{3}$
$\stackrel{0}{+}$
0

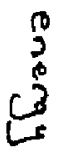

E.

I.

$\frac{5}{3}$

$\infty$

2
8
2
5

in 




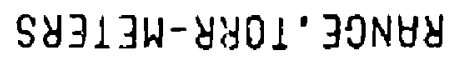

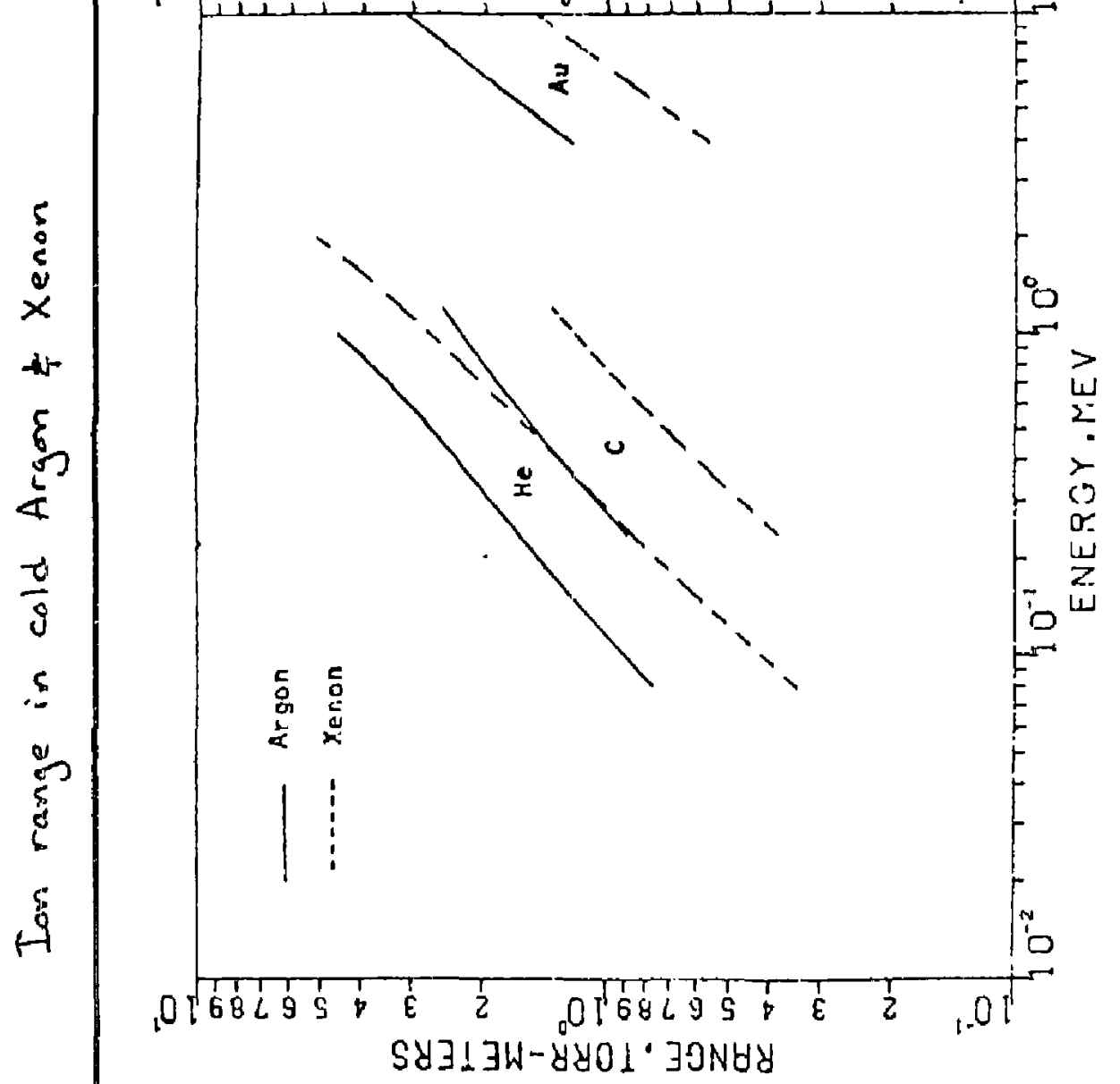




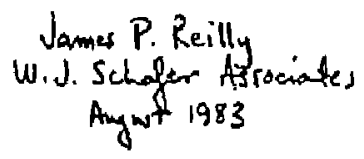

EVALUATION OF WINDOW CONCEPTS FOR REPPED-PULSE CHEHICAL LASERS

TABLE OF CONTENTS

1.0 INTRONUCTION

1.1 Purpose of the Study $1-4$

2.0 CATALOG OP WINDOH TYPES 5

2.1 Aerodynamic $\quad 5-24$

3.0 SCALINC OF OPERATIONAL REQUIREMENTS

3.1 Scaling of Power Handling Capabilities 25

3.1.1 Aerowindow Concepts 25

3.1 .2 Solid Window Concepts 26-27

3.1.3 Mechanical Window Concepts 28

3.2 Acoust ic Atcenuating Mufflers 28

4,0 WINDOW UTILIZATION CRITERIA

5.0 OPTICAL EFFECTS PRODUCED BY I-D TRANSVERSE

FLOW SUBSONIC AEROWINDOW 30

5.1 Fluid Mechanics $31-36$

5.2 Optical Effects 36

$5,2,1$ Refocus due to Curvature 36-38

5.2.2 Tilt Due to Curvature $38-42$

5.2.3 Tilt and Refocus due to Shear Layers 42-45

5.2.4 Beam Spread due to Shear Layers 45-50

5.2 .5 Bean Jitter $50-52$

5.3 Conclusion to Aerowindow Section $52-54$

6.0 OVERALL RECOMMFNDATIONS 55

$\begin{array}{ll}7.0 & \text { REFERENCES } \\ & 56-59\end{array}$ 


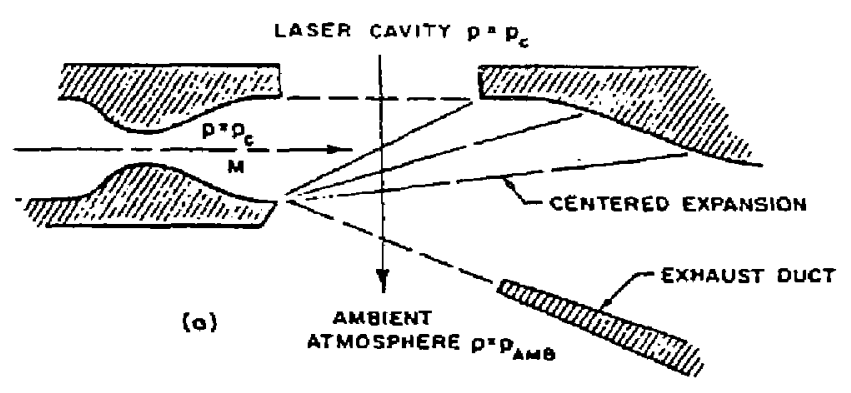

LASER CAVITY $p=p_{\mathrm{c}}$

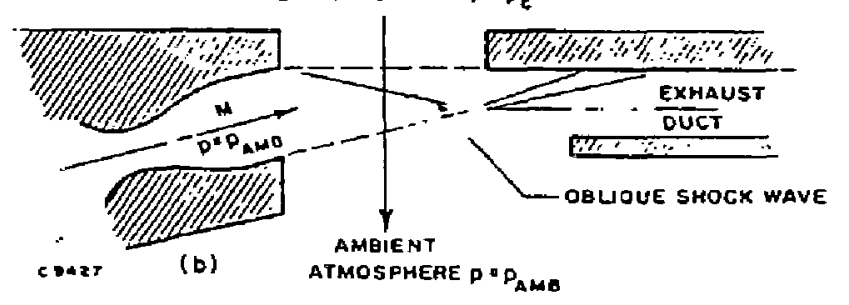

SUPERSONIC EXPANSION

AERO WINDOW

SUPERSONIC COMPRESSION AERO WINDOW 


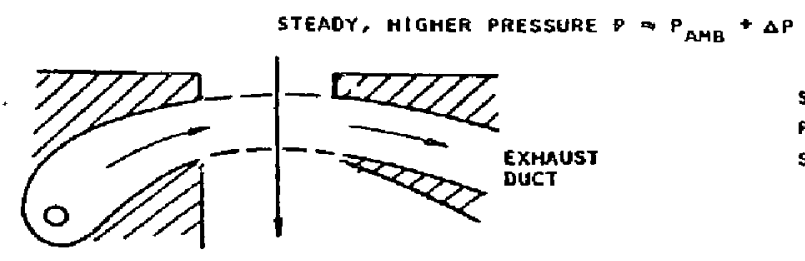

SINGLE LAYER

POTEHT IAL, VORTEX

SUBSONIC AREA HINDOH

(Refs. 11-13)

AMBIENT PRESSURE



THO-LAYER

POTENTIAL, VORTEX

SUESONIC AERO MIMOOH

(Ref. 14)

ambient PRESSUAE 




s

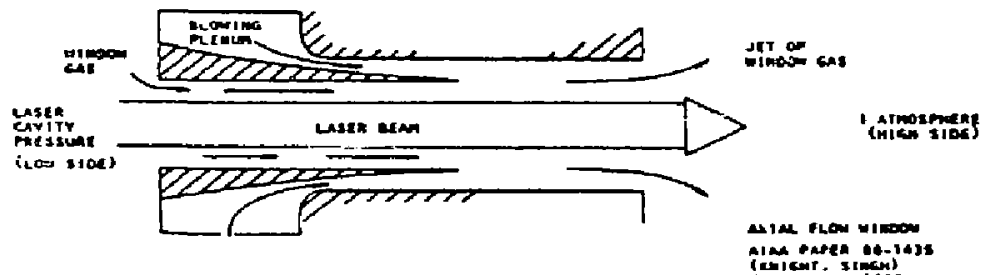

(Ref. 16)

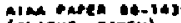
74.16 din? 


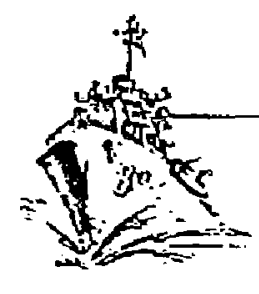

\section{UNCLASSIFIED}

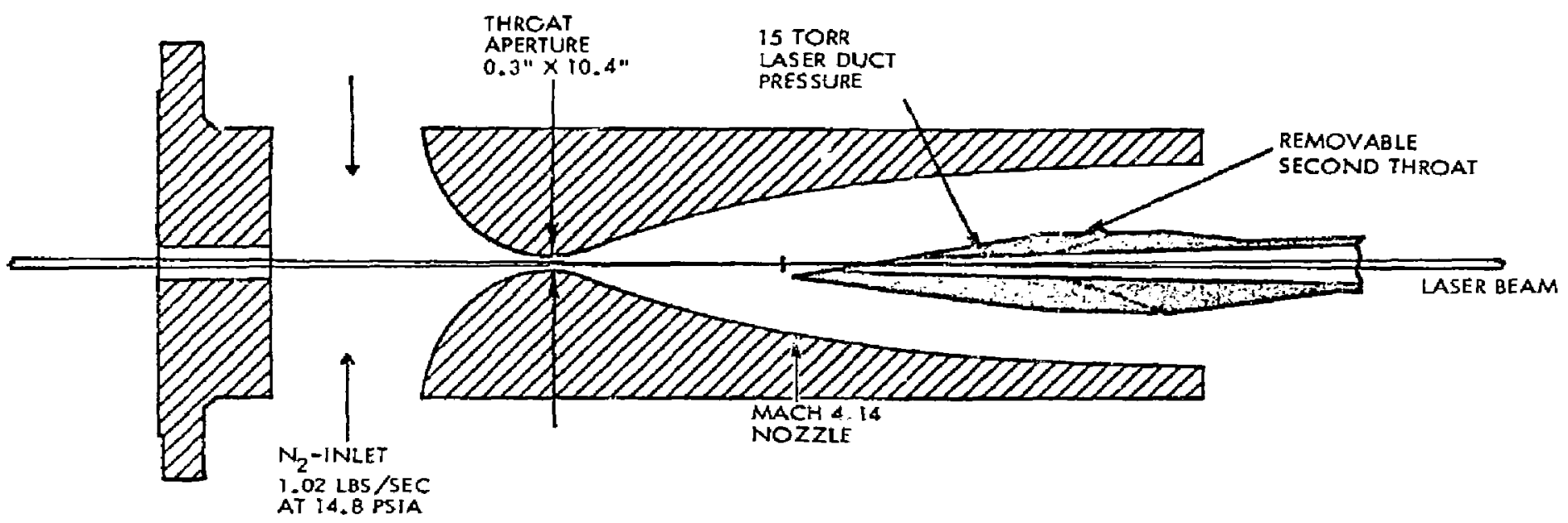




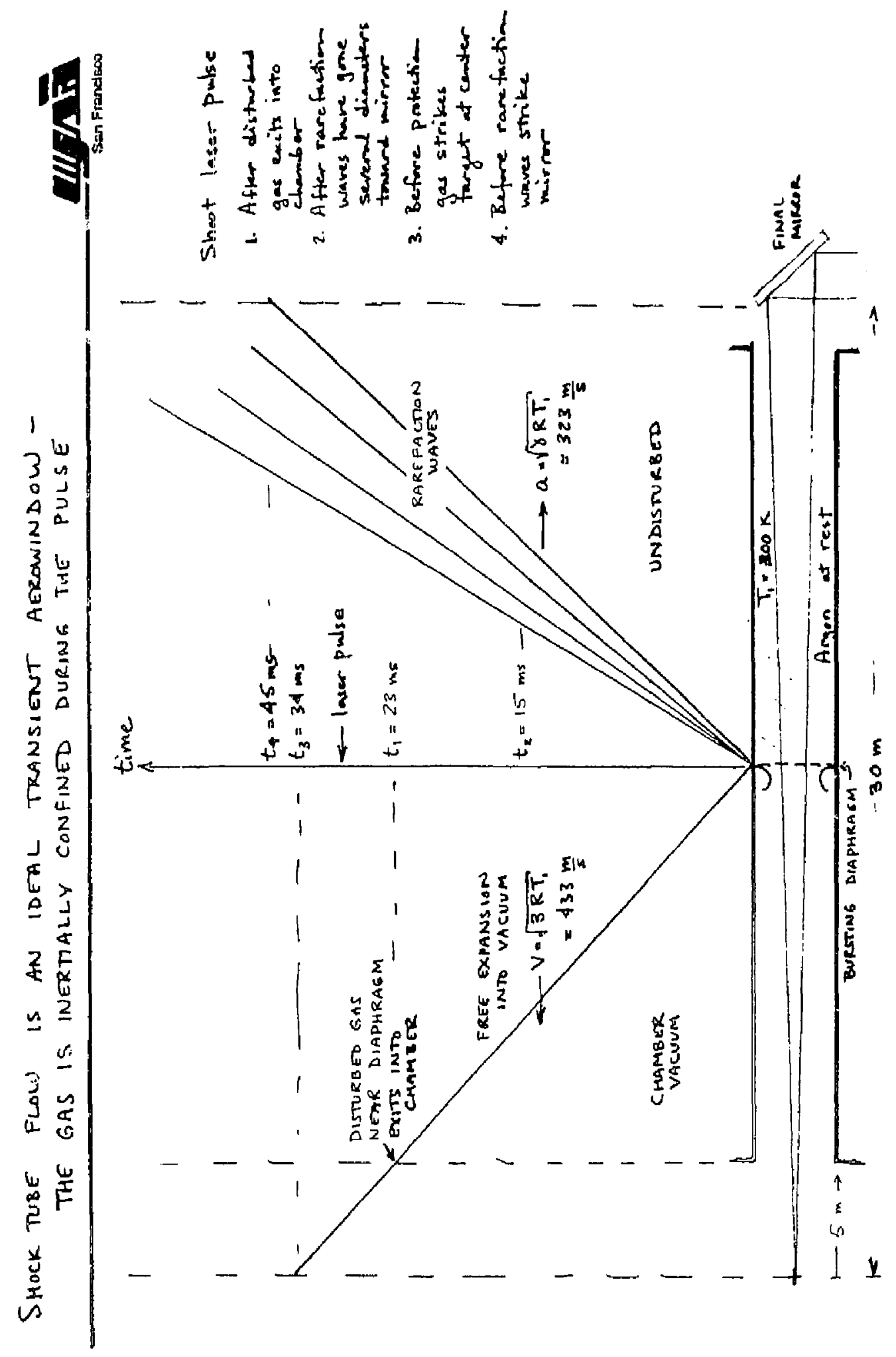


Report No. 35\$59.0901-A

\title{
Final Report \\ PULSEO AERODYAAMIC WINDOWS \\ FOR FUSION LASERS
}

for Period

This repurt has

valuable exparimental

data in it on

optical quality of shuck tube flows. $M M$.

\author{
I February 1981
}

Prepared for

Or. C. Fenstermacher, L. Division

Los Alamos Selentific Laboratory

Under LASL Contract No. P.0. 4L20-8204K-3

by

V. Kulkarny, D. McGregor, J, Shwariz and R. A. Briones

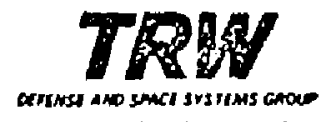

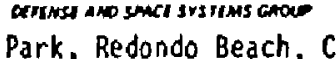

One Space Park, Redondo Beach, CA 90278 


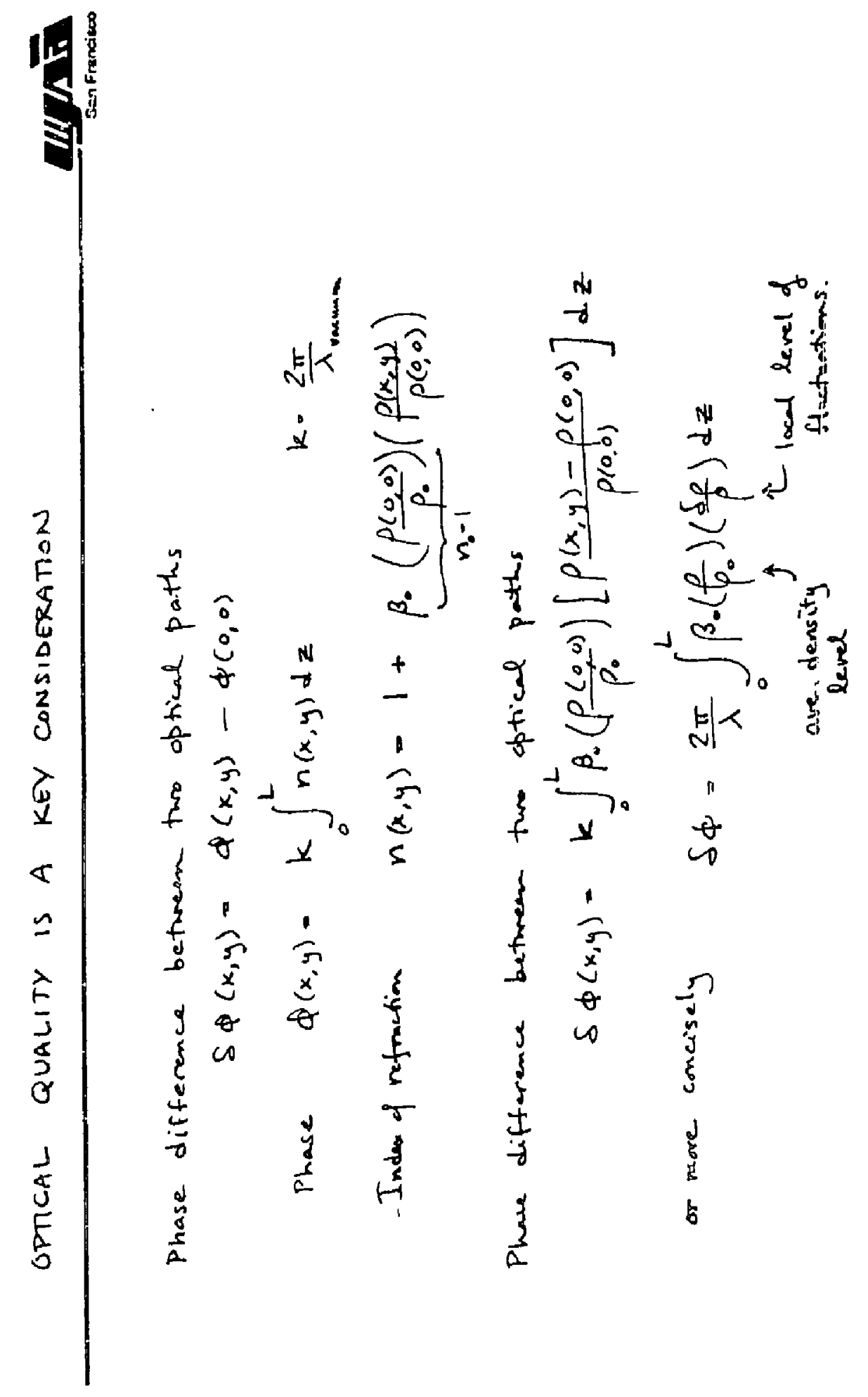




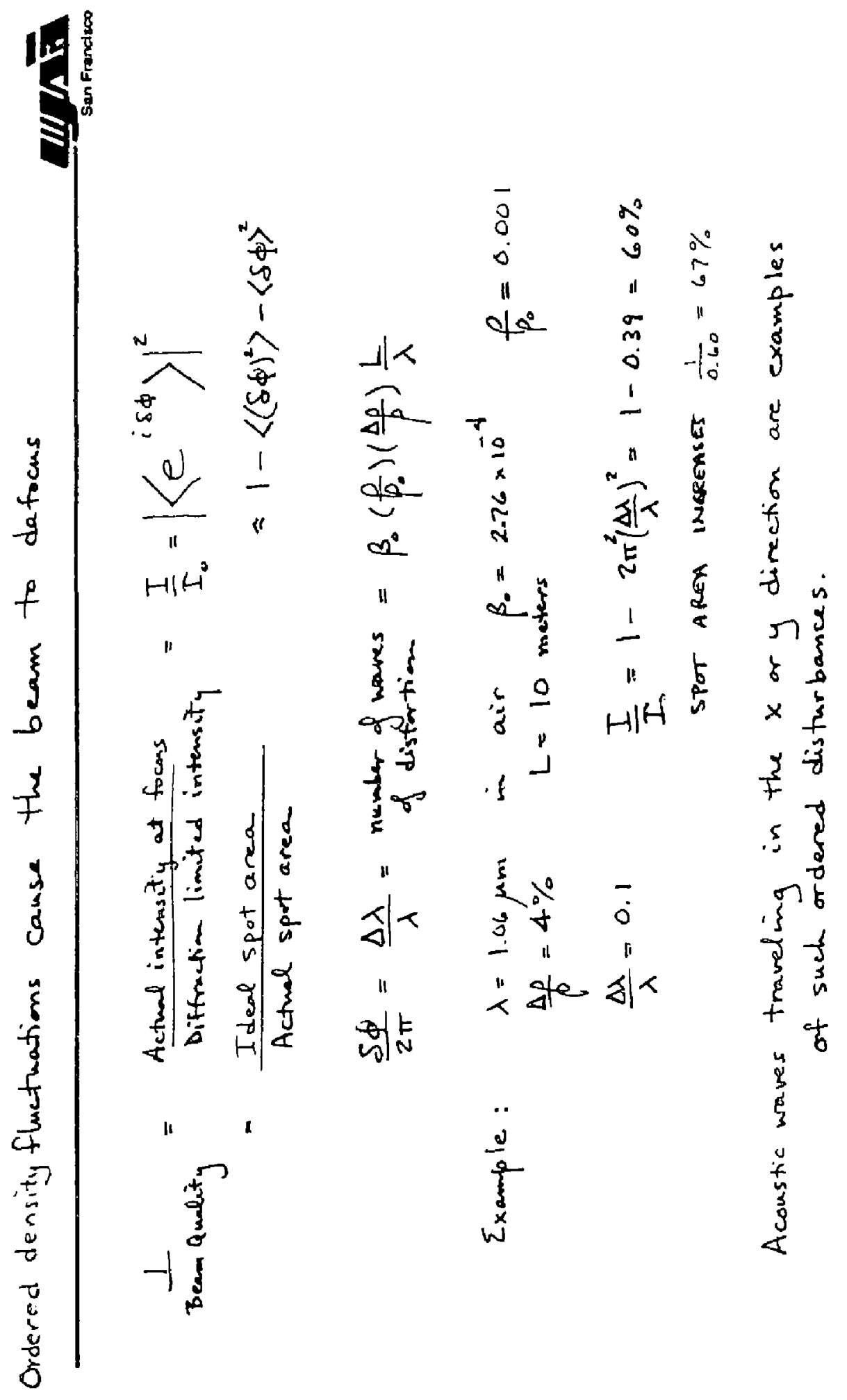


Turbulence scatters energy out of the beam

CIIT Fin

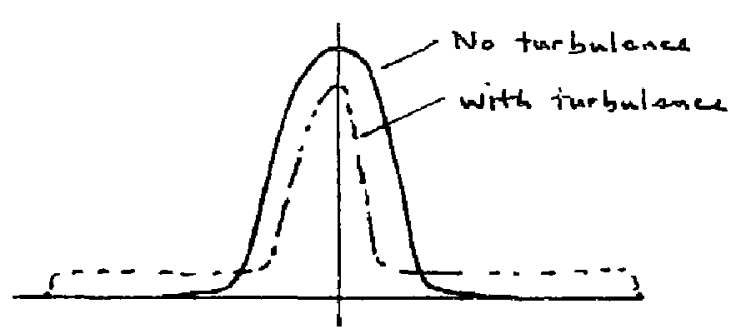

is
Light is scattered far out of focal spot, so turbulence cam be treated as an extinction phenomenon.

$$
\begin{aligned}
& k=2 \pi / \lambda \\
& \delta_{n}=\beta\left(\frac{\rho}{\rho_{0}}\right) \frac{\delta_{p}}{\rho}
\end{aligned}
$$

$\Lambda=$ turbulent scale size

$$
\alpha L=\frac{\sqrt{\pi}}{2}\left[\frac{2 \pi}{\lambda} \beta\left(f_{p_{0}}\right) \frac{\delta_{f}}{\beta}\right]^{2} \Lambda L
$$




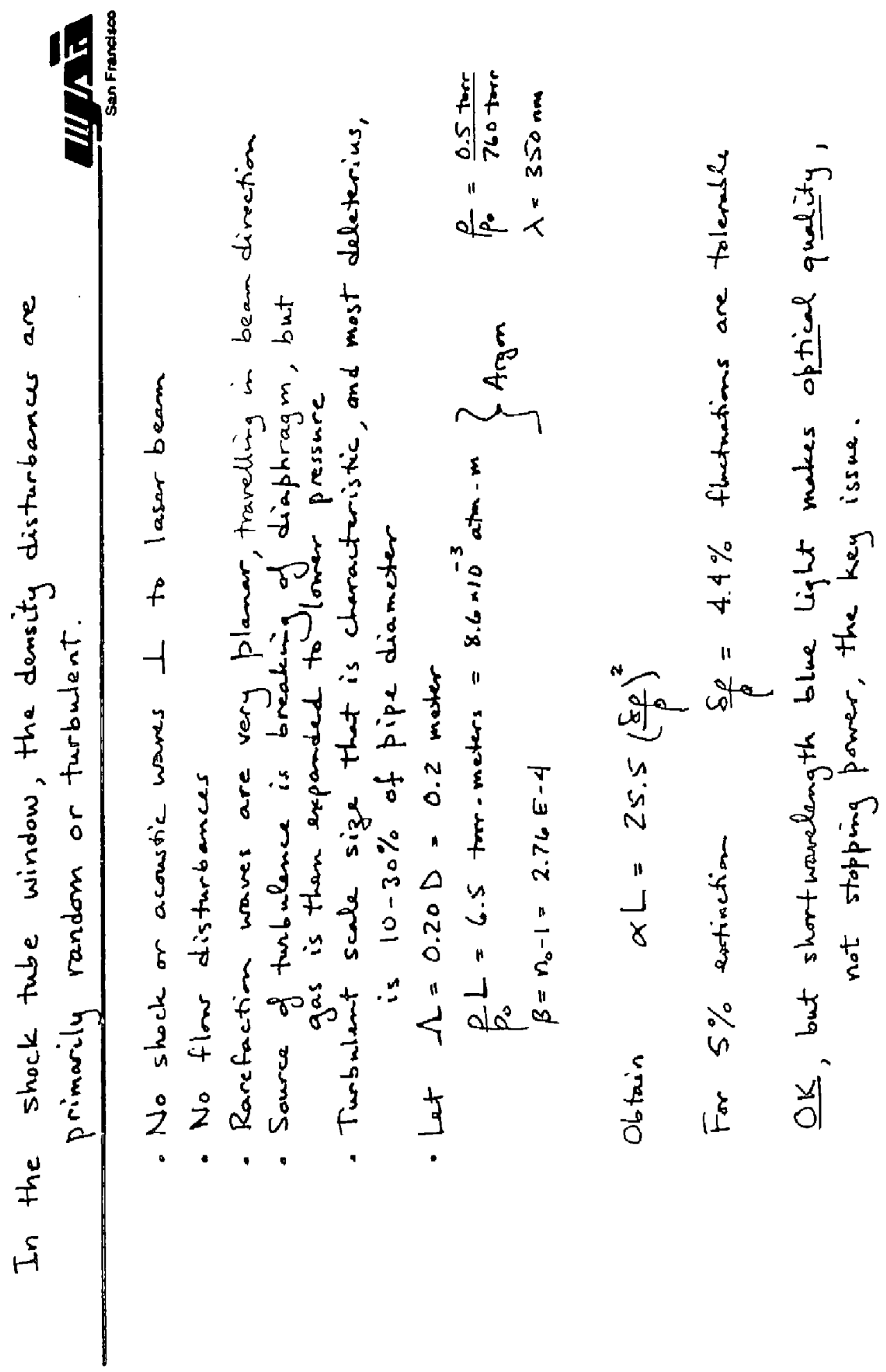




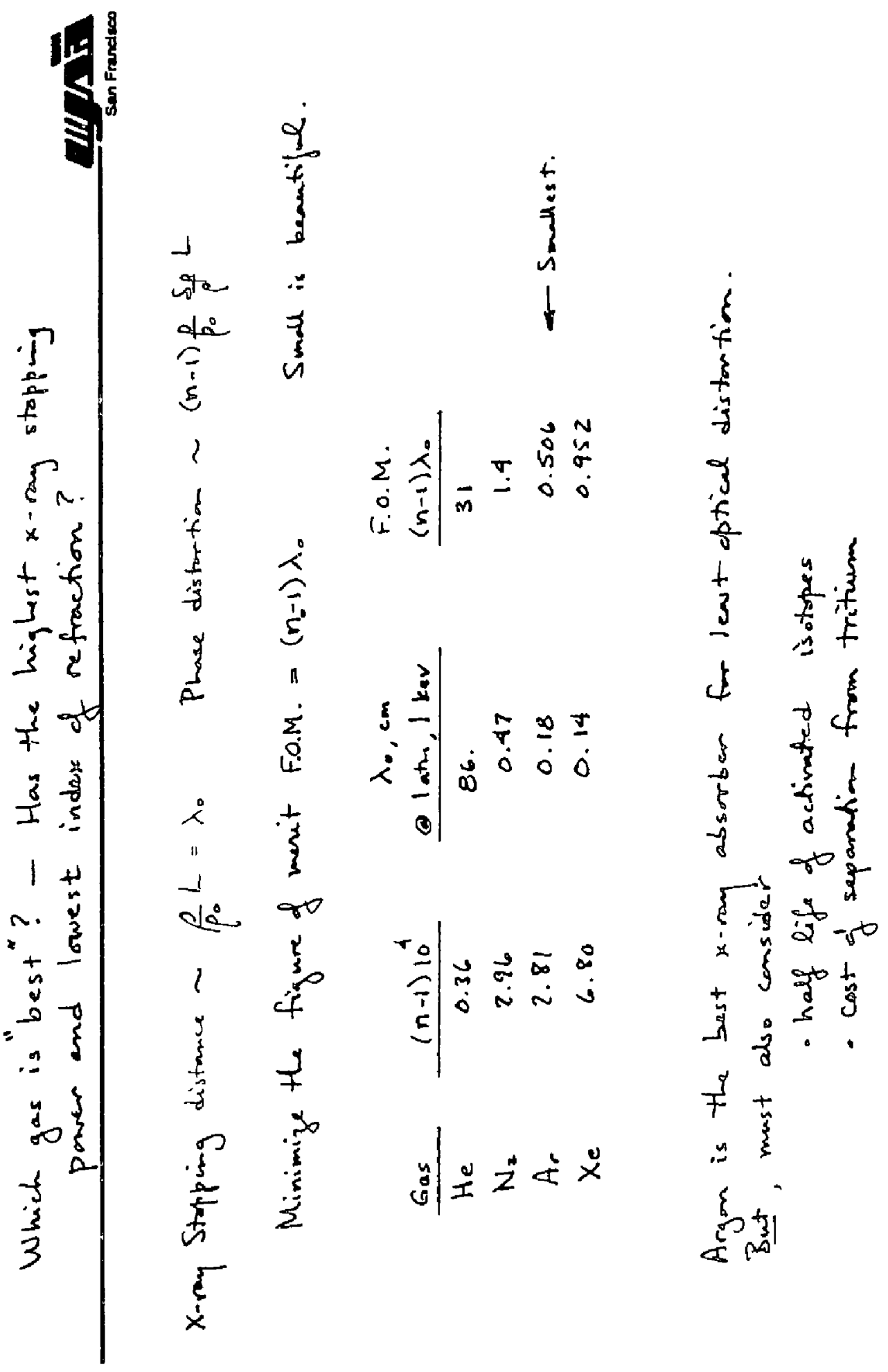




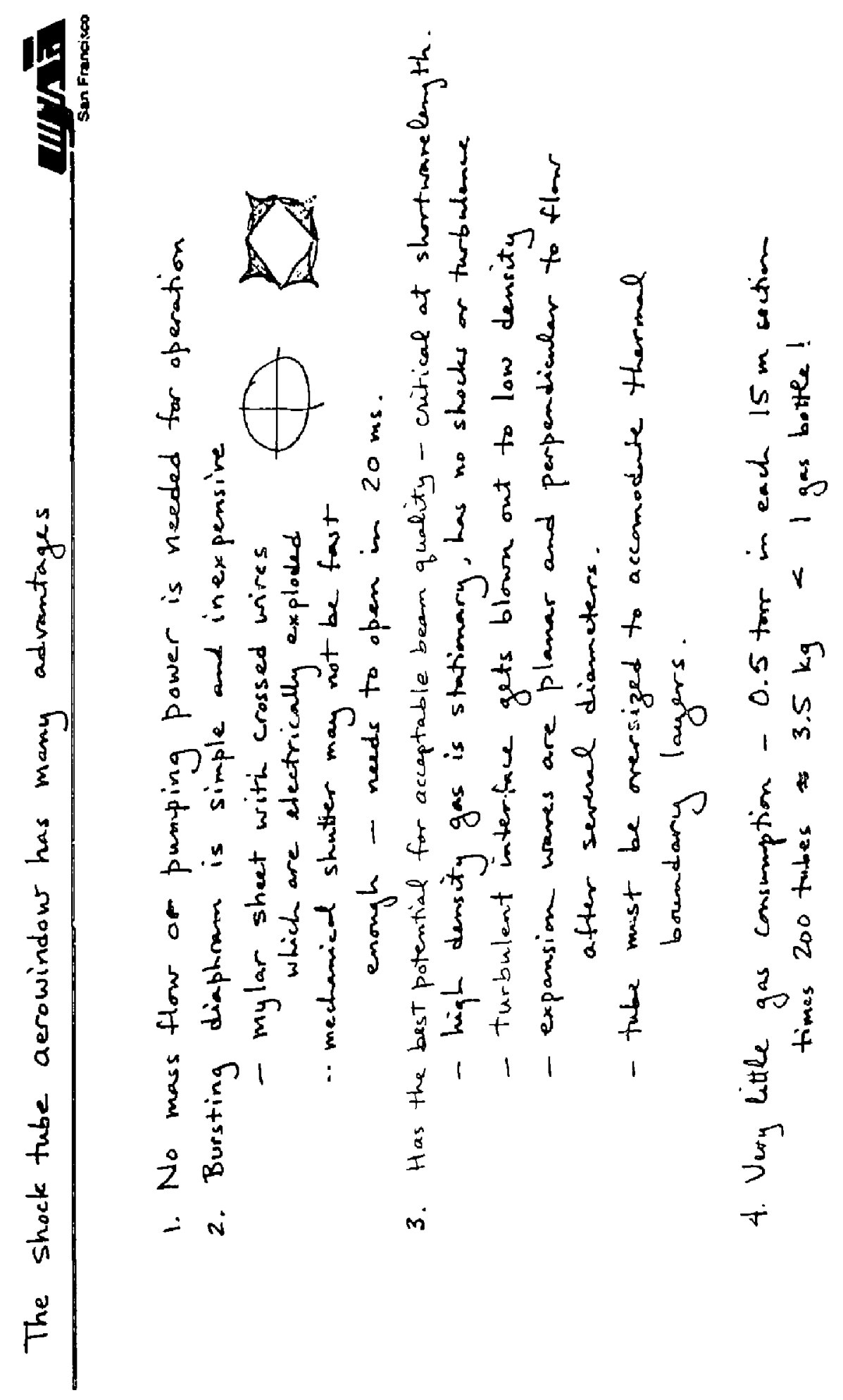


The neutron attenuation strategy uses distance, flux traps behind mirror, doglegs in optical train, large L/D ducts.

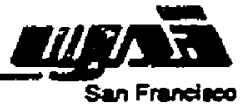

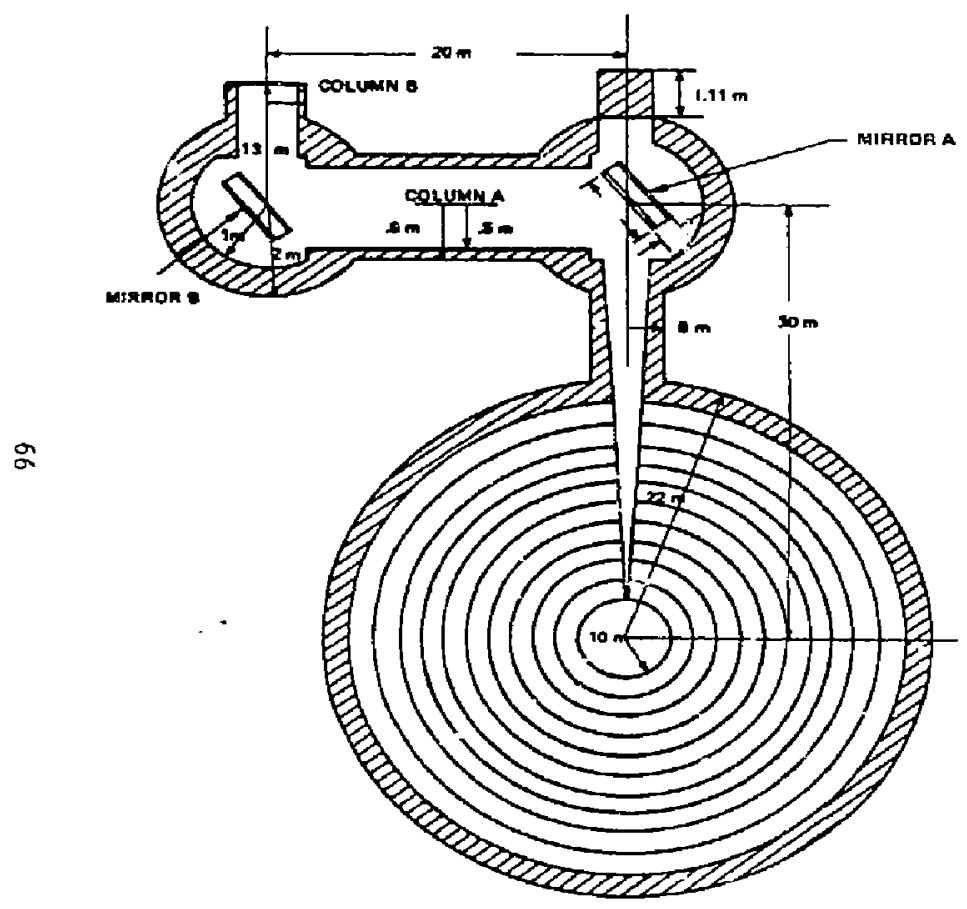

- Final mirror shamed be as tremsparcut as possible to id ike neutrons

- Flux trap behind mirror uses neutron absorber - lead ace tater solution + borak for example

- Ducts of $L / D=10-20$, with concrete shields

- Westinghouse found they coned obtain attenanations of natron flux of $10^{4} /$ bend. Two bends should be OK

- What is proper biological hazard criterion? where showed it be applied?

Caiculational Model of Westinghouse Blanket and Afro Beam-Duct Configuration.

Ref: Neutron Attenuation in the laser ducts of an ICF Reactor, F. Augustine Jr., Westinglurece Electric CAP., Nov 1981, WFPS: TME-81-031 
The interface between the laser and containment buildings

- Tritjum. activated gases and debris must be prevented from contaminating the Taser

- Windows located somewhere between the final optics and the beam tubes wi 77 provide a physical barrier

- An additional barrier will probably be required to prevert radiation leakage in the event of a window breaking

- Such a isolation system was designed for isotope separation experiments that required a beam penetration into the pu building 
Schematic of interface of line. of-sight vacuum pipe with Pu containment building $B-332$

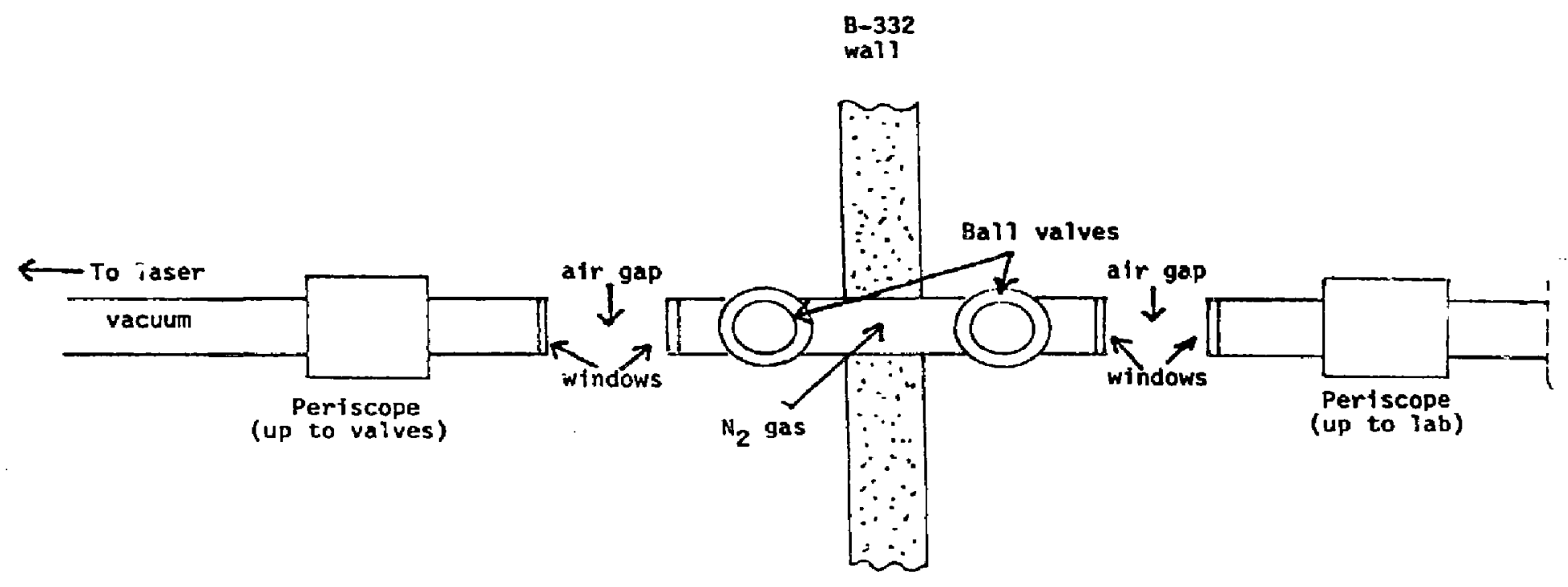


Ball valves are used to prevent radiation leakage

from the Plutonium building at LLNL

Requirements:

1. Redundancy of closure system ( 2 windows $\& 2$ valves)

2. Valves close in event of:

- power outage

- fire a larm

- criticality alarm

- setsmic signal

- Toss of pressure differential

- manual override signal

3. Valves operated by pneumatic actuators

- normally house air

- nttrogen gas botete back-up

4. Once closed. manual reset required to reopen

5. Vajve indtcators show open/closed status

6. Periodically tested with simulated signals 7. Earthquake certification comparable to critical nuclear
reactor components

8. Minimal leakage in event of firg 


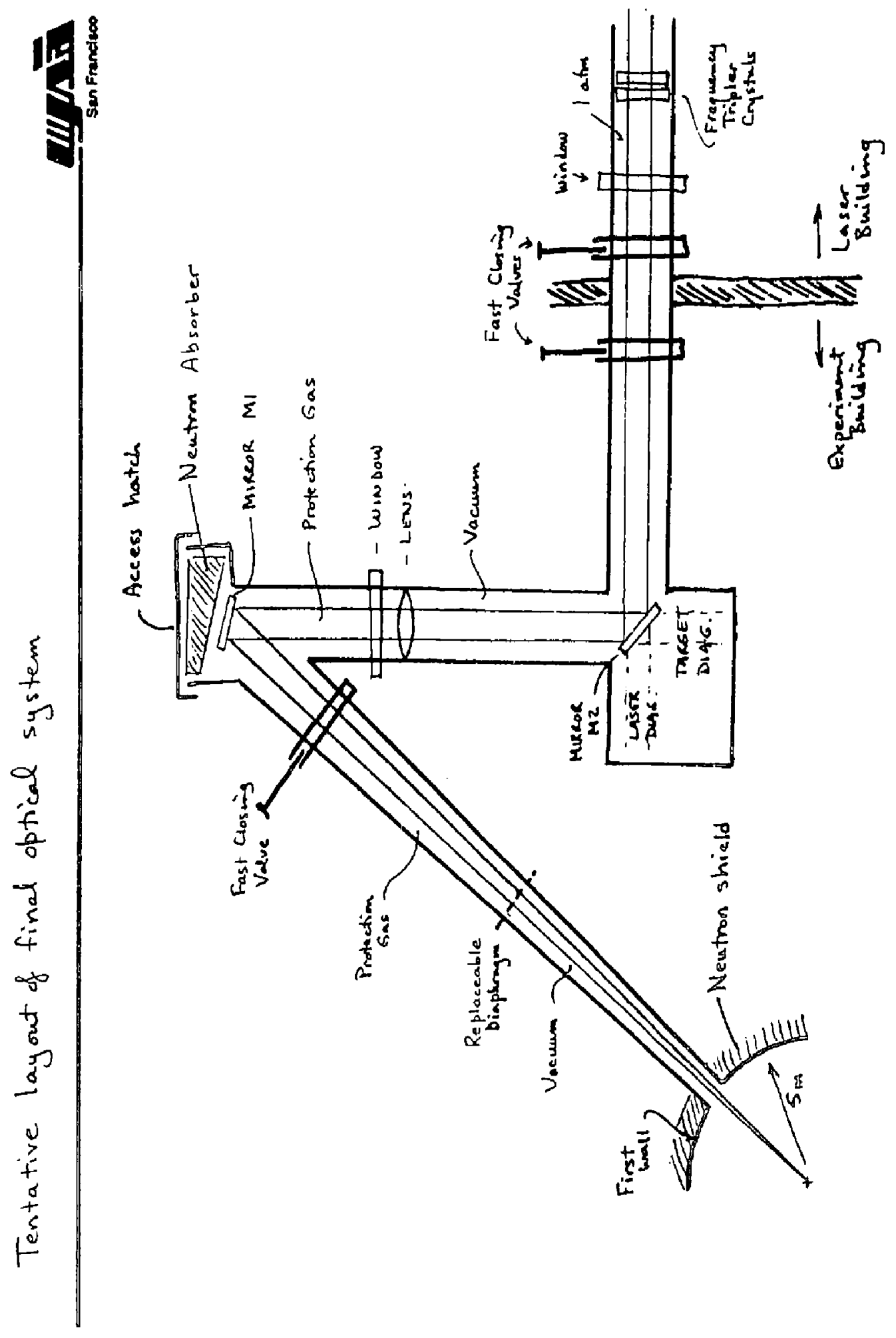




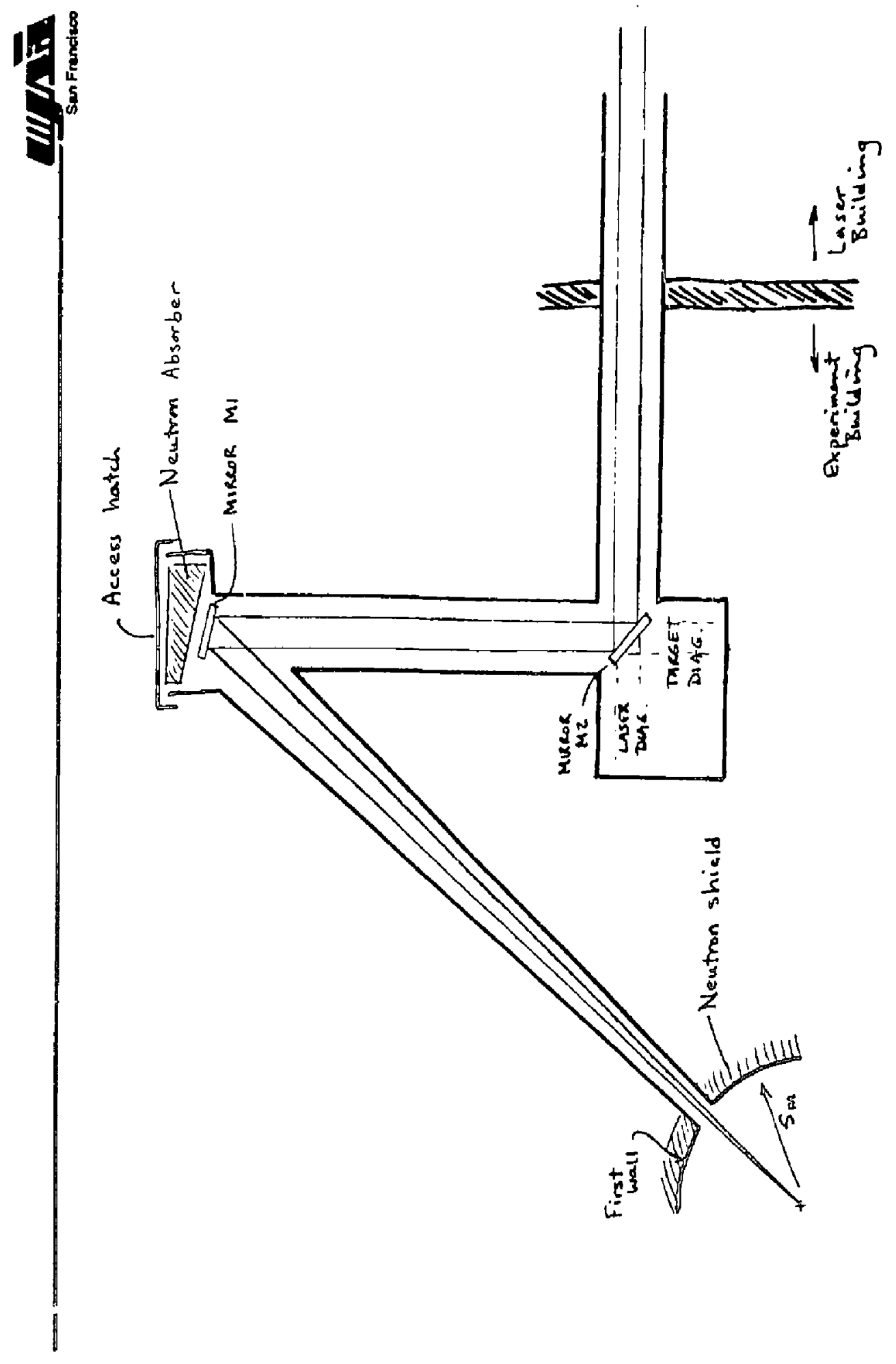




\section{Conclusions from Optics Protection Work}

The major conclusions from our optics protection work are as follows:

1. Approximately 6.5 torr $-\mathrm{m}$ of argon gas at $273 \mathrm{~K}$ are needed to adequately protect the final optics against $1 \mathrm{keV} x$-rays. This corresponds to a 13 meter region of argon in each bear I tube at a pressure of 0.5 tom, which seems quite feasible.

2. The above amount of argon corresponds to $16 \mathrm{gm}$ of argon gas. If we imagine that the target can be represented by two grams of gold ions, having a total energy of $200 \mathrm{MJ}$, we would expect $0.007 \mathrm{~g}$ of ions to head up each beamline. Since there are 2000 times more argon than gold ions, the ionic debris should be stopped.

3. In a separate calculation using range data for heavy charged particles other than gold, and scaling formula to adjust for energy per ion and atomic mass number, we confirmed that $6.5 \mathrm{icr}-\mathrm{m}$ would confidently stop the ions.

4. From gas-breakdown data, using $350 \mathrm{~nm}$ lasers and rare gases, we project that breakdown will occur at pressures above $6.4 \times 10^{-3}$ tor in the focused beam near the target. Since we plan to use 100 imes this pressure to stop the $x$-rays, we recommended conining the argon to the beam tubes where the intensity is (relatively) low and breakdown is avoided. Breakdown may, in fact, not be harmful since the plasma will not be dense enough to go opaque; but since there is no need to have gas in the chamber itself, why borrow potential trouble?

5. A simple drag calculation was perfoimed from first principles to determne that 6.5 torr-m of argon will stop all macroscopic particles (small shrapnel) in the diameler range $0<D<6.5$ microns. Larger particles do have a finite probability, and since doubling or tripling the quantity of gas will not solve the problem, we recomrsended the need for fastclosing shutters to stop large particles.

6. The outflow of the argon gas into the vacuum chamber, combined with the use of fast-acting valves te stop debris, is likely to also provide a barnier against tritium gas contamination of the final optics in normal operation. A shutter failure, of course, could lead to mixed gases reaching the final optics over larger timescales.

7. The argon gas used to provide protection against $x$-rays and ionic dehris will not furcher degrade the optical quality of the beam. 
8. The final optics are not protected from neutrons. We recommend using reflective optics, placed after the tripling crysials, so that no transmissive optics need be exposed to direct neutron radiation. Only the high-reflectance (HR) coatings would be affected, so the mirrors would have to be recoated accasionally. LLNL feels that HR coatings have unacceptable low damage thresholds, however, and that it is necessary to place the tripling crystals, lensts and transmissive coatings in the direct neutron flux. We have agreed to disagree on this point in the absence of better data.

9. While the above combination of argon gas and fast shutters provides the simplest solution, we have recommended that some attention be given to an alternate solution of a pulsed supersonic gas lens, which would bend each beam by one beam width, completely removing tise final optics form the potential harm of $x$-rays, ions, neutrons or shrapnel. Perhaps this could be studied in future work. 


\section{Bibliography for Optics Protection Work}

1. R. D. Evans, The Aromic Nucleus MoGraw-Hill, New York (1955).

2. D. I. Rosen and G. Weyl, "Laser-Induced Breakdown in $\mathrm{N}_{2}$ and Rare Gases at 0.53 and 0.35 Micrometers," J. Physics D: Applied Physics, Vol. 20, pp. 1264-1276 (1987).

3. R. K Tyagi, V. V. Rampal, and G. C. Bhar, "Laser-Induced Ionization of Air in the Presence of Preionization," IEEE Journal of Quantum Electronics, Vol. 24, No. 4 (April, 1988).

4. R. G. Pinnick, P. Chylek, M. Jarzembski, E. Creegan, V. Srivastava, G. Fernandez, J. D. Pendleton and A. Biswas, "Aerosol-Olinduced Laser Breakdown Thresholds: Wavelength Dependence," Applied Oplics, Vol. 27, No. 5 (March 1, 1988).

5. James P. Reilly, "Evaluation of Window Concepts for Repped Pulse Chemical Lasers," Internal tepor, W. J. Schafer Associates, Chelmsford, Mass. (August 26, 1983).

6. V. Kulkarny, D. McGregor, J. Shwartz and R. A. Briznes, "Pulsed Aerodynamic Windows for Fusion Lasers," Final Report \#35659, Vol. A, TRW Defense and Space Systems Group, One Space Park, Redondo Beach, CA, 90278 (February I, 1981).

7. V. A. Kulkarny, J. Shwartz, and M. Saffman, "Direct Beam Quality Measurement in Pulsed Aerodynamic Windows," Final Report DOE/DP/40141-1, TRW, One Space Park, Redondo Beach, CA (August 12, 1982).

8. M. J. Monsler and J. A. Maniscalco, "Optical Design Considerations for Laser Fusion Reactors," SPIE, Vol. 321, Optics in Adverse Environments, p. 117 (1977).

9. Shrapnel slow-down calculations were done from first principles, but the best drag coefficient data are located in the book by H. Schlichring, Boundary-Layer Theory, 6th Ed., p. 17, McGraw-Hill (1968).

10. I F. Janni, Proton Range-Energy Tables, $1 \mathrm{keV}-10 \mathrm{GeV}$, Atomic Data and Nuclear Data Tables, Vol. 27, No. 213, Academic Press, New York (March/May, i982).

11. D. K. Brice, Ion Implantation Range and Energy Deposition Distributions, Vol. I, IFLPlenum, New York (1975). 
The Analytic Hierarchy Process for Decision Nuaking

W. J. Schafer Associates

April 6, 1988 
To describe a systematic approach to choosing between several alternatives when the relative comparisons are not necessarily quantitative

Examples: rating the quality of wines

selecting members of a $4 \times 100$ relay team

selecting a college to attend

selecting a place for a vacation

selecting a first wall concept for the chamber 


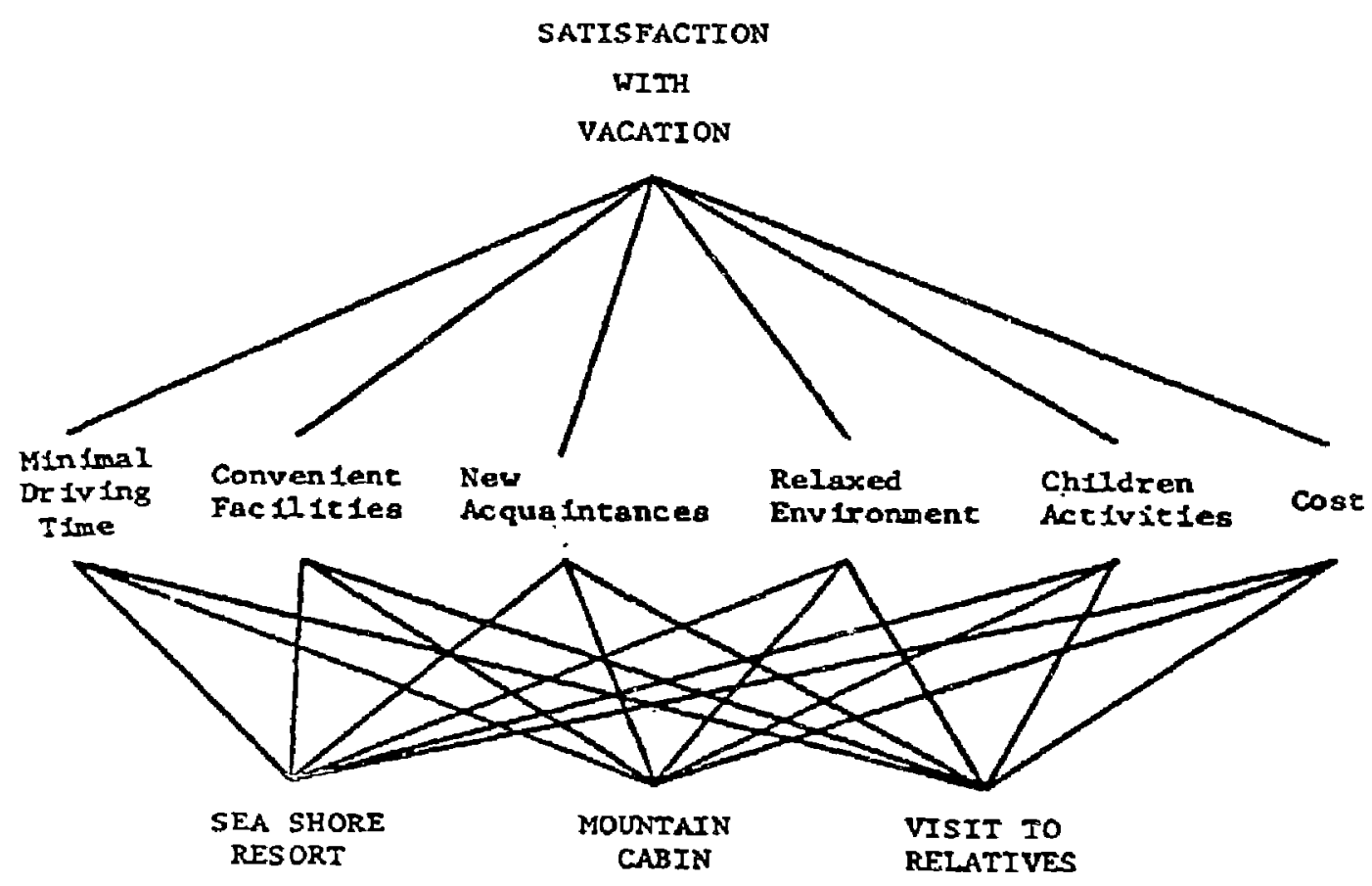


1) Establish the objective

- What do we need to do?

2) Determine possible alternatives

- What are possible courses of action?

3) Determine the criteria by which the alternatives will be compared - What factors should influence our choice?

4) Set priorities according to the importance of the various criteria - What is the relative importance of each criteria?

5) Choose best alternative or mix of alternatives 
- Adaptable to a side ranye of decision / selection type problems

- Useful when qualitative and subjective information must be taken into account

- Process of pairwise comparison simplifies the specification of weights or priorities

- Provides a method to check consistency without demanding a total self-consistent set of comparisons 


\section{Rating}

1

3

$\infty$
Moderate importance of one over ansther

$5 \quad$ Essential or strong importance

$7 \quad$ Very strong importance

$9 \quad$ Extreme importance

$2,4,6,8$ lntermediate values

\section{Explanation}

Two activinies contribute equally to the objective

Experience and judgement moderately favor one activity over another

Experience and judgement strongly favor one activity over another

An activity is strongly favored and its dominance demonstrated in practice The evidence favoring one activity is of the highest possible order of affirmatio:

When compromise is needed 
Comparison of $n$ objects, $A_{1}, A_{2}, \ldots A_{\text {诤 }}$ according to their relative weights, $w_{1}, w_{2}, \ldots w_{n}$.

\begin{tabular}{c}
$A_{1}$ \\
\cline { 2 - 5 }
\end{tabular} \begin{tabular}{lllll}
$A_{1}$ & $A_{1}$ & $A_{2}$ & $\cdots$ & $A_{n}$ \\
\cline { 2 - 5 } & $\frac{w_{1}}{w_{1}}$ & $\frac{w_{1}}{w_{2}}$ & $\cdots$ & $\frac{w_{1}}{w_{n}}$ \\
$\frac{w_{2}}{w_{1}}$ & $\frac{w_{2}}{w_{2}}$ & $\cdots$ & $\frac{w_{2}}{w_{n}}$ \\
$\vdots$ & $\vdots$ & $\ddots$ & $\vdots$ \\
$\frac{w_{n}}{w_{1}}$ & $\frac{w_{n}}{w_{2}}$ & $\cdots$ & $\frac{w_{n}}{w_{n}}$
\end{tabular}


Given matrix A, there is a vector of relative weights, wt, that satisfies

$$
A w=\lambda w
$$

where $w$ is the principal eigenvector and $\lambda$ is the principal eigenvalue.

$\lambda$ is used to check the consistency of the pairwise comparisons. 
The pairwise comparisons do not have to be totally self consistent. With a reciprocal matrix there is a tendency to compensate.

When a positive matrix of order $\mathbf{n}$ is consisient, the principal eigenvalue is equal to $n$. When it is inconsistent, $\lambda$ exceeds $n$.

Improving consistency means that the ratio estimates in the matrix are closer to being logically related than randomly chosen. 
The difference between $\lambda$ and $n$ serves as a measure of inconsistency: Consistency index $=\mathrm{Cl}=(\lambda-n) /(n-1)$

Random consistency index $=\mathbf{R I}$

$\begin{array}{lccccccc}\mathrm{n}= & 3 & 4 & 5 & 6 & 7 & 8 & 9 \\ \mathrm{RI}= & 0.58 & 0.90 & 1.12 & 1.24 & 1.32 & 1.41 & 1.45\end{array}$

Approximate fit to the above:

$R H=\ln (n-1)-0.09(n-2)$

Consistency ral̂io $=\mathrm{CR}=\mathrm{Cl} / \mathrm{Rl}$

If $\mathrm{CR}$ is not less than $10 \%$, study the problem and revise the judgments 


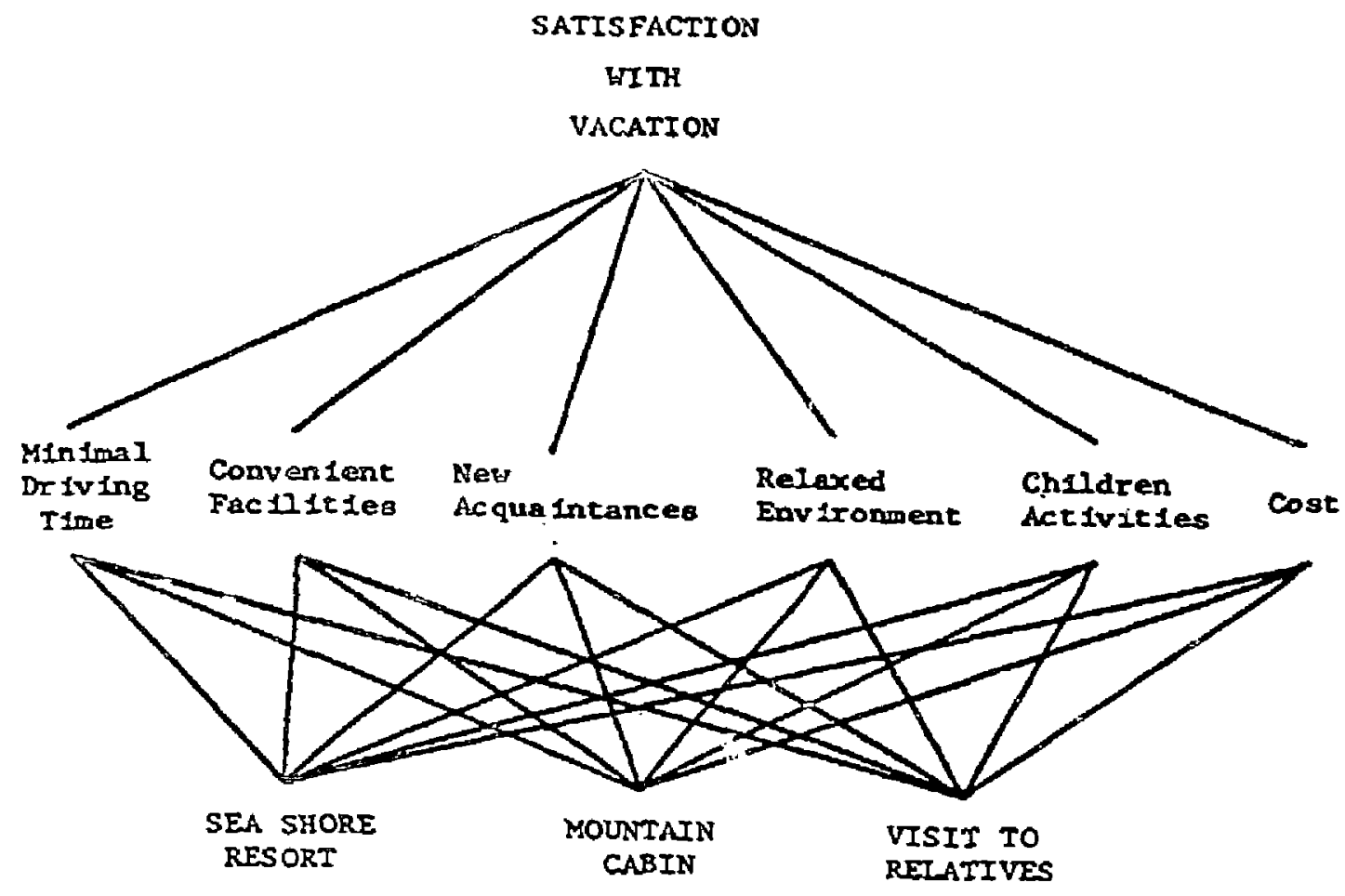




\begin{tabular}{lcccccc}
\hline & $M D T$ & $C F$ & $N A$ & $R F E$ & $C A$ & $C$ \\
\hline$M D T$ & 1 & 1 & 7 & 5 & 3 & $1 / 3$ \\
$C F$ & 1 & 1 & 5 & 3 & 1 & 1 \\
$N A$ & $1 / 7$ & $1 / 5$ & 1 & $1 / 3$ & $1 / 7$ & $1 / 9$ \\
$R F E$ & $1 / 5$ & $1 / 3$ & 3 & 1 & $1 / 3$ & $1 / 3$ \\
$C A$ & $1 / 3$ & 1 & 7 & 3 & 1 & $1 / 5$ \\
$C$ & 3 & 1 & 9 & 3 & 5 & 1 \\
\hline
\end{tabular}


Solve Aw $=\lambda$ w

$A^{b}$ coinverges to $N$ for large $b$. In this case,

$$
\begin{aligned}
& A^{b}=\left[\begin{array}{l}
0.224 \\
0.191 \\
0.028 \\
0.065 \\
0.133 \\
0.359
\end{array}\right] \\
& \lambda=6.475 \\
& C I=(6.475-6) /(6-1)=0.095 \\
& C R=0.095 / 1.24=0.077
\end{aligned}
$$

Consistency ratio is less than $10 \%$ as required 


\begin{tabular}{|c|c|c|c|c|c|c|c|}
\hline $\begin{array}{c}\text { Minimal } \\
\text { Driving } \\
\text { Time }\end{array}$ & $S S R$ & $M C$ & $V R$ & $\begin{array}{c}\text { Convenient } \\
\text { Facilities }\end{array}$ & $S S R$ & $M C$ & $V R$ \\
\hline$S S R$ & 1 & $1 / 7$ & $1 / 5$ & $S S R$ & 1 & 9 & 5 \\
\hline$M C$ & 7 & 1 & 5 & $M C$ & $1 / 9$ & 1 & $1 / 9$ \\
\hline$V R$ & 5 & $1 / 5$ & 1 & $V R$ & $1 / 5$ & 9 & 1 \\
\hline $\begin{array}{c}\text { New } \\
\text { Acquaintancos }\end{array}$ & $S S R$ & $M C$ & $V R$ & $\begin{array}{c}\text { Relaxed } \\
\text { Environment }\end{array}$ & $S S R$ & $M C$ & $V R$ \\
\hline$S S R$ & 1 & 9 & 7 & $S S R$ & 1 & $1 / 5$ & 5 \\
\hline$M C$ & $1 / 9$ & $I$ & $1 / 9$ & $M C$ & 5 & 1 & 9 \\
\hline$V R$ & $1 / 7$ & 9 & 1 & $V R$ & $1 / 5$ & $1 / 9$ & 1 \\
\hline $\begin{array}{l}\text { Children's } \\
\text { Activities }\end{array}$ & $S S R$ & $M C$ & $\mathscr{V R}$ & Cost & $S S R$ & $M C$ & $V R$ \\
\hline$S S R$ & 1 & 9 & 5 & $S S R$ & 1 & $1 / 7$ & $1 / 9$ \\
\hline$M C$ & $1 / 9$ & 1 & $1 / 7$ & $M C$ & 7 & I & $1 / 5$ \\
\hline$V R$ & $1 / 5$ & 7 & 1 & $V R$ & 9 & 5 & 1 \\
\hline
\end{tabular}


Example for minimal driving tirne:

$\left[\begin{array}{lll}1 & 0.143 & 0.2 \\ 7 & 1 & 5 \\ 5 & 0.2 & 1\end{array}\right] *\left[\begin{array}{l}0.0668 \\ 0.7147 \\ 0.2185\end{array}\right]=3.183 *\left[\begin{array}{l}0.0688 \\ 0.7147 \\ 0.2185\end{array}\right]$

Hence $w=\left[\begin{array}{l}0.0668 \\ 0.7147 \\ 0.2185\end{array}\right] \quad$ and $\lambda=3.183$ 


\begin{tabular}{llccccc} 
& $\begin{array}{c}\text { Minimal } \\
\text { Driving } \\
\text { Time }\end{array}$ & $\begin{array}{c}\text { Con- } \\
\text { venient } \\
\text { Facilities }\end{array}$ & $\begin{array}{c}\text { New } \\
\text { Acquain- } \\
\text { tances }\end{array}$ & $\begin{array}{c}\text { Relaxed } \\
\text { Environ- } \\
\text { ment }\end{array}$ & $\begin{array}{c}\text { Chil- } \\
\text { diren's } \\
\text { Activities }\end{array}$ & Cost \\
\hline$S S R$ & .0668 & .7107 & .7511. & .2067 & .7219 & .0510 \\
$V=$ & .7147 & .0462 & .0436 & .7352 & .0510 & .2271 \\
$M R$ & .2185 & .2431 & .2053 & .0581 & .2271 & .7219
\end{tabular}


Now multipoy une alternative weights matrix

$$
B^{*}\left[\begin{array}{l}
0.224 \\
0.191 \\
0.028 \\
0.065 \\
0.133 \\
0.359
\end{array}\right]=\left[\begin{array}{l}
0.300 \\
0.306 \\
0.394
\end{array}\right]=\left[\begin{array}{l}
S S R \\
M C \\
V R
\end{array}\right]
$$

Hence visiting relatives (VR) is the preferred vacation for the given criteria. 
1) Establish the focus or objective

2) Develop the hierarchy including the atternatives

3) Develop the matrix of pairwise comparisons for the criteria

4) Calculate the eigenvector and eignevalue of the of criter ia matrix. This vector is the criteria weights vector.

5) Calculate the consistency ratio and revise judgments if necessary.

6) Develop the matrices of pairwise comparisons of the alternatives. There is one matrix for each criterion.

7) Calculate the eigenvector and eigenvalue for each alternative vs alternative maírix.

8) Calculate the consistency ratio and revise judgments if necessary.

9) Form a matrix of the alternative eigenvectors; it has N(ci iteria) columns and $\mathrm{N}$ (alternatives) rows.

10) WHefipipy the alternative eigenvectors matrix by the criteria weight vector. The resulting vector gives the ranking of the alternatives. 
T. L. Saaty and L. G. Vargas, The Logic of Priopinies, Applications in Businesis, Energy, Health, and Transportation, Kluwer-Nijhoff Publ., Boston (1982)

R. W. Saaty, "The Analytic Hierarchy Process - What it is and How it is Used, Mathl klodeling, 9 , 161 (1987) 


\title{
A CARBON-FIBER BRUSH-LIKE FIRST WALL FOR THE LABORATORY MICROFUSION FACILITY
}

\author{
Michael J. Monsler and Wayne R. Meier \\ W. J. Schafer Associates, Inc.
}

Presented at the Eighth Topical Meeting on the

Technology of Fusion Energy

October 9-13, 1988

Salt Lake City, Utah 
The LMF first wall must withstand an intense $x$-ray pulse from the microexplosion

- Soft $x$-rays deposit energy near surface of material which can lead to:

- melting or vaporization of surface layer

- ablation driven shocks

- front surface cracking or rear surface spallation

- Wall radius set by either local damage or impulse to structure

- An unprotected wall would have to stand back 15-20 m

- To build a smaller chamber, the first wall must be protected in some way 
The carbon carpet is made of 2-cm-long fibers; each fiber consists of more than $10,0005 \cdot \mu \mathrm{m}$-diameter filaments

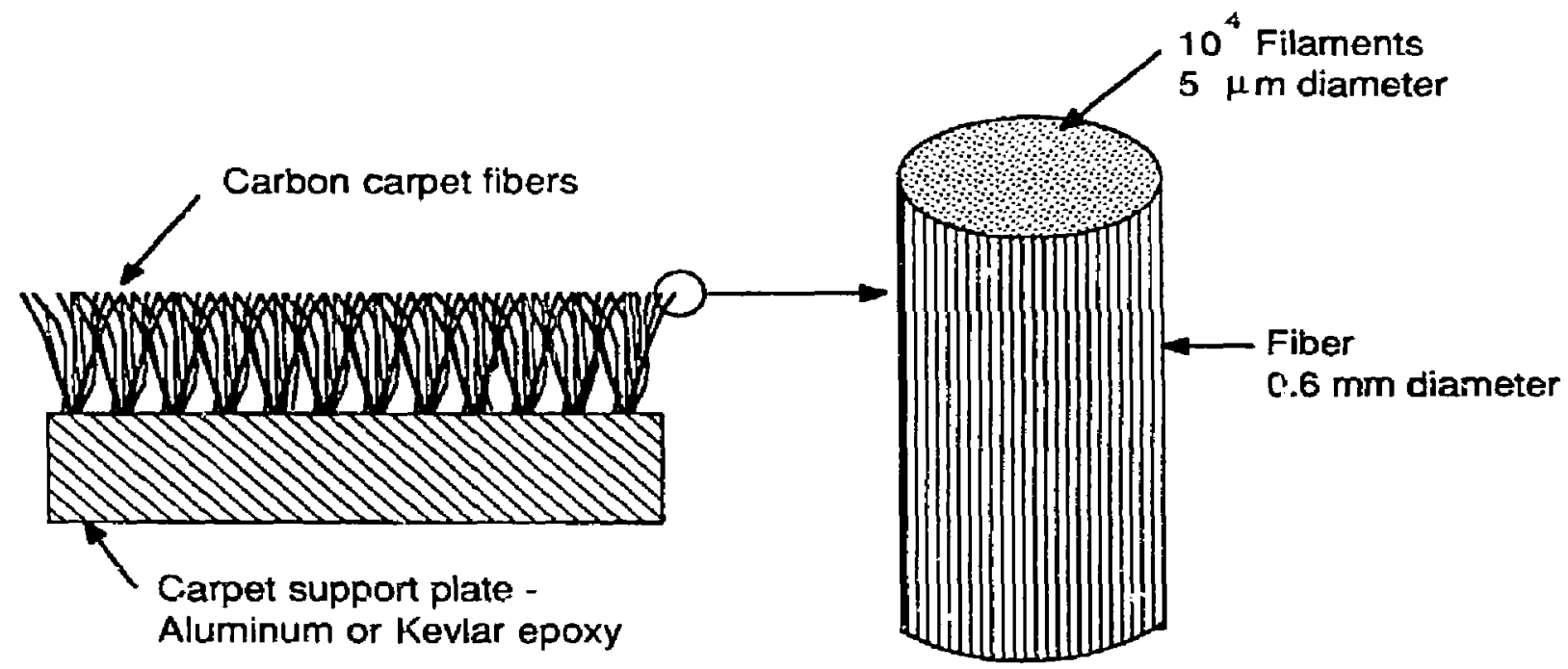


- absorbing the $x$-rays over ten times the surface area on fibers having incidence angle of $85^{\circ}$ to the $x$-ray pulse

- reducing the wall pressure by spreading out the plasma over a larger volume (2 cm fiber height vs $2 \mu \mathrm{m}$ absorption depth)

- $\quad$ spreading out the interaction time from 10 ns $x$-ray pulsewidth to $8 \mu$ s residence time of the vapor in the carpet

- reducing the total impulse by more than a factor of ten because the carbon vapor condenses back onto huge surface of fibers before it can escape from carpet

- absorbing energetic target debris in carbon vapor before it reaches the wall 
The carbon carpet reduces the peak pressure and the impulse on the wall

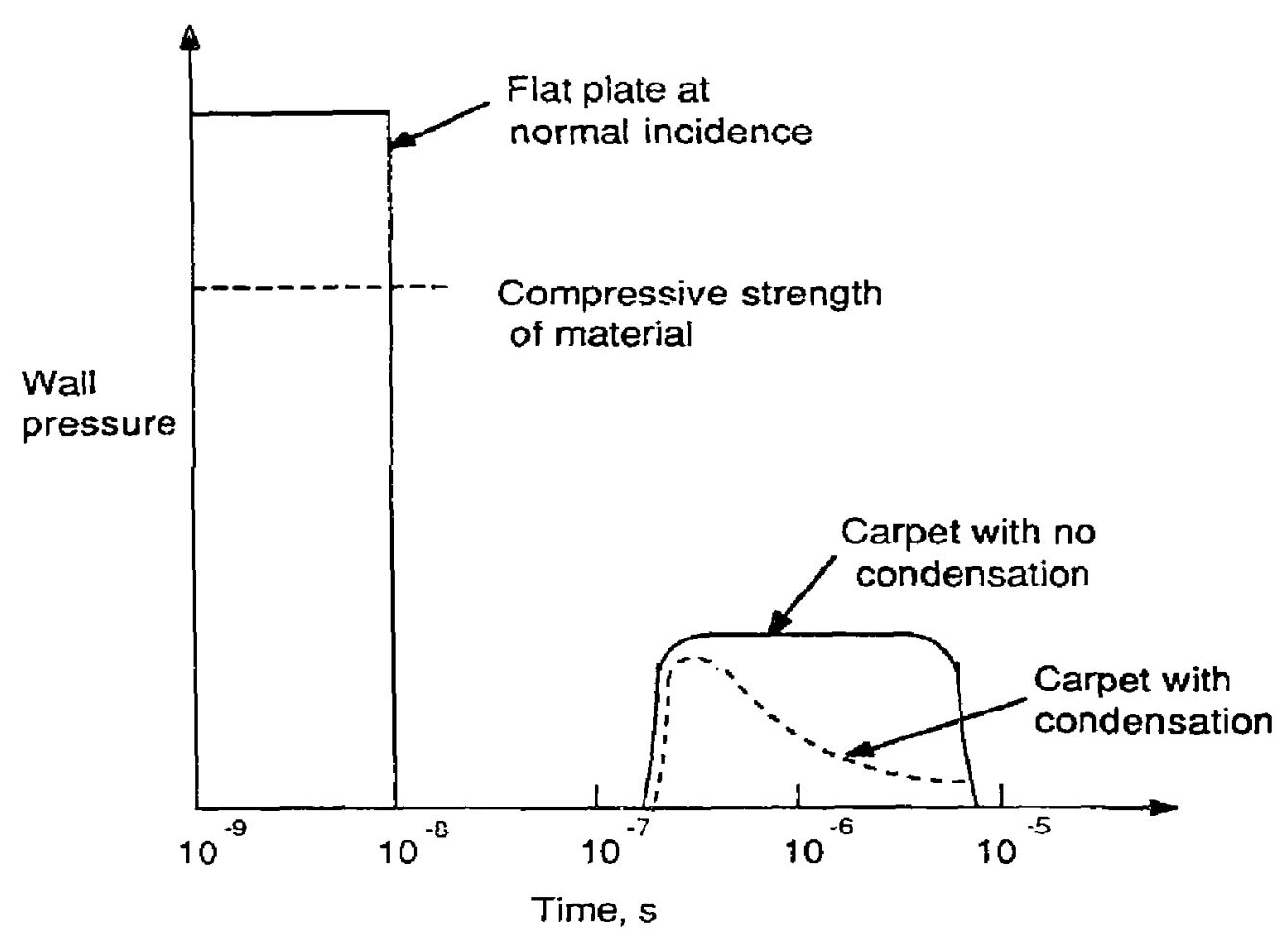


The wall pressure history is stretched-out, and the total impulse greatly reduced

- Initial vaporization moves perpendicular to fibers until inter-fiber space is filled

- Vapor moves radially to fill carpet region and begins to blow into center of chamber

- Wall does not feel pressure until vapor fills carpet, long after $x$-ray pulse has ended

- Plasma residence time is 3 times the characteristic condensation time

- Pressure decays as $90 \%$ of vaporized carbon condenses before it ever leaves the carpet region, greatly reducing the impulse 
Key timescales for the vaporization and condensation of carbon in the carbon carpet first wall

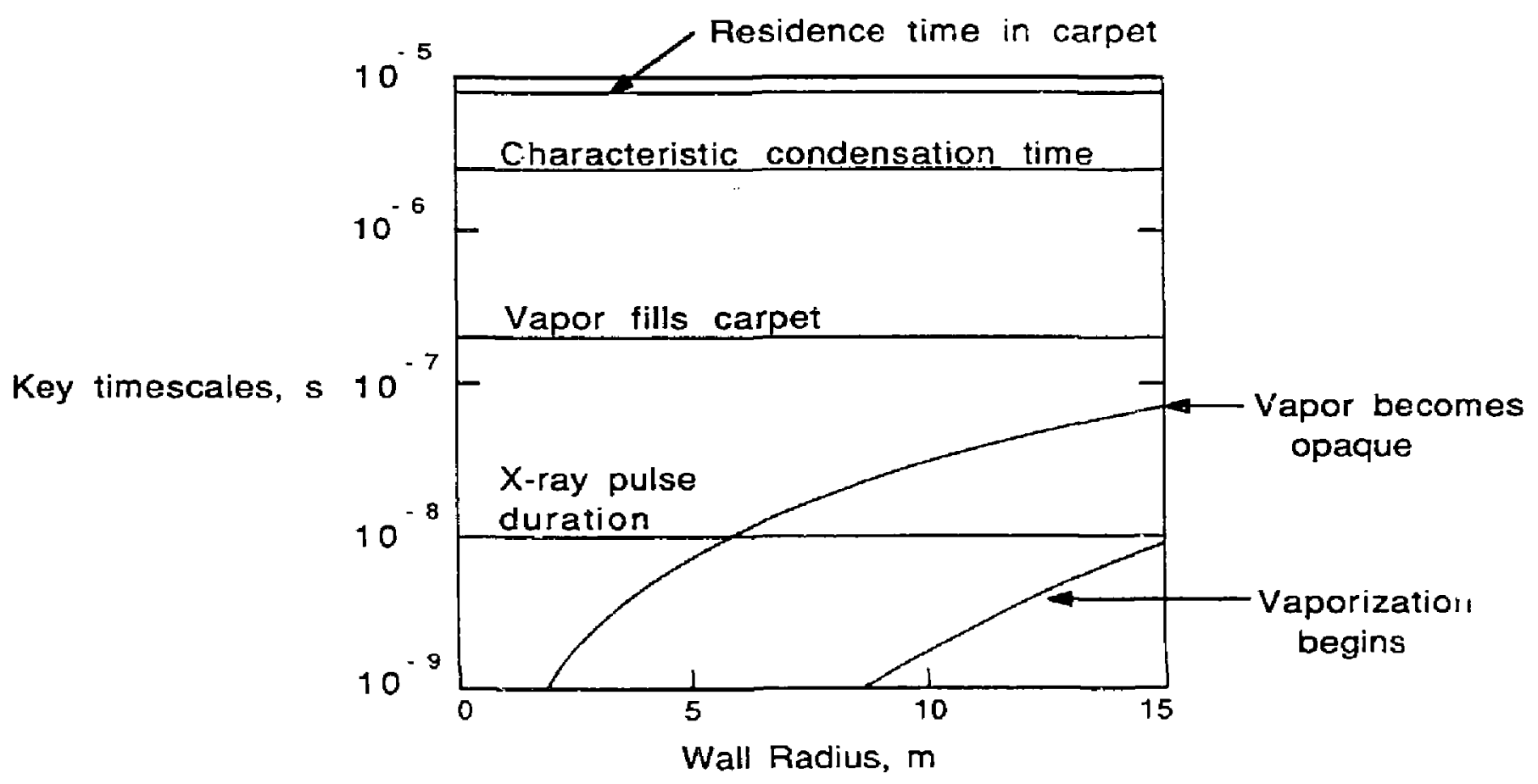


The factor by which fiber erosion is reduced by condensation depends on the fiber $L / D$ and the sticking coefficent

Reduction

factor




$95 \%$ of the vaporized carbon condenses before it escapes from the carbon carpet

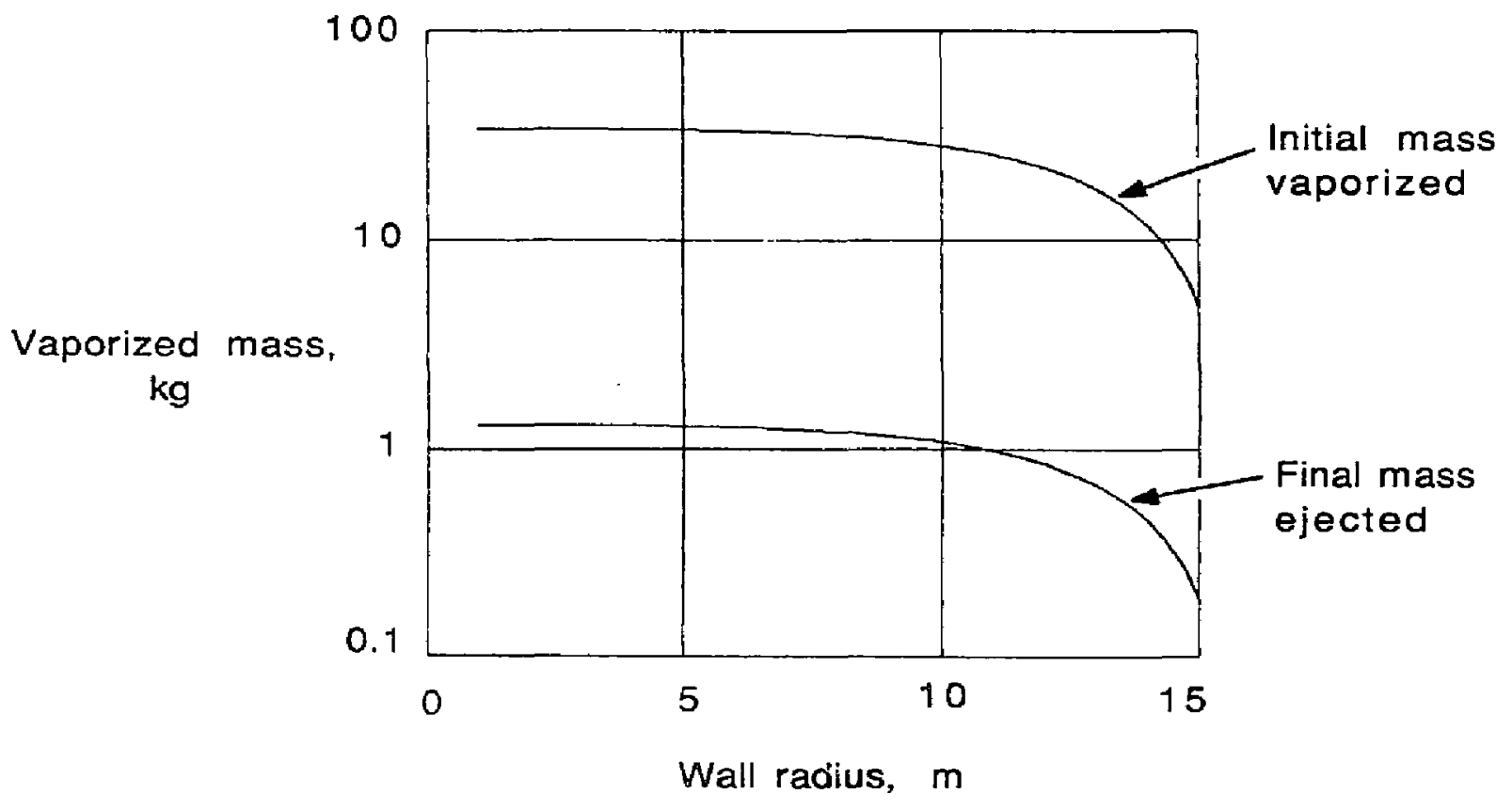


The carbon carpet reduces the impulse by more than an order of magnitude

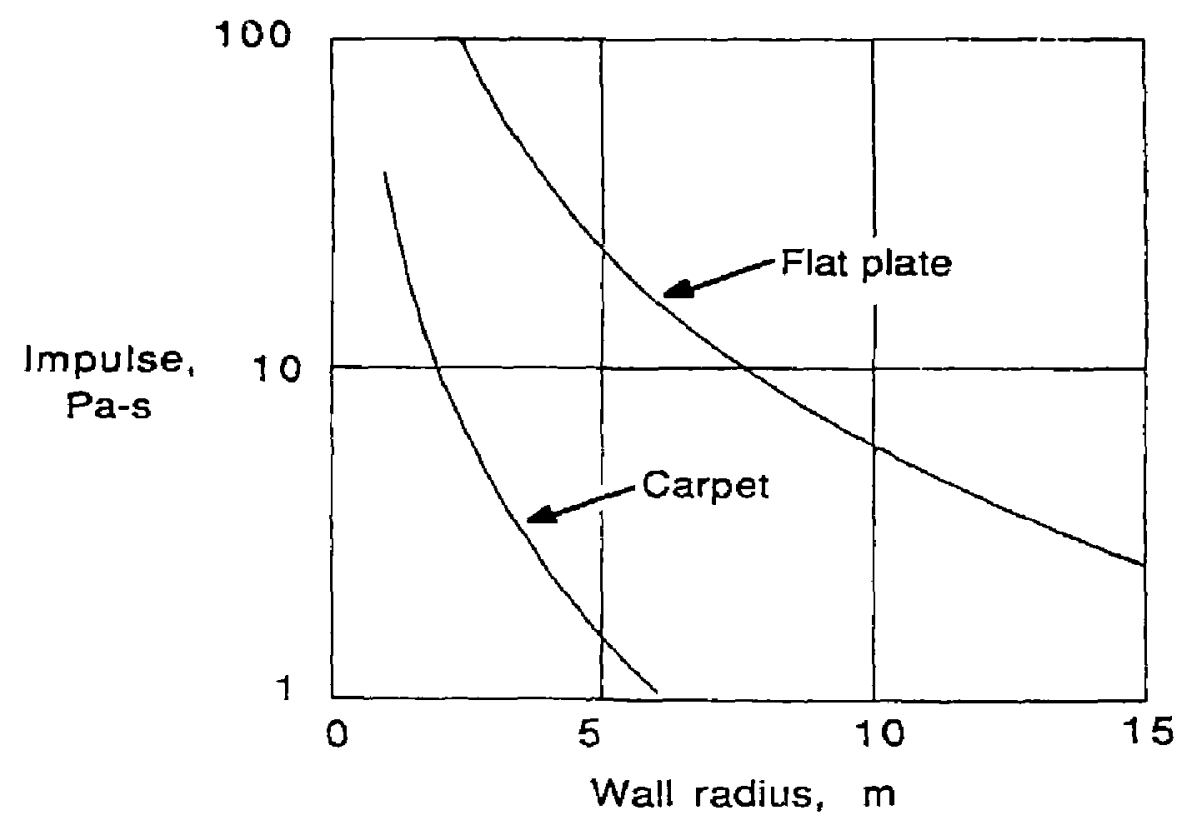


Bending stress in an aluminum flat plate due to impulsive loading is less than the design strength for radii greater than $1.5 \mathrm{~m}$

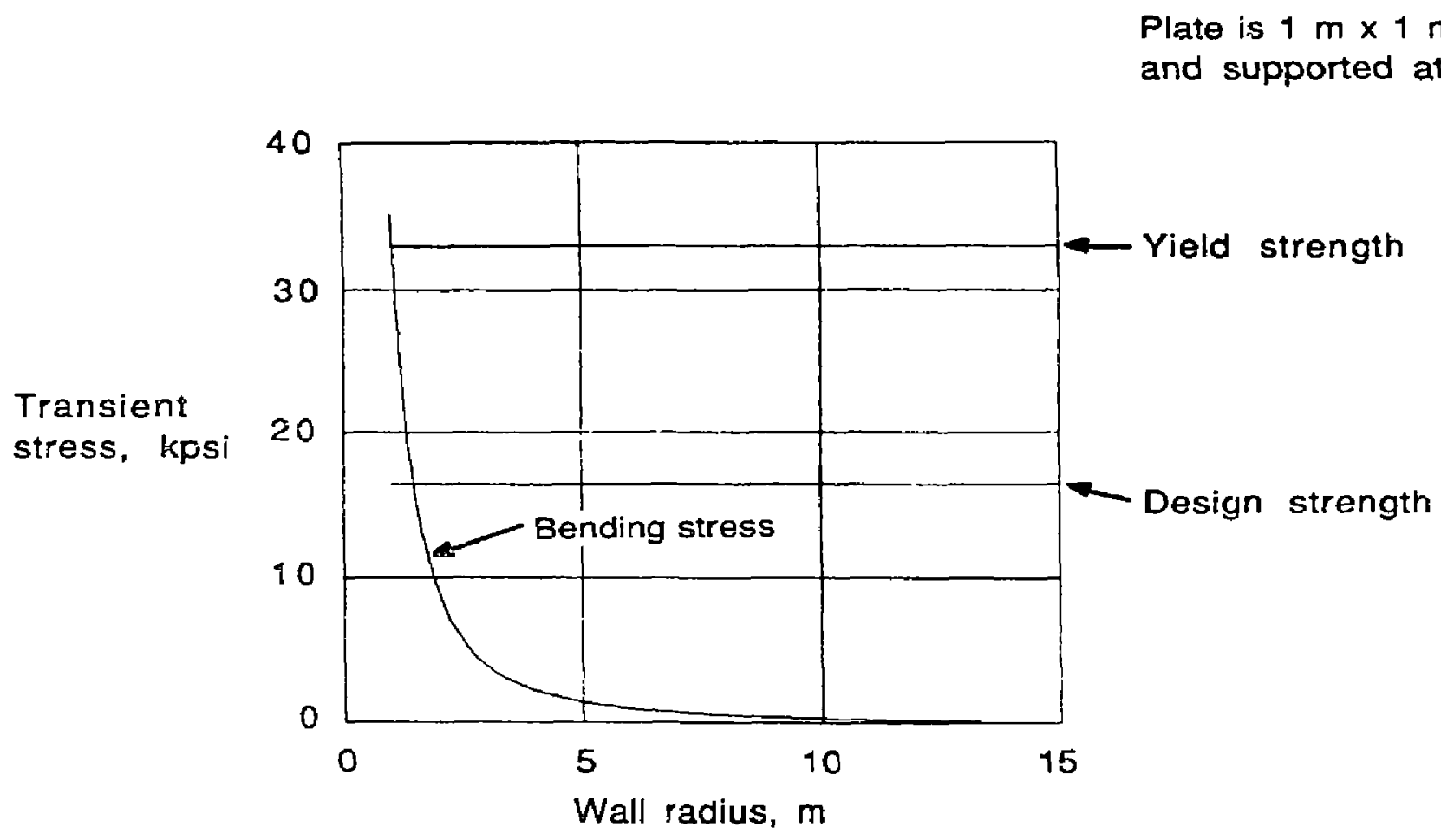


Lifetime of fibers -

- There are $10^{4}$ filaments per fiber and only outer filaments are exposed to $\mathrm{x}$-rays

- Filament diameter is about the same scale as $x$-ray absorption depth resulting in volumetric-like heating

- Material expands during 10 ns pulse time which reduces surface pressures

- Condensed carbon may protect filaments on subsequent pulse

- Modular design allows sections of first wall to be sasily replaced if necessary

- Tests are needed and are being planned 
Tritium absorption and build-up in carbon -

- Add 0.01 torr $\mathrm{CO}_{2}$ to chamber

- Microexplosion dissociates $\mathrm{CO}_{2}$

- Tritium tied up as $\mathrm{T}_{2} \mathrm{O}$ and pumped out of chamber so that it does not build up

Carbon "soot" contamination of optics -

- Optics are separately protected by fast valves and gas flow

- More than $90 \%$ of carbon condenses before it leaves carpet

- Expect most of remainder to condense in carpet at later time

Shrapnel damage -

- Carpet backed by replaceable panels of "bullet proof" kevlar epoxy

- Function of carpet not harmed by small particulate damage 
- Effectively deals with intense $x$-ray pulse from microexplosion

- Net vaporization and impulse to structural wall reduced by more than an order of magnitude

- Fiber micro-structure should reduce local damage due to $x$-ray induced shocks

- Self-protecting against target ions

- Chamber radius can be reduced to less than $2 \mathrm{~m}$, other factors are likely to set size

- Uses low activation materials and can eliminate Al from high energy neutron flux which reduces short terrn radiation hazard

- Modular panels easily removed if necessary

- First wall protection scheme does not require cryogenic cooling ('arget cooling system still needed)

- Potential solutions have been identified for major issues 


\title{
New Heavy-Ion-Beam Target Gain Curves
}

\section{for the SAFIRE Code}

\author{
W. R. Meier \\ W. J. Schafer Associates, Inc.
}

September 21, 1988 


\title{
New Heavy-Ion-Bcam Target Gain Curves
}

\author{
for the SAFInE Code
}

\begin{abstract}
A new set : target gain curves for heavy-ion-beam drivers were developed by Lawrence Livermore National Laboratory. Algorithms for these targe! gain versus driver energy relationships have been incorporated into the SAFIRE code for economic evaluation of inertial confinement fusion electric power plants. This repor describes the changes made to the SAFRE code and provides instructions for using the new gain curves.
\end{abstract}

\section{INTRODUCTION}

Algorithms for calculating the target gain as a function of diver energy for heavyion-bears (HIB) drivers were developed by Roger Bangerter in late 1987. These algorithms have been incorporated into the SAFIRE cade, which was developed to carry out economic analyses of inertial confinemeut fusion (ICF) electric power plants. The SAFIRE code is described in detail in Refs. 1-3. This report, which serves as a supplement to the previous SAFIRE reports, describes the changes to the SAFIRE code and how to use the new HIB target gain curves.

\section{SUBROUTINE HIBGAIN}

A single subroutine, HIBGAIN, was added to the code. This subroutine calculates the target gain as a function of the HIB driver energy for different types of targets and for different values of two parameters, the ion range and the beam spot radius. Inputs and outputs of the HIBGAIN subroutine are listed below. Default values, if any, are given in parenthesis.

INPUTS:

ETA

Switch for target type. The new curves are designated by ETA $=1,2$, 3, or 4. (The default is ETA $=0$, which is a target gain curve for laser drivers; see Ref. 2).

$1=$ Base case, two-sided irradiation, single shell

$2=$ Guess at single-sided

$3=$ Polarized fuel, two-sided irradiation

$4=$ Advanced concepts 
TENERG Driver energy on target, MJ

TRADIJS Beam radius at the target, $\mathrm{cm}(0.25)$

RANGE Ion penetration distarice in target, $g / \mathrm{cm}^{2}(0.1)$

OUTPUTS:

TGAIN Target gain

TYIEID Target yield, MJ

The algorithms are valid over the following ranges:

TENERG $\leq 15 \mathrm{MI}$

$0.1 \leq$ TRADIUS $\leq 0.5 \mathrm{~cm}$

$0.025 \leq$ RANGE $\leq 0.2 \mathrm{~g} / \mathrm{cm}^{2}$

With the exception of TRADIUS, all of the above variables were previously defined and used within the SAFRE code. References 2 and 3 list the common blocks and vamelist groups that contain these variables.

TRADIUS is the same as RSPOT used in the McDonnell Douglas HIB driver model. ${ }^{3}$ With the previous target gain curves, RSPOT was calculated based on specified values the target gain parameter, GAMMAH $=$ RSPOT $^{3 / 2} \times$ RANGE, and either the io range, RANGE, of the ion energy, EION. If EION was input, RANGE was calculated and vice versa. With the new curves, TRADIUS and RANGE must be inpul, and EION is calculated as a function of RANGE.

The McDonnell Douglas HIB model has an option to iterate on the ion energy to find the minimum cost accelerator. With the new gain curves, since ElON is fixed based on the specified value of RANGE, it is not possible to iterate on EION. Therefore IFIXEI in NAMELIST HIB2NL must be set equal to 1 (see Ref. 3). Also note that if ETA $=2$ (single-sided istadiation), we must set IRRAD $=1$ and $\mathrm{IACCNF}=2$ in NAMELIST HIB2NL.

\section{COMMON / TAR1 /}

TRADIUS was added to commou block TARI. 


\section{NAMELIST / TASK /}

TRADIUS and RANGE were added to NAMELIST TASK. The additional options for the value of ETA are also specified in this NAMELIST group.

\section{EXAMPLES OF NEW GAIN CURVES}

Figures 1-3 show the target gain as a function of driver energy for a representative set of target parameters. Figures 1 and 2 are for ETA $=1$ and show the effects of varying TRADIUS and RANGE, respectively. Figure 3 compares the different target types, ETA $=$ $1-4$, with TRADIUS $=0.25$ and $\mathrm{RANGE}=0.10$.

\section{USING THE NEW HIB TARGET GAIN CURVES}

The new HIB target gain curves can be used with the simple lIIB driver model (IDRIVE $=4$ ) or with the detailed McDonnell Douglas HIB driver model (IDRIVE = 5) by setting ETA $=1,2,3$, or 4 in NAMELIST TASK. TRADIUS and RANGE may also be specified in NAMELIST TASK or allowed to default. If DRVE $=5$, IFIXEI must be set equal to 1. If IDRIVE $=5$ and ETA $=2$, set IRRAD $=1$ and IACCNF $=2$.

An example input file for the Cascade chamber is shown in Fig. 4, and the corresponding output file is shown in Fig. 5. The beam radius and ion range were chosen to correspond to the example shown in Ref. 3 so that the effects of using the new basecase gain curve would be readily apparent. With these particular parameters, the new basecase target gain is somewhat lower than the gain in the example in Ref. 3. For both examples the pulse repetition rate was fixed at $5 \mathrm{~Hz}$, and the net electric power was fixed al $815 \mathrm{MWe}( \pm 1 \%$ ). With the previous curves, a driver energy of $4.2 \mathrm{MJ}$ (giving a gain of 71 and a yield of about $300 \mathrm{M}$ ) was required to get about $815 \mathrm{MWe}$. With the new base-case gain curve, a driver energy of $5.9 \mathrm{MJ}$ (giving a gain of 51 and a yield of $300 \mathrm{M}$ ) is required to achieve the specified net electric power.

\section{REFERENCE}

1. T. J. McCarville, W. R. Mejer, C. C. Carson, J. D. Gordon, and B. B. Glasgow, "SAFIRE - A Systems Analysis Code For ICF Reactor Economics," Lawrence Livermore Laboratory report UCRL-15872, Vol. 1 (Jan. 1987).

2 B. B. Glasgow, and W. R. Meier, "SAFIRE U/ser's Manual," Lawrence Livermore Laboratory repon UCRL-15872, Vol. 2 (Jan. 1987).

3. W. R. Meier, "A New Heavy-lon-Beam Diver Model for the SAFIRE Code," Lawtence Livermore Laboratory report UCRL-15872, Vol. 2, Sup. I (March 1987). 


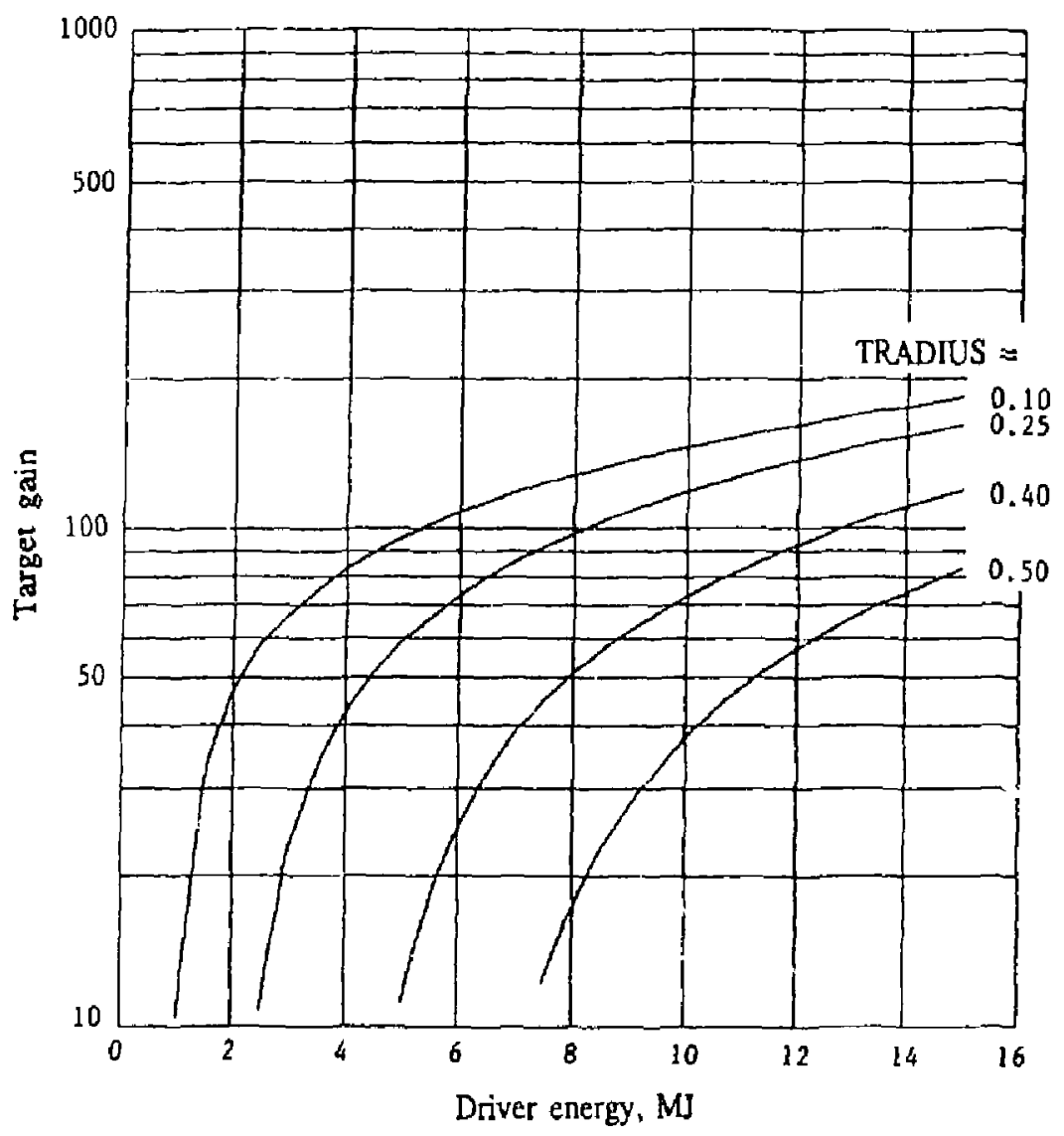

Figure 1. Target gain curves for single-shell HIB targets with two-sided irradiation $($ ETA $=1$ ). Curves are shown for beam radii (TRADIUS) of $0.10,0.25$, 0.40 , and $0.50 \mathrm{~cm}$. The ion range (RANGE) is fixed at $0.1 \mathrm{~g} / \mathrm{cm}^{2}$. 


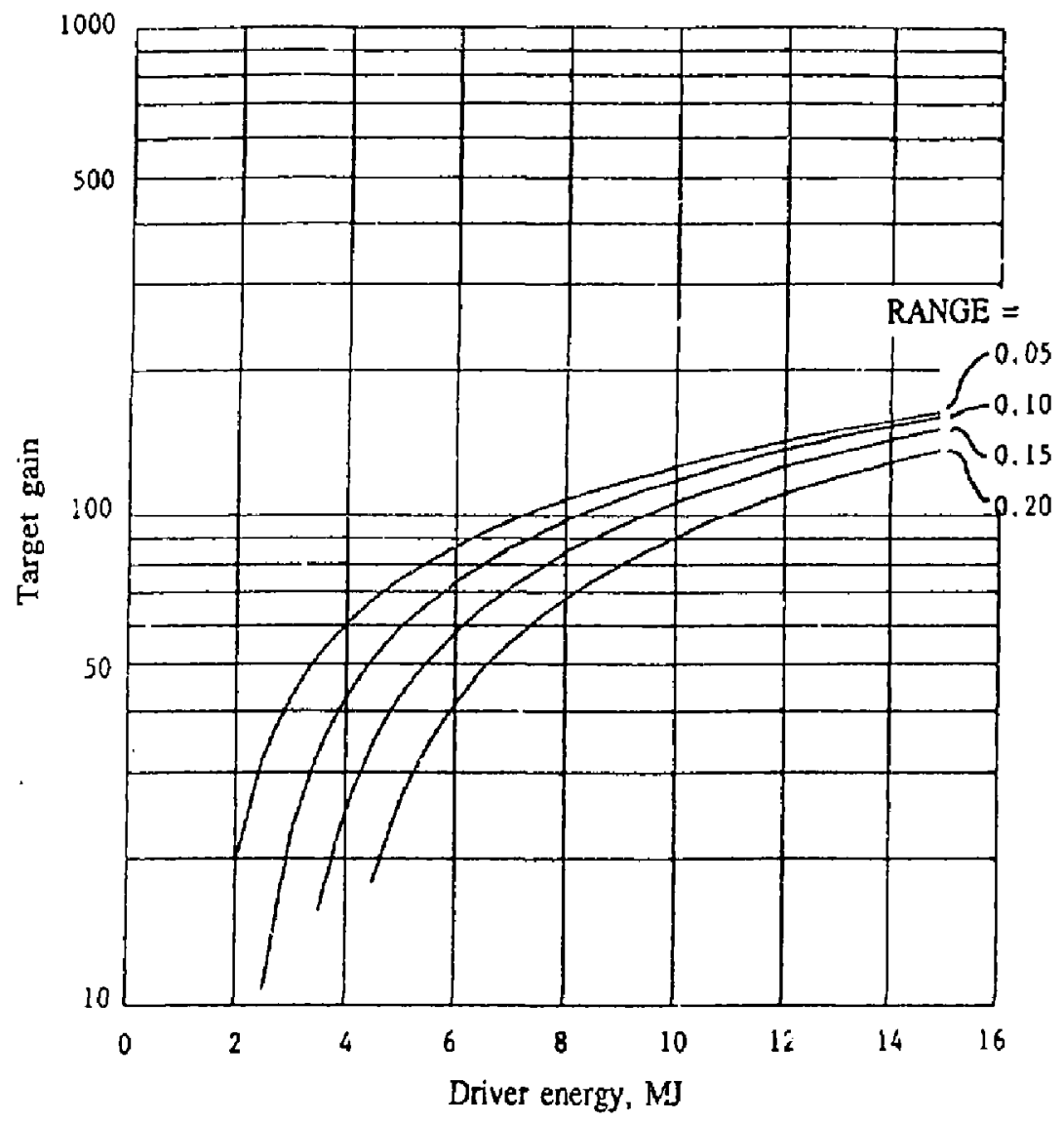

Figure 2. Target gain curves for $E T A=1$, TRADIUS $=0.25 \mathrm{~cm}$, and RANGE $=0.05$, $0.10,0.15$, and $0.20 \mathrm{~g} / \mathrm{cm}^{2}$. 


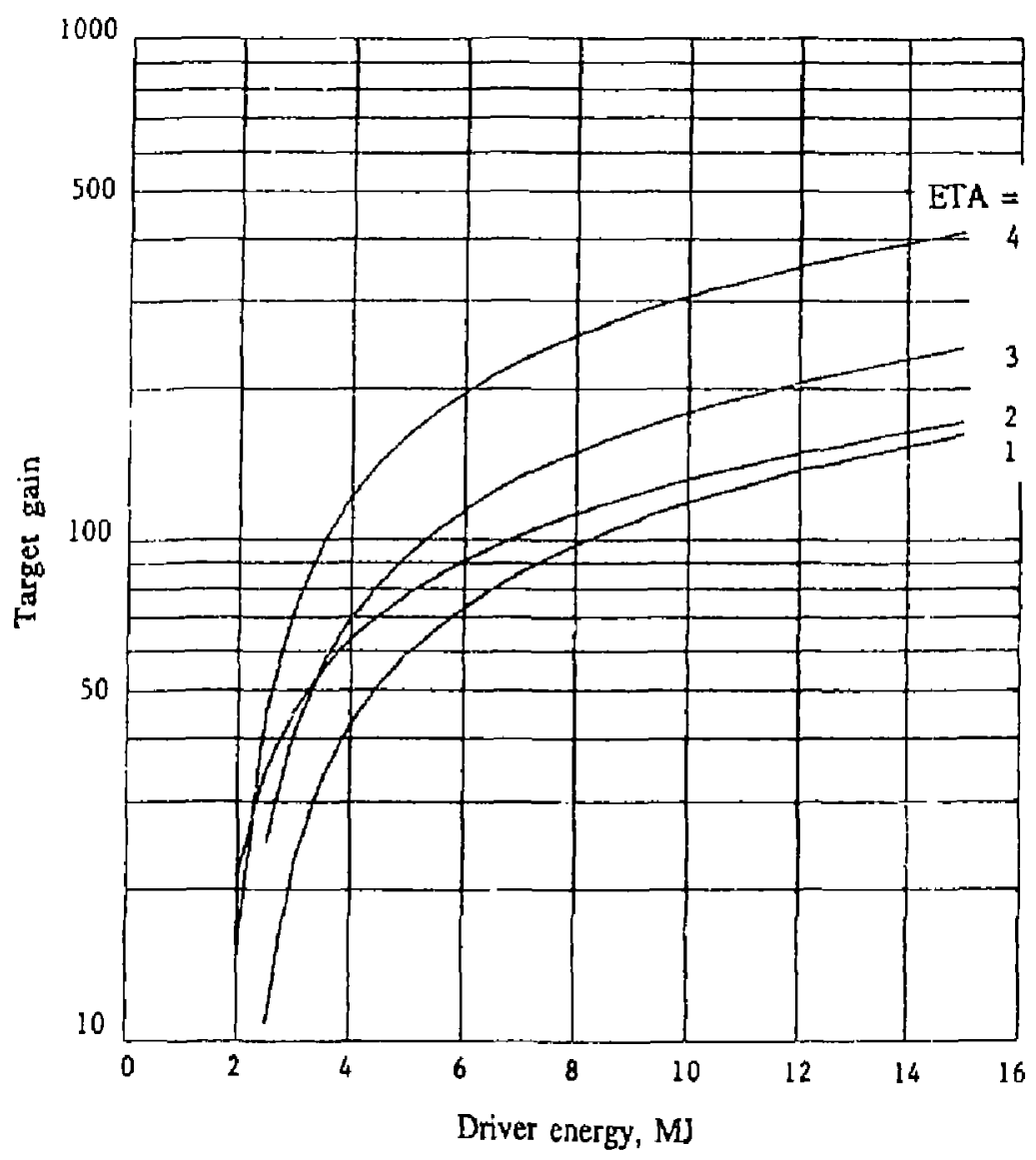

Figure 3. Target gain curves for TRADIUS $=0.25 \mathrm{~cm}$, RANGE $0.10 \mathrm{~g} / \mathrm{cm}^{2}$, and $\mathrm{ETA}=1,2,3$, and 4 . 


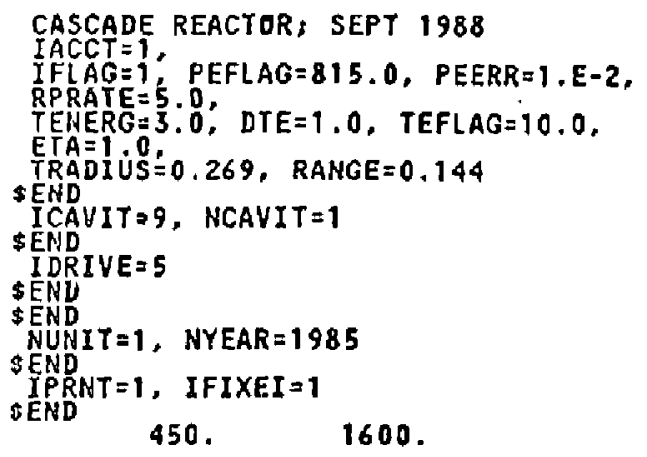

Figure 4. Input file for Cascade chamber with the McDonnell Douglas HIB driver model (DRJVE $=5$ ) and the new target gain algorithm for single-shell HDB targets with two-sided irradiation (ETA $=1)$. 


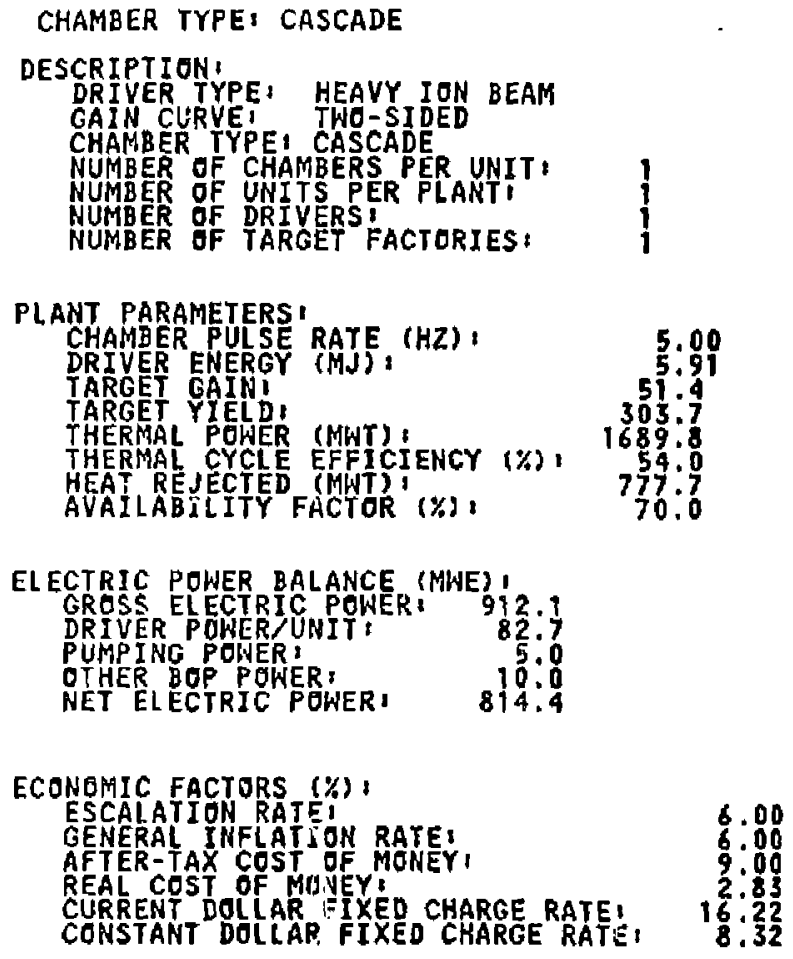

ELECTRIC POWER BALANCE (MWE)

OTHER BOP POWER :

NET ELECTRIC POWER I $814: 4$

\section{ECONOMIC FACTORS (\%) \\ ESCALATION RATEI 6.00 \\ GENERAL INFLATION RATE: \\ AFTER-TAX COST OF MONEYI \\ $\begin{array}{ll}\text { CURRENT DOLLAR EIXED CHARGE RATEL, } & 16.22 \\ \text { CONSTANT DOLLAR, FIXED CHARGE RATE, } & \mathbf{8} .32\end{array}$}

REAL COST OF MGYEY

Figure 5. Part of the SAFIRE code output for the input shown in illustration 1. 
HEAVY ION BEAM DRIVER INFURMATION

BASED ON MCDONNELL DOUGLAS MODEL

FINAL TRANSPORT SUMMARY FOR POLE TIP FIELD (T)
IOW ENERGY TGEV)
ION MAS (AMU)
IUN CHARGE STATE
GAIN PARAMETER (R*R**1,5)

GAIN RANGE IN TARGET (G;CN**2) TARGEY AVERAGE Z

BEAM SIIFFNESS (T-H)

FINAL TRANSPORT BEND RADIUS (M)

FINÁ FUCUS CONVERGENCE ANGLE (RAD)

CHAMBER RADIUS + SIANDOFF (M)

FINAL MAGNEI LENGTH (M)

FINAL MAGNET RADIUS (M)

FINAL FQCUS SYSTEM LENGTH (M)

FINAL SPOT SIZE (CM)

BEAM POHER DENSITY (TW/CM**2)

FINAL PUL SE LENGTH (NSEC)

UNNORMALIZED EMITTANCE (UR-M)

BEAMLET PERVEANCE

FINAL TRANSPORT SYSTEM LENGTH (M)

DELAY LINE LENGTH (M)

SWITCH YARD LENGTH (M)

CURRENT PER BEAMLET (A)

NUMBER BEAMLETS IN FINAL TRANSPORT

DOUBLE-SIDED IRRADIATION,

$\begin{array}{ll}= & \\ = & \\ = & 1 \\ = & \\ = & \\ = & \\ = & \end{array}$

1.0000
6.0376

130.0000

3.0000

0.0000

0.1440

13.0000

43.0407

215204

7.0000

0.6836

0.5257

66.2031

0.2690

1842.9443

14.0976

33.89

0.000175

154.3705

0.0000

0.0000

1285.0181

ACCELERATOR SUMMARY,

NORMALIZED ACCELERATOR CUST (M\$)

ACCELERATOR REPETITION RATE

HUMBER OF BEAMS IN ACCEL ERATOR

ACCELERATOR LENGTH (K.t)

ACCELERATOR OPERATING SCENARIO

54

DFIVER COST SUMMARY,



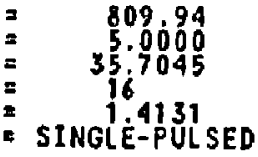

1079,90

153.36

766.79

0.00

43.16

\%.2.

4.61

5.50

25.00

Figure 5. (Continued) 
ICF ECONOMIC EVALUATION FOR 1 UNIT POWER PLANT

\begin{tabular}{|c|c|c|c|}
\hline ACCOUNT & ACCJUNT TITLE & \multicolumn{2}{|r|}{$M \$$} \\
\hline 20 & LAND AND LAND RIGHTS & \multicolumn{2}{|r|}{5.0} \\
\hline 21 & STRUCTURES AND IMPROVEMENTS & \multicolumn{2}{|r|}{84,5} \\
\hline 22 & REACTOR PLANT EQUIPMENT & \multicolumn{2}{|r|}{284.0} \\
\hline 23 & TURBINE PLANT EQUIPMENT & \multicolumn{2}{|r|}{185.6} \\
\hline 24 & ELECTRIC PLANT EQUIPHENT & \multicolumn{2}{|r|}{70.8} \\
\hline 25 & MISCELLANEOUS PLANT EQUIPMENT & \multicolumn{2}{|r|}{16.3} \\
\hline 26 & MAIN HEAT REJECTION EQUIPMENT & \multicolumn{2}{|r|}{21.7} \\
\hline 27 & DRIVER EQUIPMENT & \multicolumn{2}{|c|}{1079.9} \\
\hline 28 & TARGET FACTORY EQUIPMENT & \multicolumn{2}{|r|}{86.4} \\
\hline & TOTAL DIRECT COST & \multicolumn{2}{|c|}{1834.2} \\
\hline 91 & CONSTRUCTION SERVICES & \multicolumn{2}{|r|}{366.8} \\
\hline 92 & HOME OFFICE ENGINEERING AND SERVICES & \multicolumn{2}{|r|}{275.1} \\
\hline 93 & FIELD OFFICE ENGINEERING AND SERVICES & \multicolumn{2}{|r|}{183.4} \\
\hline 94 & DNNER'S COST & \multicolumn{2}{|c|}{128.4} \\
\hline \multirow[t]{3}{*}{95} & PROJECT CONTINGENCY & \multicolumn{2}{|r|}{278.8} \\
\hline & TOTAL OVERNIGHT COST & \multicolumn{2}{|c|}{3066.8} \\
\hline & & CURRENT\$ & CONSTANT $\$$ \\
\hline 96 & ESCALATION DURING CONSTRUCTIOK & 989.7 & 0.0 \\
\hline \multirow[t]{4}{*}{97} & INTEREST DURING CONSTRUCTION & 1288.1 & 286.5 \\
\hline & TOTAL CAPITAL COST & 5344.6 & 3353.3 \\
\hline & COST OF ELECTRICITY & & \\
\hline & $\begin{array}{l}\text { CAPITAL } \\
\text { FUEL } \\
\text { OSH } \\
\text { IOTAL }\end{array}$ & $\begin{array}{r}17.35 \\
0.02 \\
5.73 \\
23.11\end{array}$ & $\begin{array}{l}5.58 \\
0.01 \\
1.84 \\
7.43\end{array}$ \\
\hline
\end{tabular}

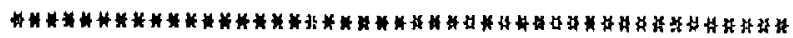

Figure 5. (Continued) 


\title{
Parametric Economic Studies for HYLIFE:
}

\section{Implications for a New Molten Salt Reactor}

\author{
Wayne R. Meier
}

W. J. P.hafer Associates, Inc.

November 1, 1988 


\section{INTRODUCTION}

Economic studies were carried out to invesugate various aspect of a Heavy Ion Beam (HIB) driven HYLIFE reactor as a commercial electric power plant. The purpose of these studies was to $\mathrm{g}$ in an understanding of the factors that are most important in determining the cost of electricity for a reactor that stales like HYLIFE. This information can help guide our research on the molten salt version of HYLIFE, tentatively called HXLIFE- $\Gamma_{1}$. The results fresented here thus serve as a point of reference as we begin our investigation of HYLIFE-II, I've evaluated the cost of electricity (COE) as a function of several system design parameters including: the characteristics of the target, which determine the gain versus energy relationship; the chamter pulse repetition rate; the net electric power per reaclor, and the number of reactor units serviced by a single driver. The SAFIRE code, which is fully documented in Refs. 1-4, was used for this study. Ali costs are in constant, January 1988 dollars.

The base case power plant configuration is a single HIB driver operating a single HYLIFE reactor that produces a net electric power of $1.0 \mathrm{GW}$. The McDonnell Disuglas (MDAC) cost-performance model for the HIB driver ${ }^{3}$ and the new HIB target gain relarionships ${ }^{4}$ were used in these analyses. The focus of this study is on the reactor design and plant configuration, not on the driver design. The HIB driver was selected because it is the most detailed driver model in the SAFIRE code, and using it also gave me a chance to use the new HIB carget gain relationships. The base case chanber pulse repetition rate is $1.5 \mathrm{~Hz}$, and the corresponding target yield is $1660 \mathrm{MJ}$. The driver energy at this point is $8.5 \mathrm{MJ}$, and the target gain is 195. A list of system design parameters is given in Table I. If only one value is listed, the quantity is held constant; if more than one value is listed, the quantity is either used as an independent variable or is varied as a parameter.

\section{RESULTS}

\section{Target Parameters}

New HIB target gain algorithms, developed by LLNL, were recently incorporated into the SAFIRE code. These algorithms give the target gain as a function of driver energy for four different types of target: 1) Base-case, two-sided irradiation, single shell; 2) Single-sided; 3) Polarized fuel, two-sided irradiation; and 4) Advanced concepts. For each target type there is a family of curves dependent on two paramelers, the ion range 
and the beam spot size (i.e., there is a unique gain versus energy curve each combination of ion range and spot size). A representative sample of curves is shown in Fig. 1, and Ref. 4 contains additionai examples that show the variation with range and spot size. In general, the gain decreases with increasing spot size for a given range and decreases with increasing sange for a given spot size. I originally intended to use the Base case, twosided iradiation target, but found that the driver energy required to produce $1 \mathrm{GW}_{\mathrm{t}}$ at $1.5 \mathrm{~Hz}$ exceeded $10 \mathrm{MJ}$, and unfortunately the MDAC driver model is not valid above $10 \mathrm{MJ}$ (some of the fitting routines it uses give non-physical results above $10 \mathrm{MJ}$ ). Therefore, the Advance concepts target, which is more optimistic, was selected for this study.

The COE from future coal and fission power planls (evaluated on the same economic basis as we use for ICF) is in the range of about 4 to $5 \mathrm{k} / \mathrm{kWh}_{\mathrm{e}}$. To be economically competitive, we would like to show that ICF can at least approach these electricity costs. The COE as a function of the beam spot radius is shown in Fig. 2 for three values of the ion range, $0.10,0.15$, and $0.20 \mathrm{~g} / \mathrm{cm}^{2}$. For the $130 \mathrm{amu},+3$ ions used throughout this study, the three ranges comespond to ion energies of $4.73,6.20$ and $7.45 \mathrm{GeV}$. The results in Fig. 2 are for a single unit, $1.0 \mathrm{GW}_{\mathrm{e}}$ power plant with the chamber pulse rate fixed at $1.5 \mathrm{~Hz}$. The $\mathrm{COE}$ is a minimum at the intermediate beam spot radius $(0.25 \mathrm{~cm})$ and decteases with increasing ion range. The minimum at $0.25 \mathrm{~cm}$ is the result of competing factors that influince the cost of the HIB driver. Increasing the spot size allows a higher bearn emittance which reduces the driver cost. On the other inand, the target gain decreases with increasing spot size, and bence, more driver energy is required to get the yield necessary for the desired net electric power, and this increases the driver cost. The minimum at $0.25 \mathrm{~cm}$ is essentially a trade-off beiween driver energy and beam emittance. For the remainder of the analyses, the beam spot size and ion range are fixed at $0.25 \mathrm{~cm}$ and $0.20 \mathrm{~g} / \mathrm{cm}^{2}$, respectively. For the single unit, $1.5 \mathrm{~Hz}$ plant, the $\mathrm{COE}$ is $8.8 \mathrm{k} / \mathrm{kW}_{\mathrm{c}} \mathrm{h}$ with these target parameters, significantly higher than coal and fission.

\section{HYLIFE Reference Case}

The capital cost summary for the single unit HYLIFE plant is shown in Table 2. The total direct capital cost is $\$ 2672 \mathrm{M}$, with the driver cost of $\$ 1284 \mathrm{M}$ being the largest single item. The driver energy is $8.5 \mathrm{MJ}$, so the driver bas a direct capital cost of 
$\$ 150 / \mathrm{J}$ at this particular energy and pulse rate. The direct capital cost of the reactor (i.e., chamber plus balance of plant, accounts 20 through 26) is $\$ 130 \$ \mathrm{M}$, with the reactor plant equipment cost of $\$ 602 \mathrm{M}$ accounting for $46 \%$. Table 3 stows a breakdown on the reactor plant equipment, and we note that the heat tanspon system cost of $\$ 484 \mathrm{M}$ dominates this account. Table 4 shows the breakdown on the beat vansport system cost The recirculating jet array system, which includes all the large liquid metal pumps and associated piping needed to establish the flowing blanket, is the most expensive item at $\$ 147 \mathrm{M}$. The sodjum secondary loop equipment (including the intermediate heat exchanger) contributes a total of $\$ 143 \mathrm{M}$

If we postulate a reactor without the large flow rate of HYLIFE (i.e., no jet array) and without an intermediate coolant loop, we could save $\$ 290 \mathrm{M}$ and bring the cost of the reactor down to about $\$ 1 \mathrm{~B}$. Eliminating the recirculating and intermediate heat transfer loops would also reduce the size and cost of the containment building somewhat. A billion dollars is thus the probable minimum cost of a lithium cooled reactor, assuming that the intermediate coolant loop could somehow be eliminated. How will a FLiBe cooled reactor compare? The principal differences will be in the cost of the chambes and heal transpor: system. The cost will depend on whether $c^{r}$ not a bigh tlow rate blanket and an iniermediate coolant loop are used. Even if HYLIFE-II does not use a high flow rate blanket, we need to determine the cost of FLiBe pumps, piping, heat exchangers, clean-up systems, tritium removal and containment systems, etc, and compare the FliBe system costs to HYLIFE's lithium-primary, sodjum-secondary beat transfer system. 1 propose to address these questions in the comilg year as HYLIFE-I is better defined.

\section{Dependence on Net Electric Power}

Now let's turn our attention to some of the parametric sudies with the HYLIFE reactor to see which system parameters and design variables are important in determining the $\mathrm{COE}$. The $\mathrm{COE}$ as a function of the plant net electric power is shown in Fig. 3 for plants that are made up of a single driver and 1 - 4 reactor units rated at $0.5-1.5 \mathrm{GW}_{\mathrm{c}}$ each The uppermost line is the COE for plants made up of 1 to 4 units each producing $0.5 \mathrm{GW}_{e}$, giving a total net power of 0.5 to $2.0 \mathrm{GW}_{\mathrm{e}}$. The next line down is for plants with $1.0 \mathrm{GW}_{\mathrm{e}}$ units, and the dashed line is for $1.5 \mathrm{GW}_{\mathrm{e}}$ units. We note several things. A single $0.5 \mathrm{GW}_{\mathrm{c}}$ unit has a very high $\mathrm{COE}(13.5 \mathrm{c} / \mathrm{kW} \mathrm{c})$ since the investment in the driver can not be covered by such a small electric outpul. Driving four $0.5 \mathrm{GW}_{t}$ units 
with a single driver reduces the $\operatorname{COE}$ to $7.1 \& / \mathrm{kW}_{\mathrm{c}} \mathrm{b}$. A plant with two $1 \mathrm{GW}_{\mathrm{c}}$ units has a COE of $6.2 \% / \mathrm{kW}_{e} \mathrm{~h}$, which is $30 \%$ lower than the single unit $1 \mathrm{GW}_{\mathrm{e}}$ plant, but it is sijll higher than coal and nuclear. At $3 \mathrm{GW}_{\mathrm{e}}$, there is little difference between a 2 or 3 unit plant. To produce $1.5 \mathrm{GW}_{\mathrm{c}}$ in a single reactor requires such a high yield and driver energy that the reactor economies of scale are essentially cancelled out. While a $3 \mathrm{GW}_{\mathrm{f}}$ plant has a lower $C O E$ than a $2 \mathrm{GW}_{\mathrm{e}}$ plant $\left(5.4\right.$ compared to $\left.6.2 \mathrm{f} / \mathrm{kW}_{\mathrm{c}} \mathrm{b}\right)$, the total capital investment is $28 \%$ higher ( $\$ 8.9 \mathrm{~B}$ compared to $\$ 6.9 \mathrm{~B}$ ). Three $\mathrm{GW}_{\mathrm{c}}$ is also larger than current dual unit nuclear plants. Therefore, a $2 \mathrm{GW}_{\mathrm{c}}$ plant is probably a more appropriate choice when comparing to nuclear and coal plants.

\section{Dependence on Chamber Pulse Rate}

One important variable for the HYLIFE-Il design team to consider is the chamber pulse rate. HYLIFE is by nature a low pulse rate (i.e., less than a few $\mathrm{Hz}$ ) charnber because of the need to clear the chamber and reestablish the jet array between shots. A high pulse rate requires a high injection velocity and a high liquid metal flow rate. The injezion velocity is provided by a head of Li on top of the injection plate, so increasing the injection velocity also increases the height of the vessel and the lotal $\mathrm{Li}$ inventory. On the other hand, for a fixed net power, a higher pulse rate comesponds to a lower targel yield and smaller, less expensive driver. The driver power, bowever, will increase if the pulse rate increases faster than the driver energy decreases. It all depends on the shape of the gain curve at the particular design point and on the driver efficiency, which is also a function of the driver energy and pulse rate. Figure 4 sbows the COE as a function of chamber pulse rate for single and dual unit power plants (I and $2 \mathrm{GW}_{\mathrm{e}}$ net). The single unit plant is more sensitive to increasing pulse rale, decreasing from 9.4 to

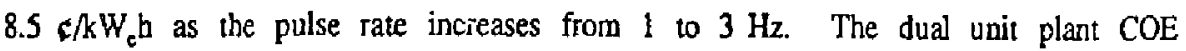
decreases from about 6.6 to $6.1 \mathrm{~g} / \mathrm{kW} \mathrm{h}$ over the same range of pulse rates with most of the decrease between 1 and $2 \mathrm{~Hz}$. Therefore, for a dual unit plant, HYLIFE chamber pulse rates of 1.5 to $2 \mathrm{~Hz}$ are adequate. Note that this conclusion is based on the assumption that the Adyance concepts targets will be available and perform as predicted.

Some of the HYLIFE design parameters are shown in Fig. 5 as a function of the chamber pulse rate. The chamber diameter decreases (from $11.6 \mathrm{~m}$ to $6.8 \mathrm{~m}$ ) with increasing pulse rate, since the yield and resulting impact stresses on the wall are diminished. The lithium flow rate increases from $7210118 \mathrm{~m}^{3} / \mathrm{s}$, and the required 
injection head increases from 3.4 to $12.8 \mathrm{~m}$. The chamber height is defined as the sum of the injection head plus $80 \%$ of the chamber diameter. This is the distance from the wop of the lithium pool above the injection plate to the lidium pool at the bottom of the chamber. The vacuum vessel height will be a few meters more than this to alluw for space above the injection pool and a region at the bottom to collect $\mathrm{Li}$. As indicated the chamber height has a minimum of $11.3 \mathrm{~m}$ at $1.4 \mathrm{~Hz}$ and increases to $18.2 \mathrm{~m}$ at $3 \mathrm{~Hz}$. At $3 \mathrm{~Hz}$, HYLIFE would require a very tall vessel!

\section{Allowable Reactor Cost for Fixed COE}

None of the previous results with the FYLIFE reactor produced a COE less than $5 \pm / \mathrm{k} \mathrm{W}_{\mathrm{e}} \mathrm{h}$. Using the same HIB driver cost model and target gain relationships as before, bow much can the reactor cost if we want an ICF plant with a COE that is competitive with fission and coal? To answer this, I considered a dual unit plant with a total net power of $2 \mathrm{GWe}$. In this hypothetical example, the thermal conversion efficiency is fixed at about 37\%. Figure 6 shows the direct capital cost of the driver and target factor. The driver cost decreases from $\$ 1.6 \mathrm{~B}$ at a chamber pulse rate of $1 \mathrm{~Hz} 10 \$ 1.1 \mathrm{~B}$ at $10 \mathrm{~Hz}$, and the driver energy decrease from $10.4 \mathrm{MJ}$ to $4.6 \mathrm{MJ}$ over this range. (Note that the driver pulse rate is twice the chamber pulse rate.) The direct capital cost of the target factory, which supplies both reactors, increases from $\$ 0.1$ B to $\$ 0.2$ B as the chamber pulse rate increases from 1 to $10 \mathrm{~Hz}$. In our economics model, the COE is essentially directly proportional to the total capital cost. Therefore, for a fixed $\mathrm{COE}$, the bigher the sum of the driver and target factory costs, the lower the allowable cost for the two reactors making up the duai unit plant.

Figure 7 shows the allowable direct capital cost of the first reactor unit for a specified $\mathrm{COE}$ as a function of chamber pulse rate over the range of 1 to $10 \mathrm{~Hz}$. The HYLIFE direct capital cost is shown for reference. (SAFIRE's costing for multi-unit plants is based on the cost of the first unit. The direct cost of the second unit is $80 \%$ of the first, and the indirect costs of the second unit are $60 \%$ of the first unit's indirect cost) We see that it is advantageous 10 go from 1 to about $3 \mathrm{~Hz}$, but there is litue incentive beyond $3 \mathrm{~Hz}$. To break below $5 \mathrm{k} / \mathrm{kW}_{\mathrm{e}} \mathrm{b}$ requires a reactor with a direct capital cost of $\$ 0.94 \mathrm{~B}$ at $3 \mathrm{~Hz}$, and to get down to $4 \mathrm{q} / \mathrm{kW}_{\mathrm{c}} \mathrm{b}$ reguires a reactor cost of about $\$ 0.59 \mathrm{~B}$ at $3 \mathrm{hz}$. (Note that for every dollar that the reactor first unit direct capital cost exceeds the allowable cost given here, the driver direct capital cost must be reduced by a 
$\$ 1.73$ in order to maintain the fixed $\mathrm{COE}$ ). As previously stated, $\$ 1 \mathrm{~B}$ is about the lower limit of a Li cooled renctor, and this may not be far off from what we will be able to do with a FLiBe cooled plant. It seems unlikely that $4 \phi / \mathrm{kW}_{\mathrm{e}} \mathrm{b}$ is achievable with the current estimates for the HIB driver cost and target gain.

\section{CONCLUSIONS}

Various economic aspects of a HIB driven ICF power plant using a HYLIFE reactor have been investigated. The following points summarize the findings.

1) To get $1 \mathrm{GW}_{e}$ in a single unit plant operating at $1.5 \mathrm{~Hz}$ with a driver energy less than $10 \mathrm{MJ}$ requires target designs that are more advanced than the Base-case, two-sided, single shell targets. A gain of 166 is needed at $10 \mathrm{MJ}$, which is more than a factor of two higher than the Base case target gain of about 80 at $10 \mathrm{MJ}$ (icr ion range $=0.20 \mathrm{~g} / \mathrm{cm}^{2}$, spot size $=0.25 \mathrm{~cm}$ )

2) For the paricular case examined, an jon range of $0.2 \mathrm{~g} / \mathrm{cm}^{2}$ and a spot size of $0.25 \mathrm{~cm}$ are the larget parameters that result in the lowest driver cost and COE. HIB expers say that these parameters are very reasonable.

3) Eliminating the lithium pumps and piping required to maintain the jet array in the HYLIFE chamber, and eliminating the intermediate heat transfer loop, would reduce the direct capital cost of the reactor by $23 \%$ to about $\$ 1 \mathrm{~B}$. Costs estimates for FLiBe heal transfer components need to be made befor: we can determine whether or not a FLiBe cooled seactor will be cheaper than HYLIFE.

4) The COE decreases with increasing unit size and with increasing aumbst of units per plant A single unit, $1 \mathrm{GW}_{\mathrm{e}}$ plant is not economically competitive with coal or cuclear. A dual unit, $2 \mathrm{GW}_{\mathrm{e}}$ plant has a $\operatorname{COE}$ of $6.2 \mathrm{c} / \mathrm{kW} \mathrm{h}$, which is about $24 \%$ higher than coal fired power plants.

4) For the HYI.IFE reactor, a chamber pulse rate of 1.5 to $2.0 \mathrm{~Hz}$ is adequate; increasing the pulse rate further does not reduce the COE significantly. 
5) To reduce the $\operatorname{COE}$ to less than $5 / \mathrm{kW}_{\mathrm{c}} \mathrm{h}$ requires a reactor cost of less than $\$ 1 \mathrm{~B}$. A chamber pulse rate of about $3 \mathrm{~Hz}$ is desirable based on driver and gain considerations and not on reactor scaling.

For HYLIFE-II to be significantly less expensive than HYLIFE, the FLiBE hardware (pumps, pipes, heat exchangers, etc.) has to be much less expensive, and/or the total flow rate must be much smaller, and/or the intermediate loop must be very cheap or eliminated. A chamber pulse rate of a few $\mathrm{Hz}$ should be adequate. Obviously, lower driver costs and higher ti-get gains would benefit HYLIFE as well as HYLIFE-II.

\section{REFERENCES}

1. T. J. McCarville, W. R. Meier, C. C. Carson, J. D. Gordon, and B. B. Glasgow, -SAFIRE - A Syssems Analysis Code For ICF Reactor Economics," Lawrence Livermore Laboratory report UCRL-15872, Vol. 1 (Jan. 1987).

2. B. B. Glasgow, and W R. Meier, "SAFIRE User's Manual," Lawrence Livermore Laboratory report UCRL-15872, Vol. 2 (Jan. 1987).

3. W. R. Meier, "A New Heary-Ion-Bearn Driver Model for the SAFIRE Code," Lawrence Livermore Laboratory report UCRL-15872, Vol. 2, Sup. 1 (March 1987).

4. W. R. Meier, "New Heavy-Ion-Beam Target Gain Curves for the SAFIRE Code," to be published as a UCRL, draft available on request. 
Table 1. System Design Parameters

Target

Type

Adr anced Concepts (Case 4 in Fig. 1)

Ion range, $\mathrm{g} / \mathrm{cm}^{2}$

$0.10,0.15,0.20$

Beam spot size, cm

$0.15,0.25,0.35$

\section{Reactor}

Type

Thermal efficiency, \%

HYLIFE, Generic

Chamber pulse rate, $\mathrm{Hz}$

41, 37

Net power per unit, GW.

$1-10$

$0.5,1.0,1.5$

Units per plant

$1-4$

Driver

Type

Ion mass, amu

Ion charge state

Ion energy, $\mathrm{GeV}$

Beam energy, $M J$

Driver pulse rate, $\mathrm{Hz}$

Efficiency
KIB Induction Linac, Single pulsed 130

$+3$

$4.73,6.20,7.45$

$\leq 10$

Varies

Varies 
Table 2. Capital cost and COE summary for a single-unit, $1 \mathrm{GW}_{\mathrm{c}}$ HYLIFE power plant.

ICF ECONOMIC EVALUATION FOR 1 UNIT POWER PLANT

$\begin{array}{cl}\text { ACCOUNT } & \text { ACCOUNT IITLE } \\ 20 & \text { LAND AND LAND RIGKTS } \\ 21 & \text { STRUCTURES AND IMPROVEMENTS } \\ 22 & \text { REACTOR PLANT EQUIPMENT } \\ 23 & \text { TURBINE PLANT EQUIPMENT } \\ 24 & \text { ELECTRIC PLANT EQUIPMENT } \\ 25 & \text { MISCELLANEOUS PLANT EQUIPMENT } \\ 26 & \text { MAIN HEAT REJECTION EQUIPMENT } \\ 27 & \text { DRIVER EQUIPMENT } \\ 28 & \text { TARGET FACTORY EQUIPMENT } \\ & \text { TOTAL DIRECT COST } \\ 91 & \text { CONSTRUCTION SERVICES } \\ 92 & \text { HOME OFFICE ENGINEERING AND SERVICES } \\ 95 & \text { FIELD OFFICE ENGINEERING AND SERVICES } \\ 94 & \text { OWNER S COST } \\ 95 & \text { PROJECT CONTINGENCY } \\ & \text { TOTAL OVERNIGHT COST }\end{array}$

96 ESCALATION DURIMO CONSTRUCTIOH

97 INTEREST DURING CONSTRUCTION

TOTAL CAPITAL COST

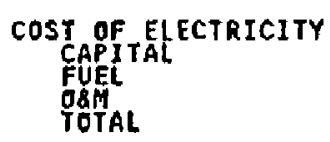

$\mathrm{Mn}$

5,0

282.2

602.9

226.6

91.7

59.9

36,5

1284.1

82.8

2671.8

534.4

400.8

267.2

187.0

406.1

4467.2

$\begin{array}{cc}\text { CURRENT } & \text { CONSTANT } \\ 1441.7 & 0.0 \\ 1876.3 & 417.3 \\ 7785.2 & 4884.6\end{array}$

20.51

27.79

6.60

0.01

2.78 
Table 3. Direct capital cost of HYLIFE's Reactor Plant Equipment (Account 22).

Tracking and alignment systems

30.4

First wall systems

Tritium extraction systems

25.8

Blarket and shield

60.2

Yeat transport system

$\underline{484.1}$

Total Reactor Plant Equipment Cost

602.9

Table 4. Direct capital cost of HYLIFE's Heat Transport System

Recirculating jet array system

147.0

Intermediate heat exchanger

40.2

Primary loop piping

Primary coolant cleanup plant

Primary coolant pumps and motors

40.0

Secondary loop piping

24.7

Stean generator

Secondary coolant pumps and motors

Secondary coolant cleamup plant

Steam separator

10.3

Water loop piping

Steam superheater 


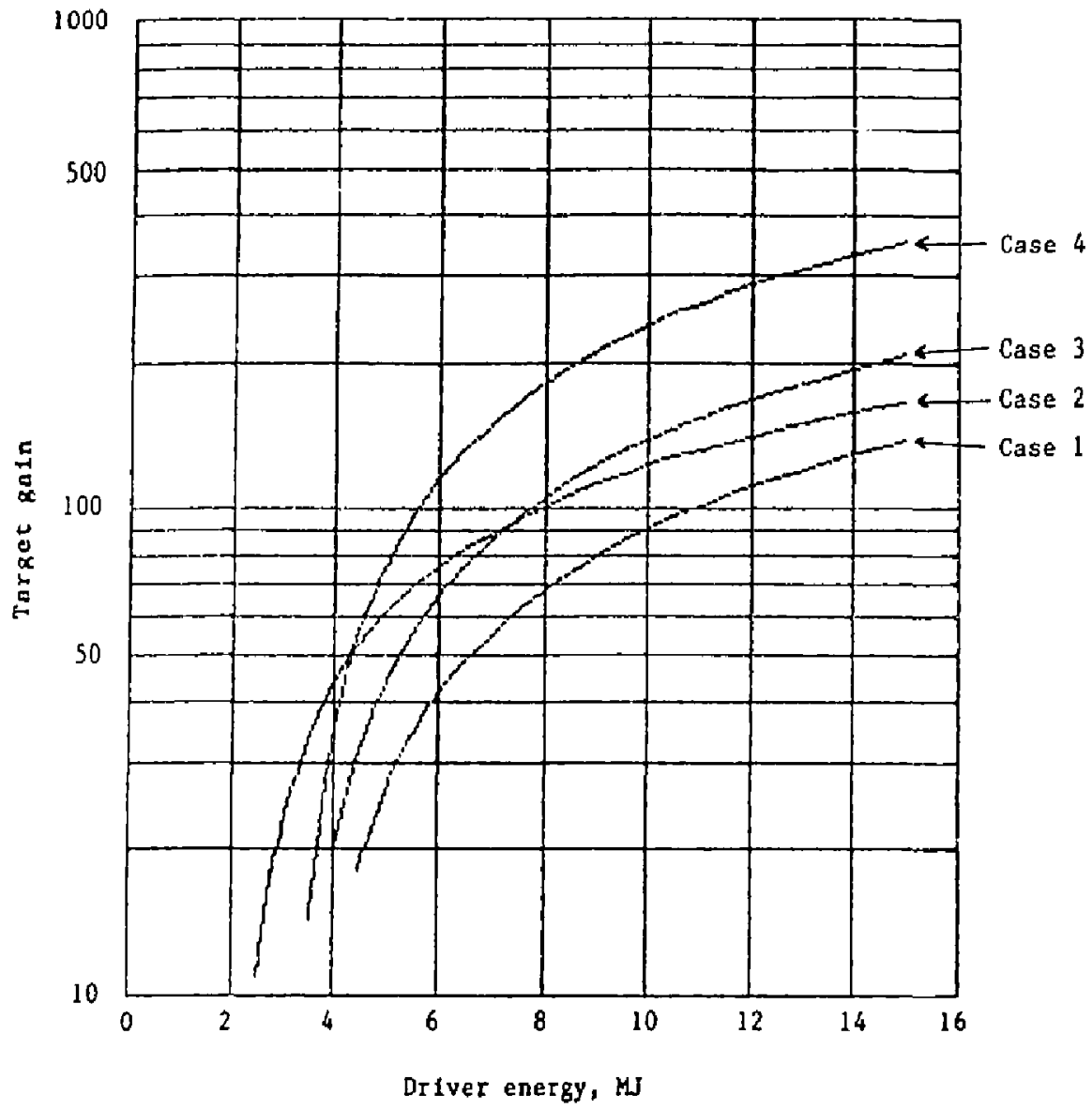

Figure 1. HIB target gain curves for an ion range of $0.20 \mathrm{~g} / \mathrm{cm}^{2}$ and a spot size of $0.25 \mathrm{~cm}$. The four cases are:

1. Base-cain, two-sided irradiation, single shell

2. Guess at single-sided irradiation

3. Polarized fuel, two-sided ілаdiation

4. Advanced concepts 
HYLIFE reactor

Chamber pulse rate $=1.5 \mathrm{~Hz}$

HIB driver

Single untt plant

Total net power $=1.0 \mathrm{GH}_{\mathrm{e}}$

Acivanced Concepts target

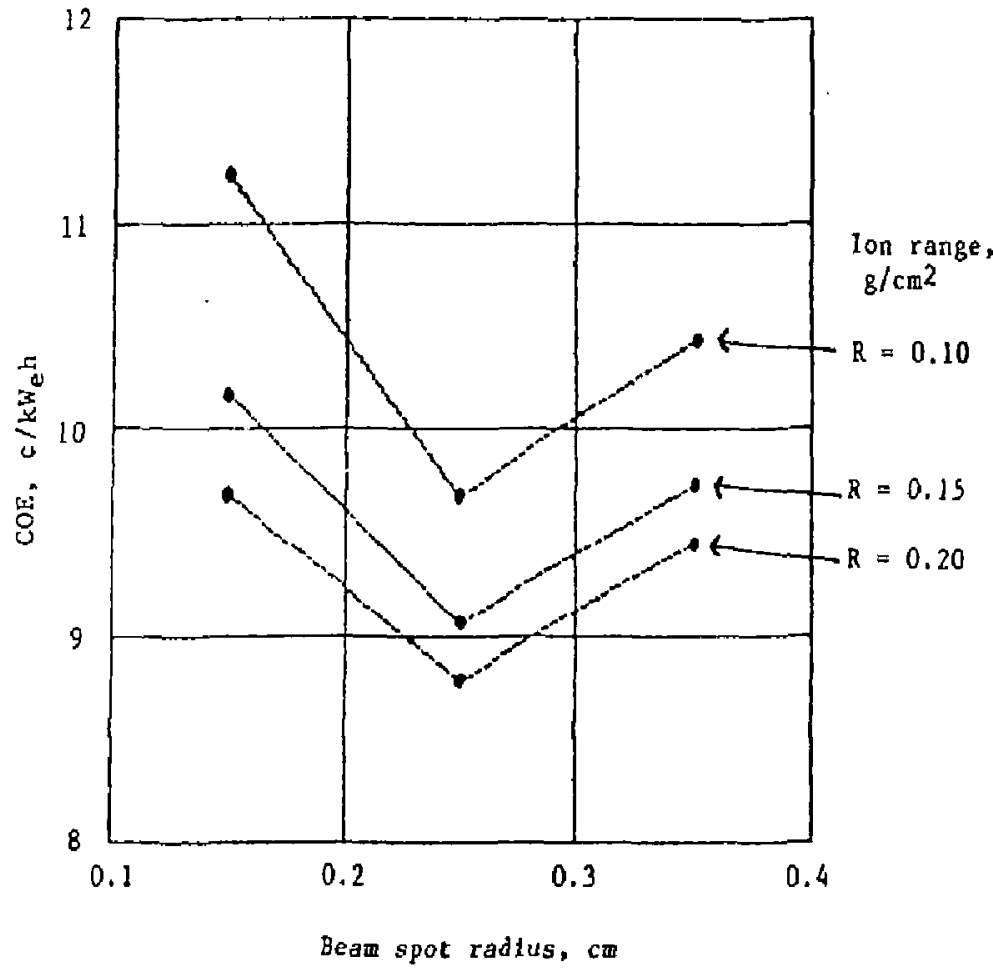

Figure 2. COE versus beam spot size for different ion ranges. A spot size of $0.25 \mathrm{~cm}$ and an ion range of $0.20 \mathrm{~g} / \mathrm{cm}^{2}$ produces the lowest COE for the cases examined. 


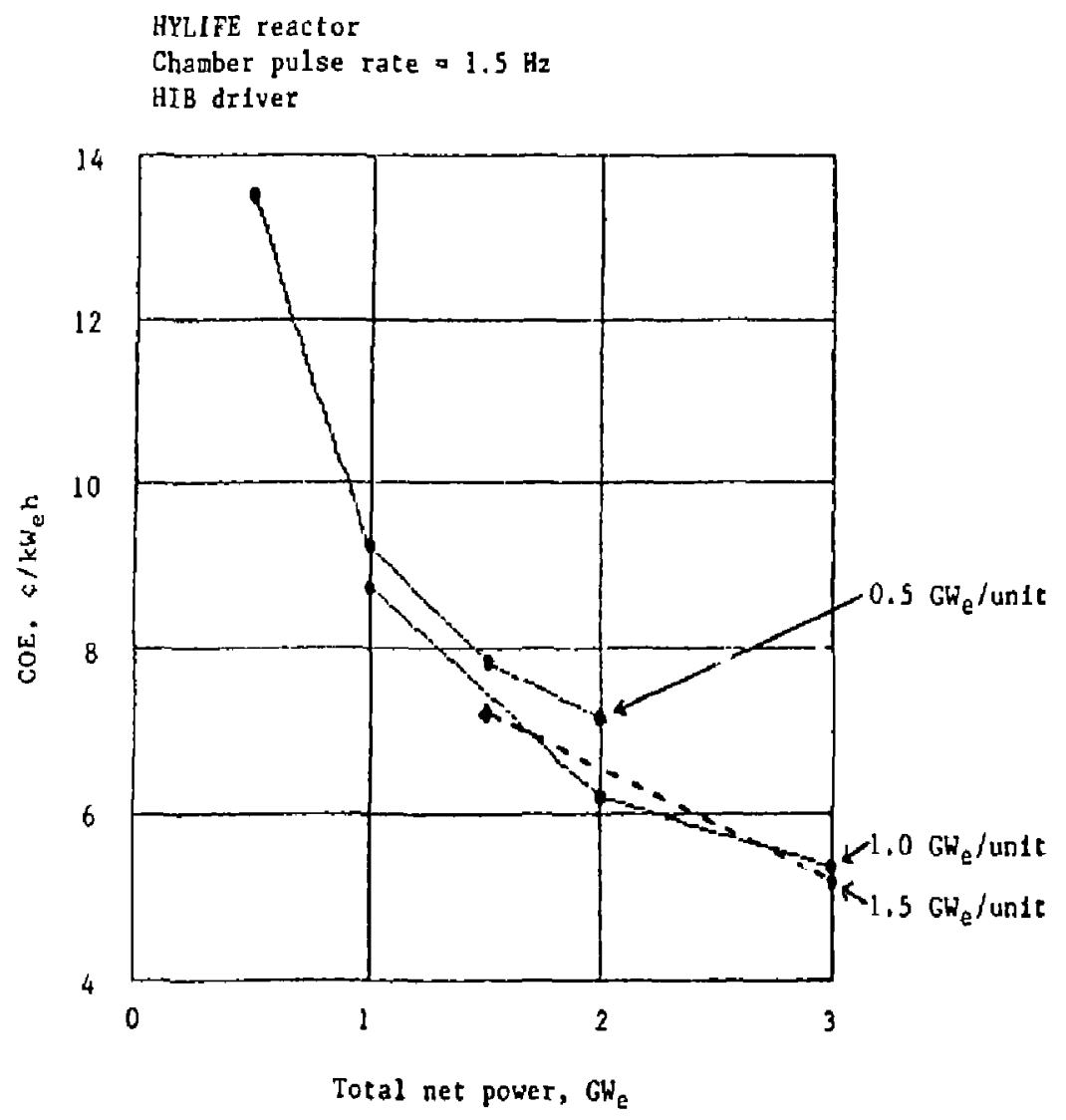

Figure 3. The COE versus total net electric power for power plants with a single driver and multiple HYLIFE teactor units of different sizes. The COE decreases with increasing unit size and with increasing total net power. 


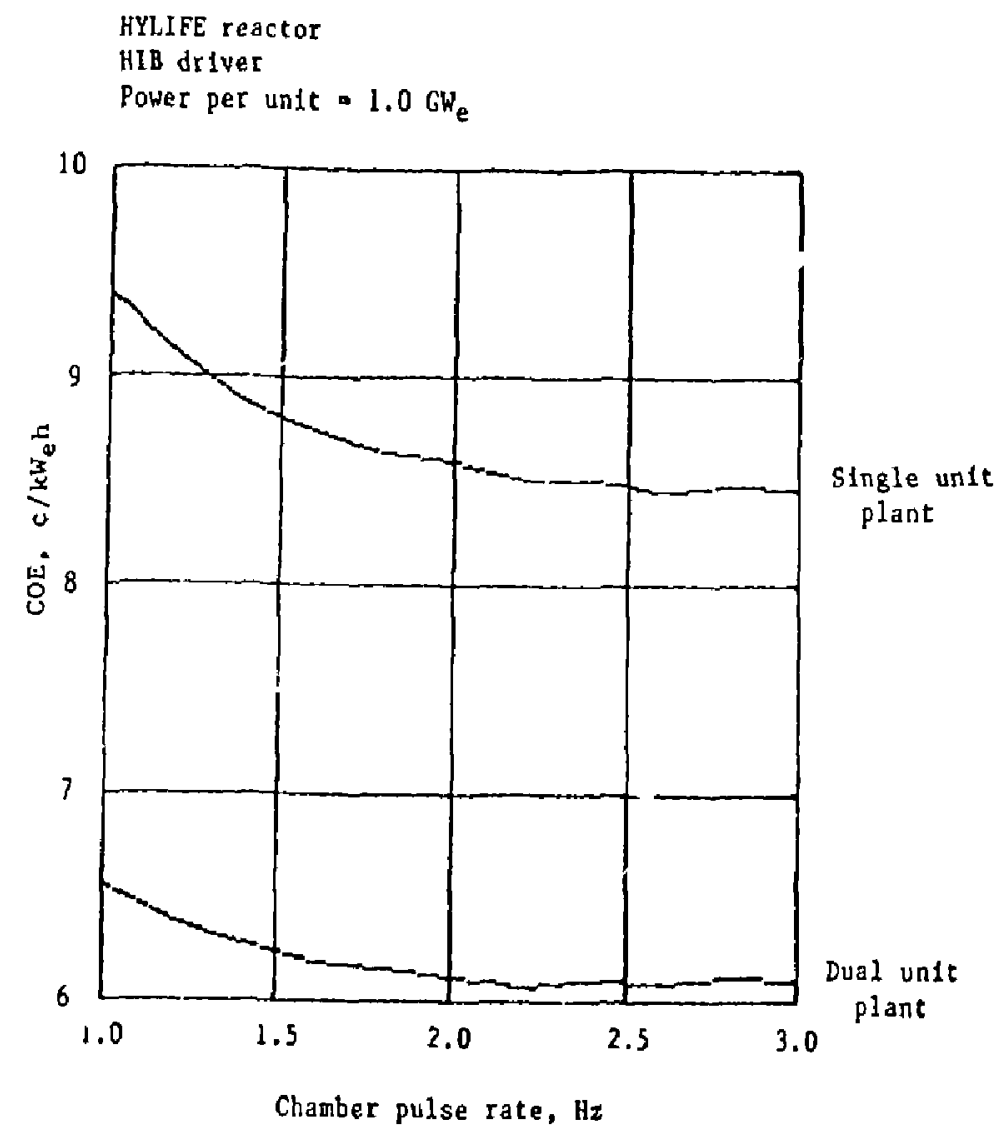

Figure 4. The COE versus HYLIFE chamber pulse rate for single and dual unit power plants. A chamber pulse rate of 1.5 to $2.0 \mathrm{~Hz}$ is desirahle. 
HIB driver

Single unit plant

Total net power $=1.0 \mathrm{GW}_{e}$

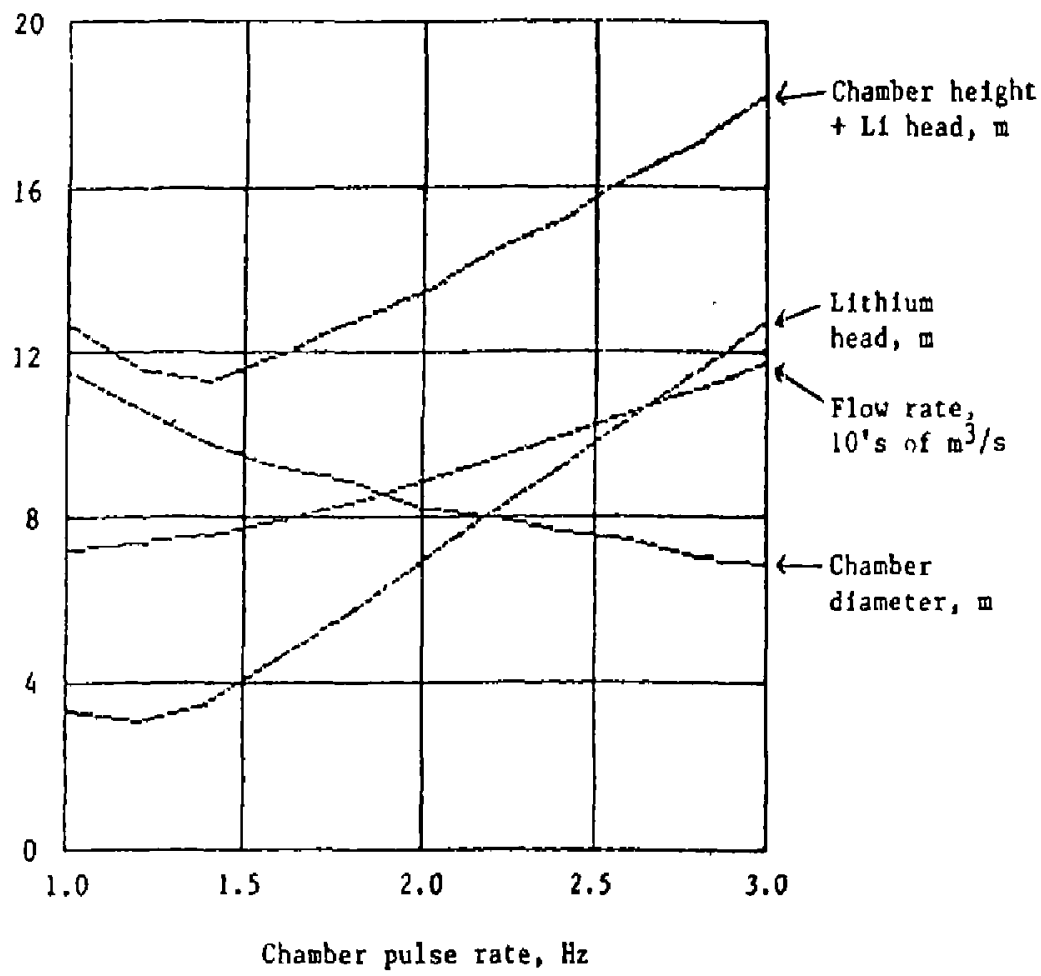

Figure 5. HYLLFE design parameters as a function of the chamber pulse ratc. Increasing the pulse rate increases the lithium flow rate and the chamber height. 


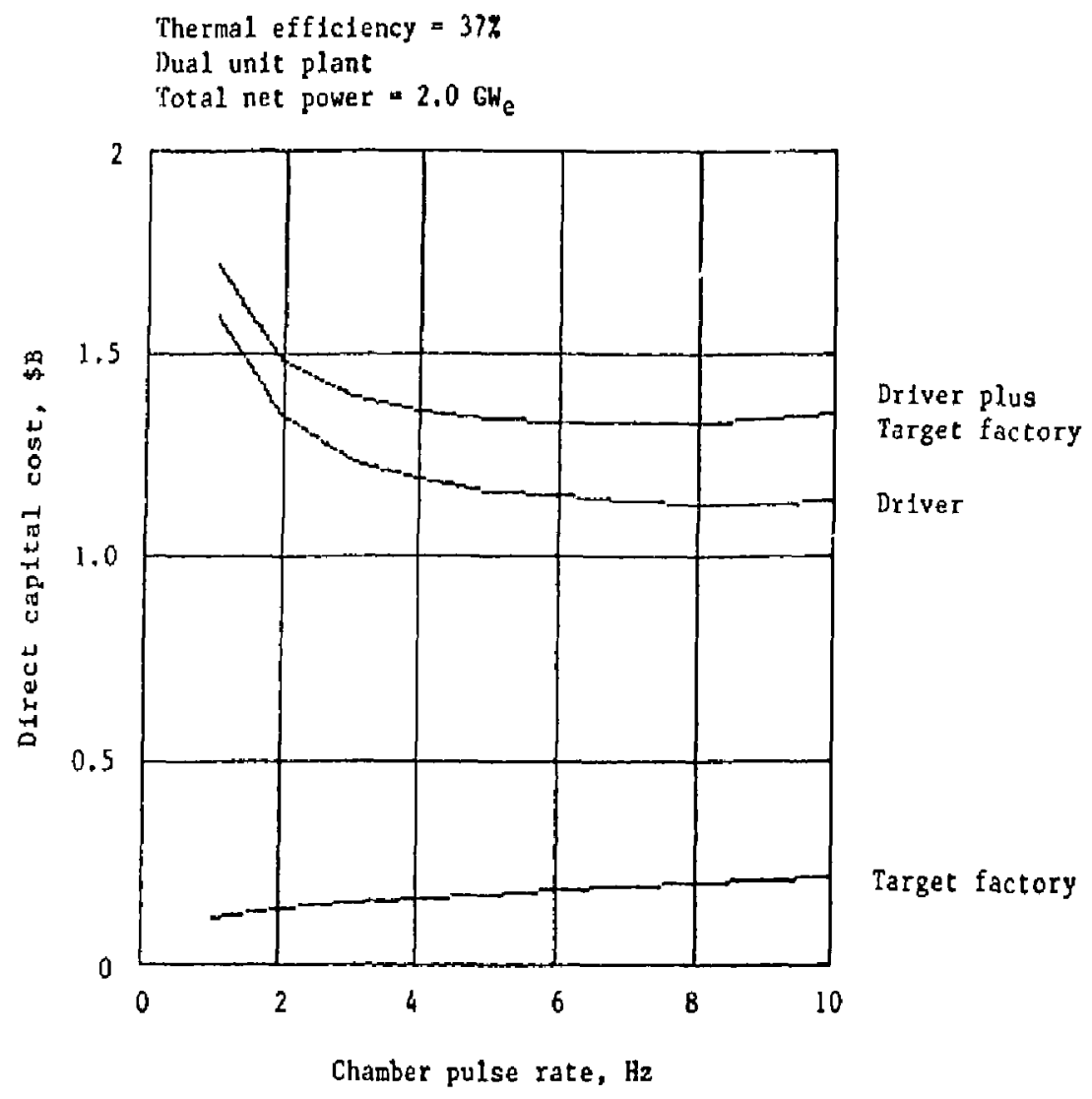

Figure 6. HIB driver and target factory direct capital cost as a function of the chamber pulse rate. The sum of these two costs decreases sharply between 1 and $3 \mathrm{~Hz}$ and has a shallow minimum at $6.8 \mathrm{~Hz}$. 
Thermal efficlency $=372$

HIB oriver

Dual unit plant

Total net power $=2.0 \mathrm{GWe}_{\mathrm{e}}$

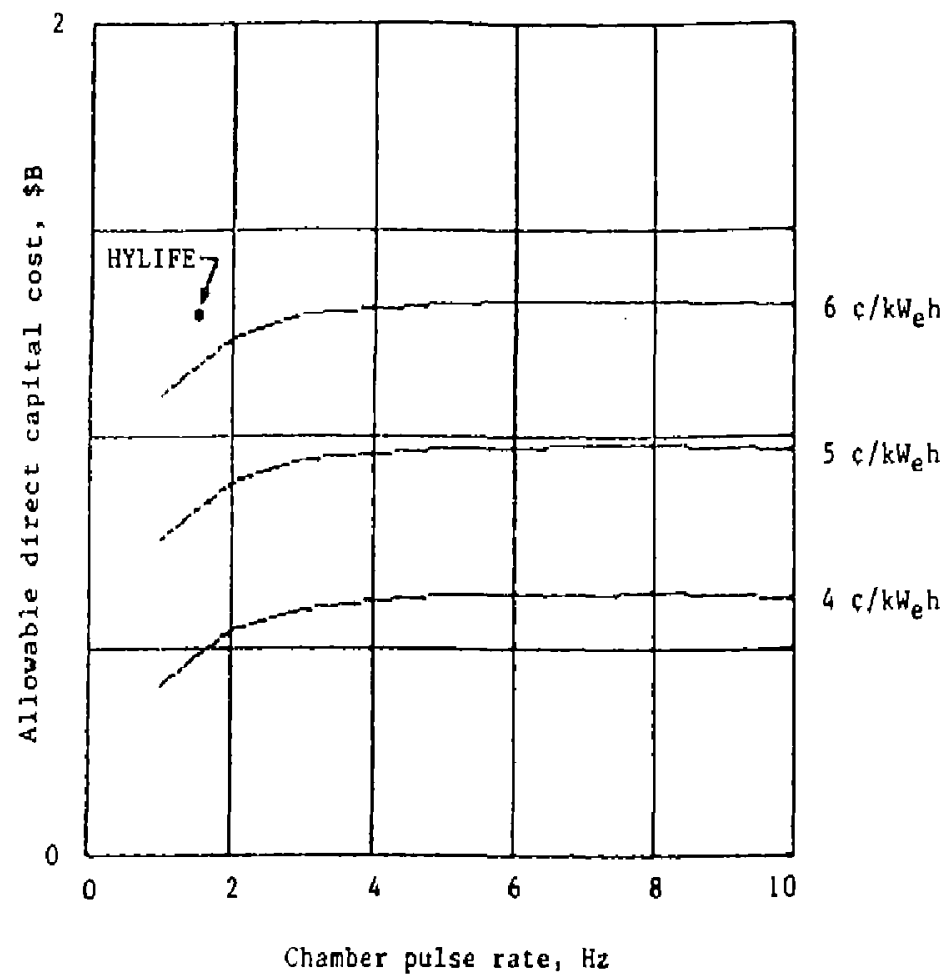

Figure 7. Allowable reactor direct capital cost (1st unit) versus chamber pulse rate for a fixed COE. The reactor cost must be less than $\$ 1 \mathrm{~B}$ to get a COE less than $5 \notin / \mathrm{kW}_{\mathrm{e}} \mathrm{h}$. 
Review of HYLIEE Fluio Dynamics

\author{
Wayne R. Meier \\ W. J. Schafer Associates, Inc.
}

June 23, 1988 
Jim Blink

Lew Glenn

Mike Hoffman

Jack Hovingh

Michael Monsler
LLNL

LLNL

UC Davis

LLNL

WJSA 
1) HYLIFE Report (UCRL-53559) summarizes the concept and contains an extensive annotated bibliography.

2) Laser Program Annual Reports 1977 - 1981 
- What has been done to date?

- What are key uncertainties?

- What needs to be done to resolve uncertainties? 


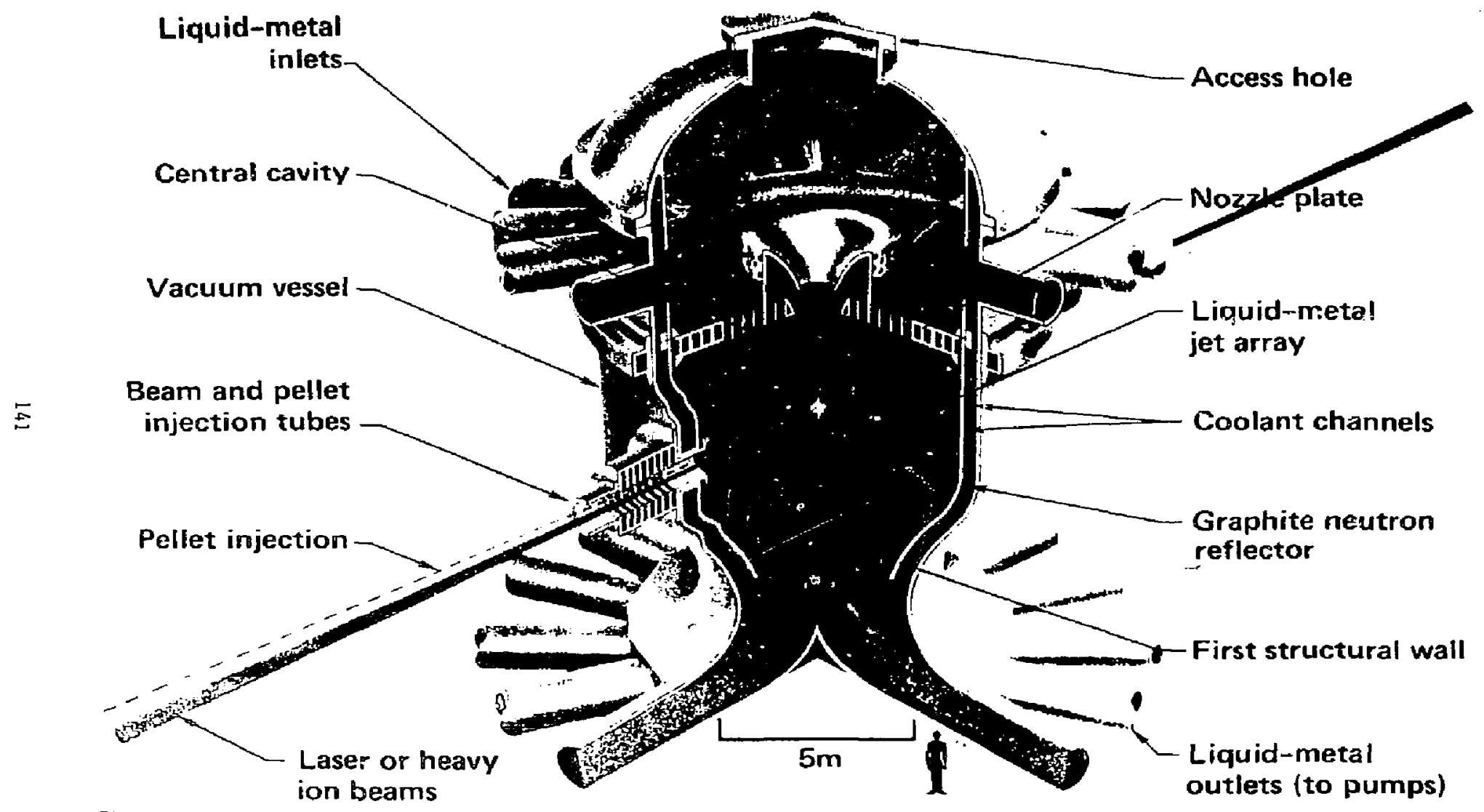

Figure 2. HYLIFE reaction chamber. The liquid lithium free falls through the nozzle plate into the vacuum chamber, forming 175 jets that protect the wall of the chamber from the damaging effects of the fusion energy pulses at its center. (Ref. 1 ) 


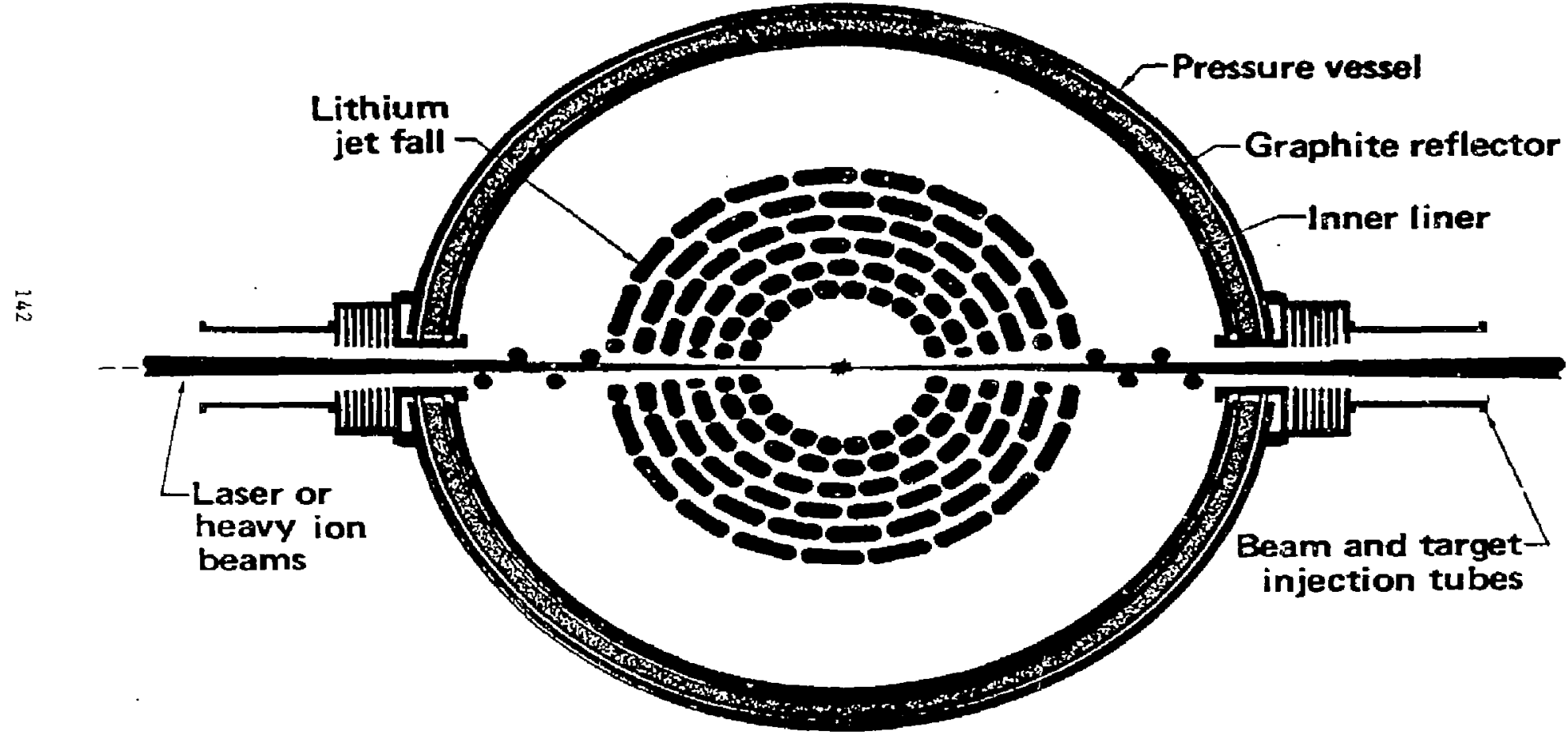




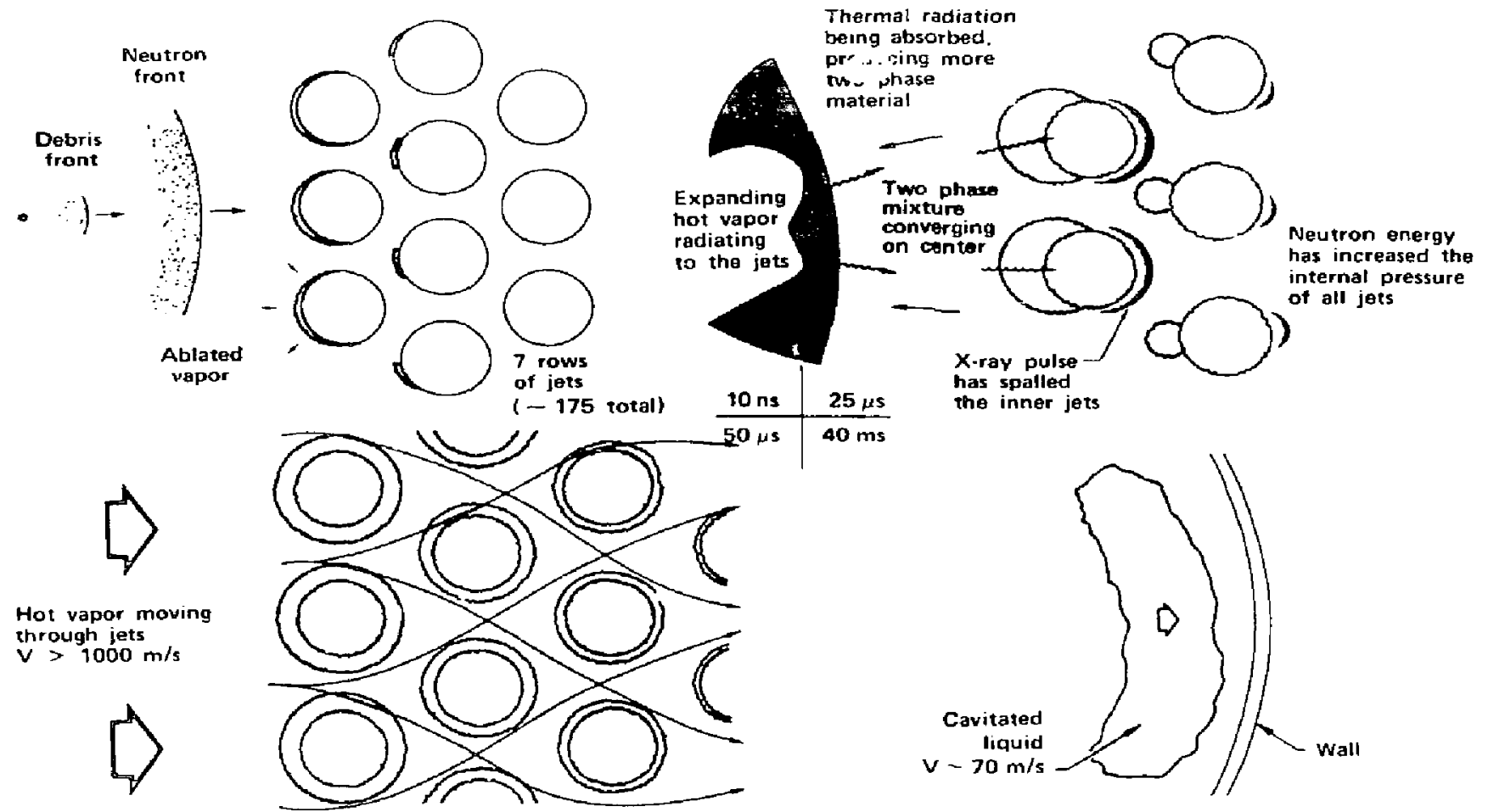



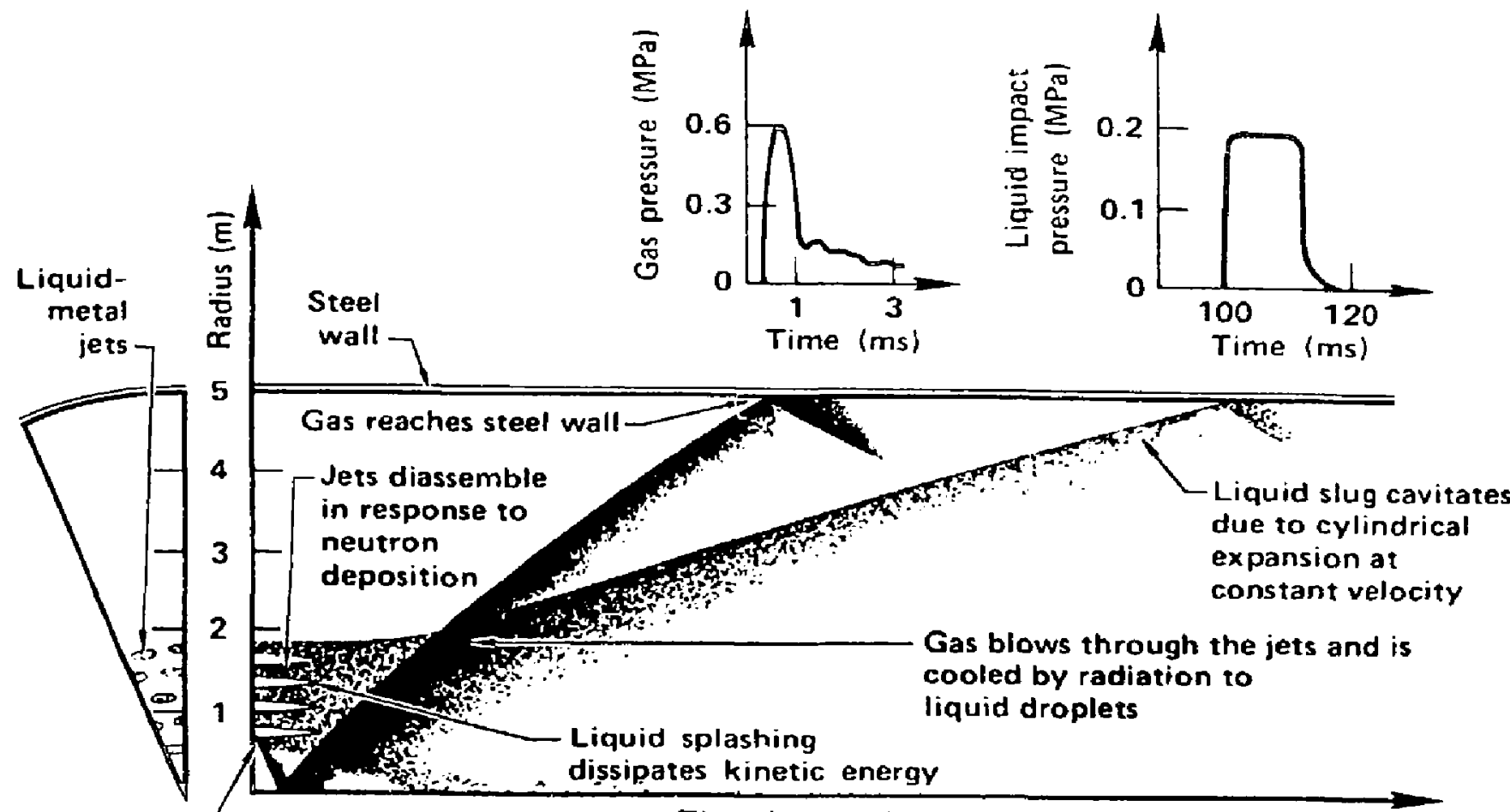

1

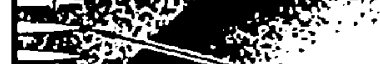

Fatiost

isting

Gas blows through the jets and is cooled by radiation to

liquid droplets

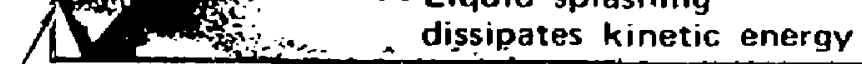

$\angle$ Ablation due to Time (nonuniform scale)

$x$ rays \& debris

Figure 8. Hydrodynamic response to fusion-energy deposition in HYLIFE (I800-MJ yield). The peak gas pressure of $0.6 \mathrm{MPa}$ produces a $38-\mathrm{MPa}$ stress in the $40-\mathrm{mm}$-thick $\mathrm{FSW}$, and later the liquid impact pressure of $0.2 \mathrm{MPa}$ produces a 46-MPa stress in the FSW. (Ref. 1) 


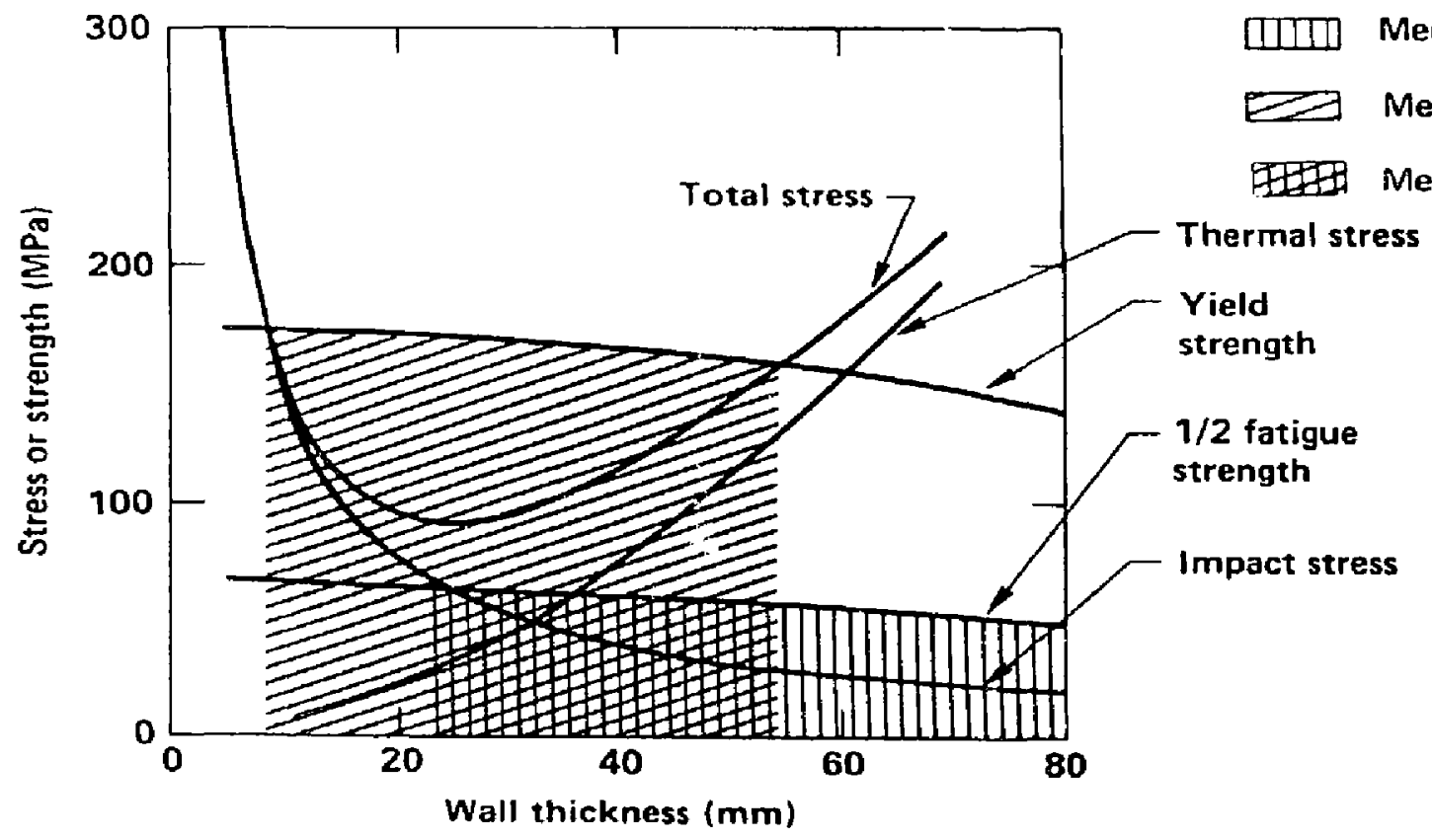

Figure 11. Pulsed and steady stresses vs wall thickness and the limiting levels under the ASME code. Wall thicknesses in the 25- to $55-\mathrm{mm}$ range satisfy both ASME criteria: total stress less than yield strength and pulsed stress less than one-half the fatigue strength. This figure is based on an early HYLIFE design with a $2700-M J$ yield. The jet array in this early design has a $0.75-m$ inner radius, is $1.0 \mathrm{~m}$ thick, and has a midplane packing fraction of $50 \%$. ( $R_{\mathrm{e}} .1$ ) 
ASME DESIGN POINT FOR A $1.0 \mathrm{~m}$ EFFECTIVE ARRAY THICKNESS, $5.0 \mathrm{~m}$ WALL RADIUS, $1 \mathrm{~Hz}-2700 \mathrm{MJ}$ FUSION

PULSES AND 30 YEAR LIFETIME

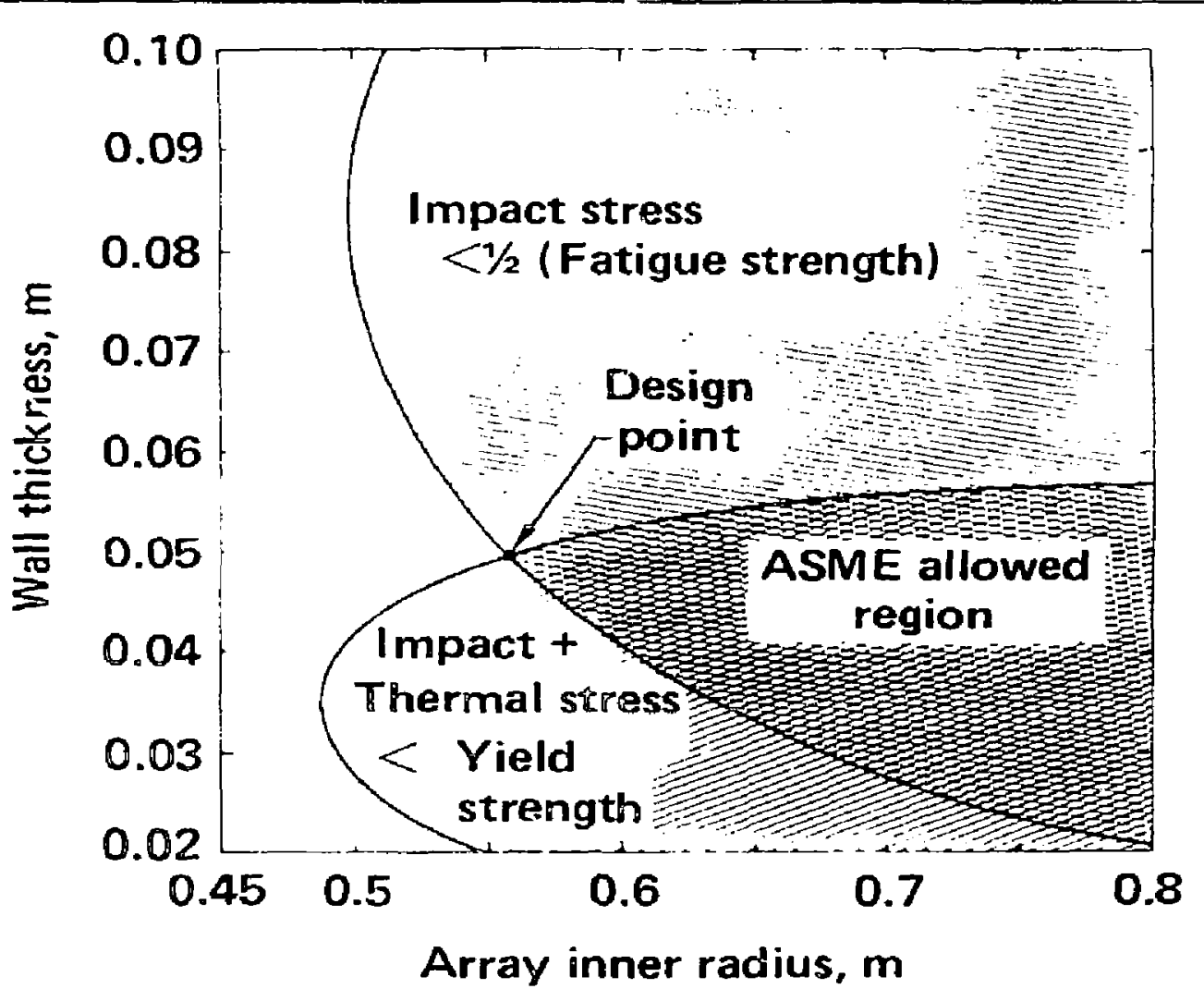


LIVIW AND WALL DINIENSIONS THAT MEET BOTH THE FATIGUE AND YIELD ASME DESIGN CRITERIA

$5 \mathrm{~m}$ Wall Radius, $2700 \mathrm{MJ}-1 \mathrm{~Hz}$ Pulses, 50\% Packing Fraction, $773^{\circ} \mathrm{K} \mathrm{Li}$

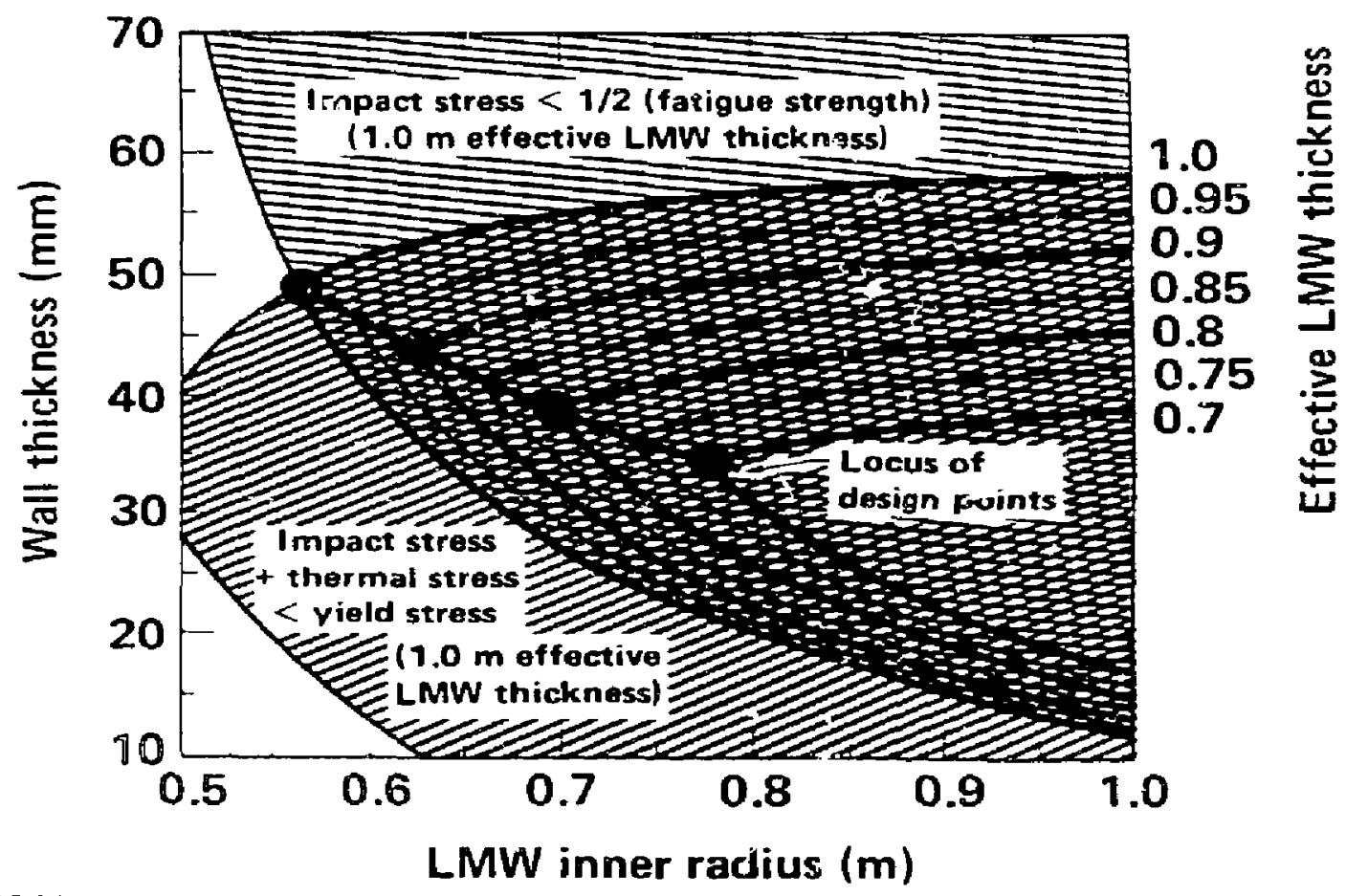


DESIGN POINT NORMALIZED ARRAY FLOW RATE FOR CONSTANT INJECTION VELOCITY

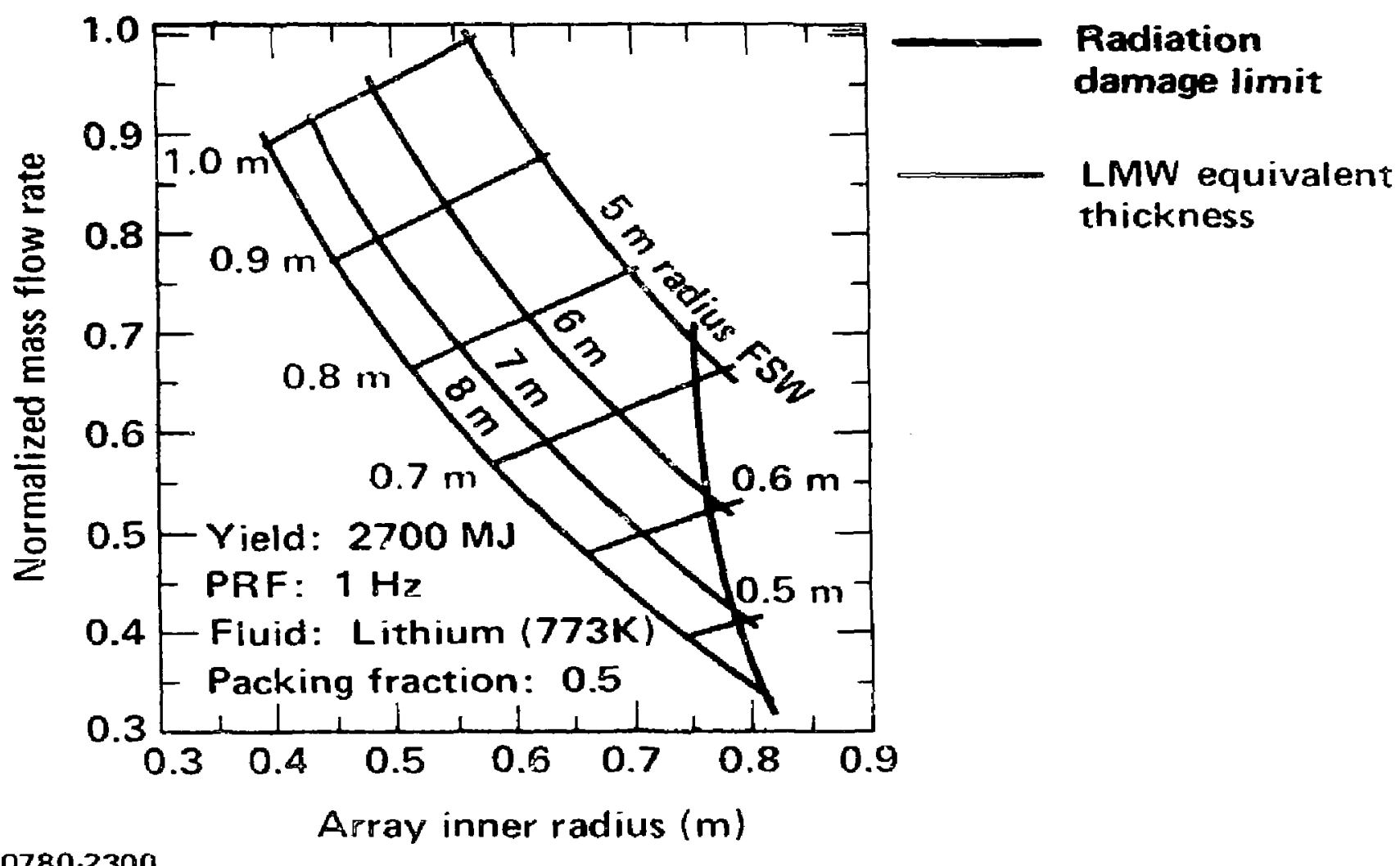


1) Establishing the desired LM jet array before the fusion pulse

2) Response of the LM jet array to the fusion energy deposition

3) Recondensation and chamber clearing prior to next pulse 
Issue: Can a stable configuration of LM jets be established to provide a fairly uniform blanket around the fusion pulse?

Status: Theory and experiments with water at UC Davis (Mike Hoffman and students) concluded that we can establish and maintain the array of jets within the chamber. The LM jets will not break-up before reaching the bottom of the chamber.

Needs: No need for more work in this area at this time. 
Issue: The short range x-rays and debris with valporize the innermost layer of lithium and cause spall off the back of the exposed jets. What are the implications?

Status: We can calculate the mass and temperature of vaporized lithium with fairly high confidence. The spall off the back of the inner jets is not a significant problem because it merely impacts the next row of jets. The hot vapor expands out through the jets and pressurizes the chamber, but the resulting stresses appear to be acceptable. These processes have been modeled in significant detail by $L$. Glenn.

Needs: Check with Gienn for his recommendations. 
Issues: Isochoric heating of jets causes infernal pressurization, and the jets to blow apart nearly axi-symmetrically. As adjacent jets impact each other, kinetic energy is converted to thermal energy. The large surface area of LM created in the process is needed to condense the hot LM vapor prior to the next shot. How do the jets explode? What is the drop size distribution? Do liquid drops fly up to the top of the chamber and take a long time to clear beam paths?

Status: Theoretical modeling of the jet break-up predicts drop sizes on the order of $1-2 \mathrm{~mm}$ in radius leading to a couple orders of magnitude increase in surface area available for cooling and recondensation.

Needs: Experiments on the break-up of the LM jets. Proposed methods all have draw backs (see Blink UCRL-53604). New theoretical work may give a different answer but will probably not dimension uncertainty. 
Issue: The hot vapor blows through the exploding jets causing some radial acceleration. Also the inner jets explode more violently, and there is a net oufward push which compacts the LM into an annulus moving outward. The annulus of fluid cavitates as it diverges at constant velocity. Does the LM hit the wall as a uniform rain $\mathbf{O}^{\cdots}$ as a series of relatively large slugs of fluid? What are the implications?

Status: Analytical models of the processes, including calculations of stresses in the chamber wall, have been developed and used.

Needs: More work on how the fluid toars itself apart as it expands. What are the resulting wall loading for a series of slugs versus a more uniform shower of LM? 
Issue: One of the limits on the pulse repetition rate for the HYLIFE chamber may be the time require to recondense the vaporized lithium and/or the time required for the lithium drops caused by the exploding jets to clear out of the beam paths.

Status: Recondensation times have been estimated to range from $\leq \mathbf{5 0}$ ms to about $500 \mathrm{~ms}$ (no jet break-up). The recondensation time is dominated by the time required for the hot vapor to cool. It is assumed that since the fluid initially has a downward velocity of $9.5 \mathrm{~m} / \mathrm{s}$, and since the neutron heating only adds radial velccity, the net flow of drops will still be primarily downward and thus easily clear below the beam line before the next pulse.

Needs: Experimental verification of the above processes. 
Preliminary Neutronics Considerations for HYLIFE-II

\author{
Wayne R. Meier \\ W. J. Schafer Associates, Inc.
}

August 23, 1988 
There are two primary considerations:

$\bar{s}$ 1) Flibe thickness needed for equivalent radiation damage protection

2) Flibe thickness needed for adequate tritium breeding 


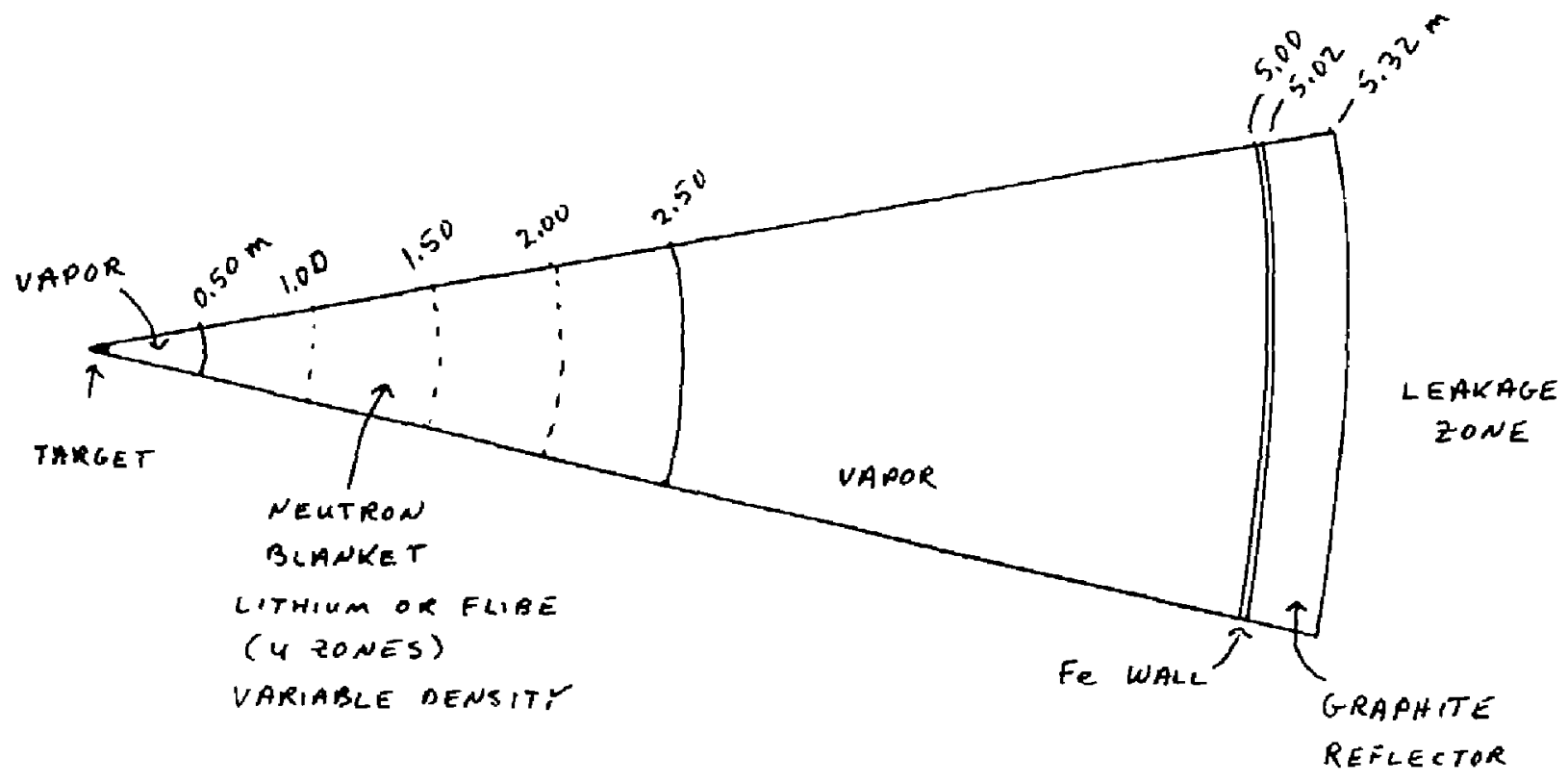


Comparison of spectra of neutrons incident on first wall (no graphite reflector)

Veutron flux incident on chamber wall

Neutrons/(sqommeV) per DT reaction

Na11 radius $=5 \mathrm{~m}$

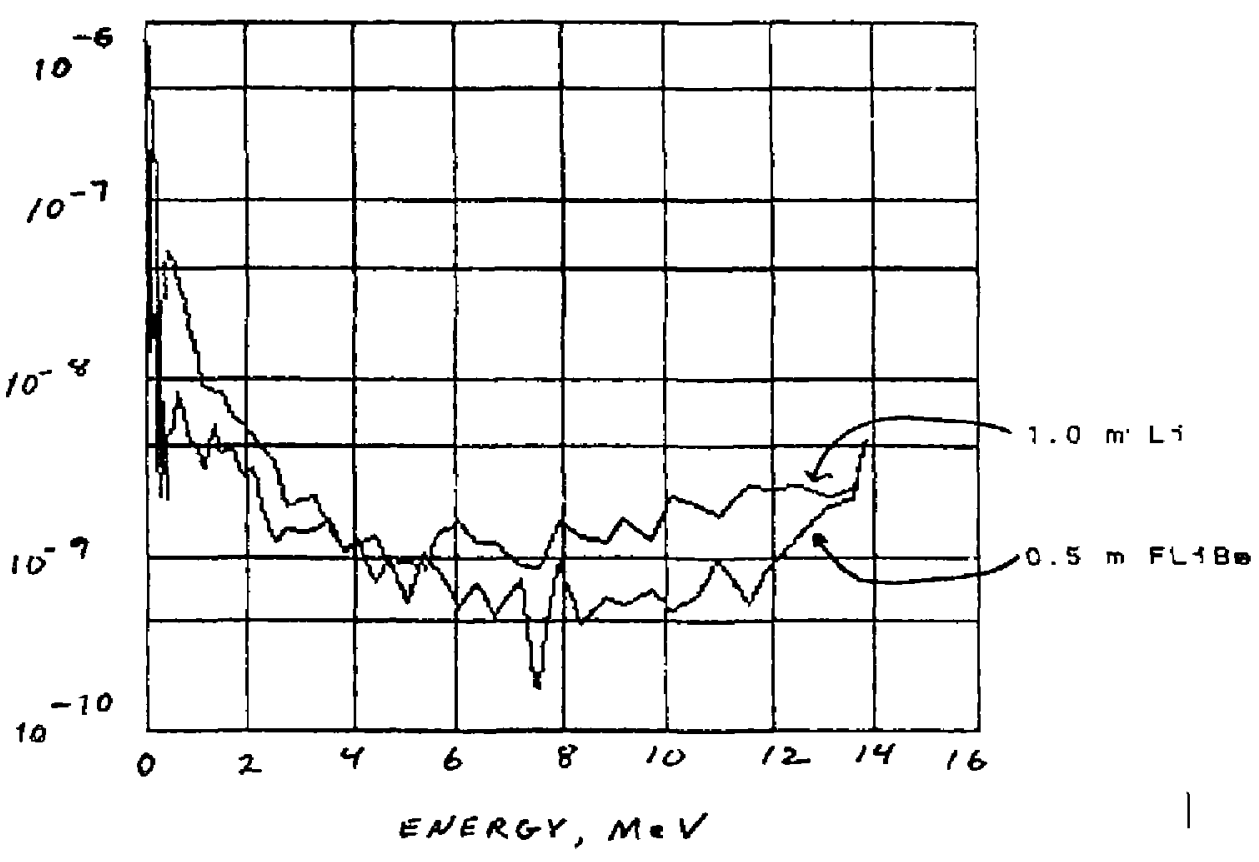


About $80 \%$ of the neutron passing through $100 \mathrm{~cm}$ of $\mathrm{Li}$ or $50 \mathrm{~cm}$ of Flibe have energies below $1 \mathrm{MeV}$

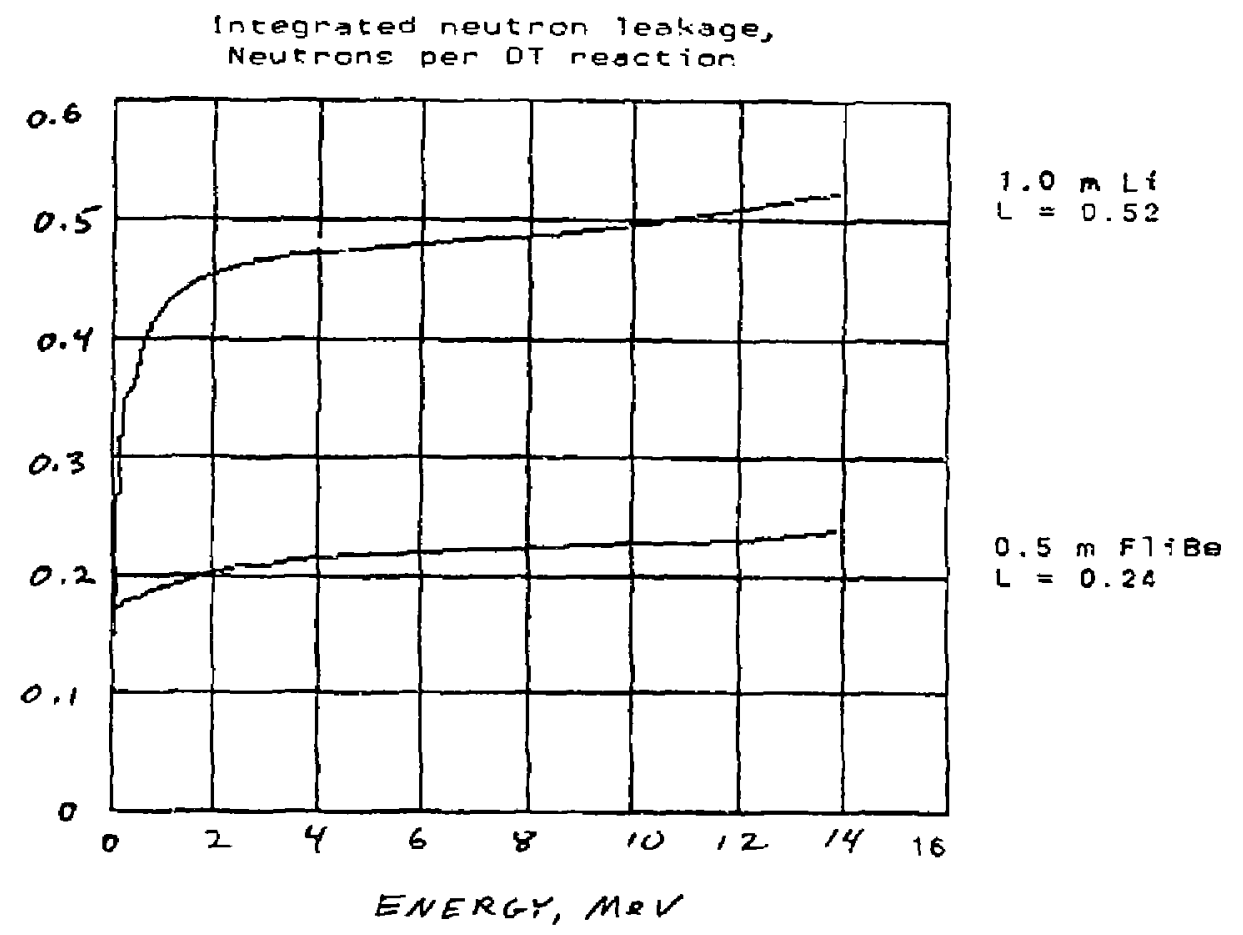




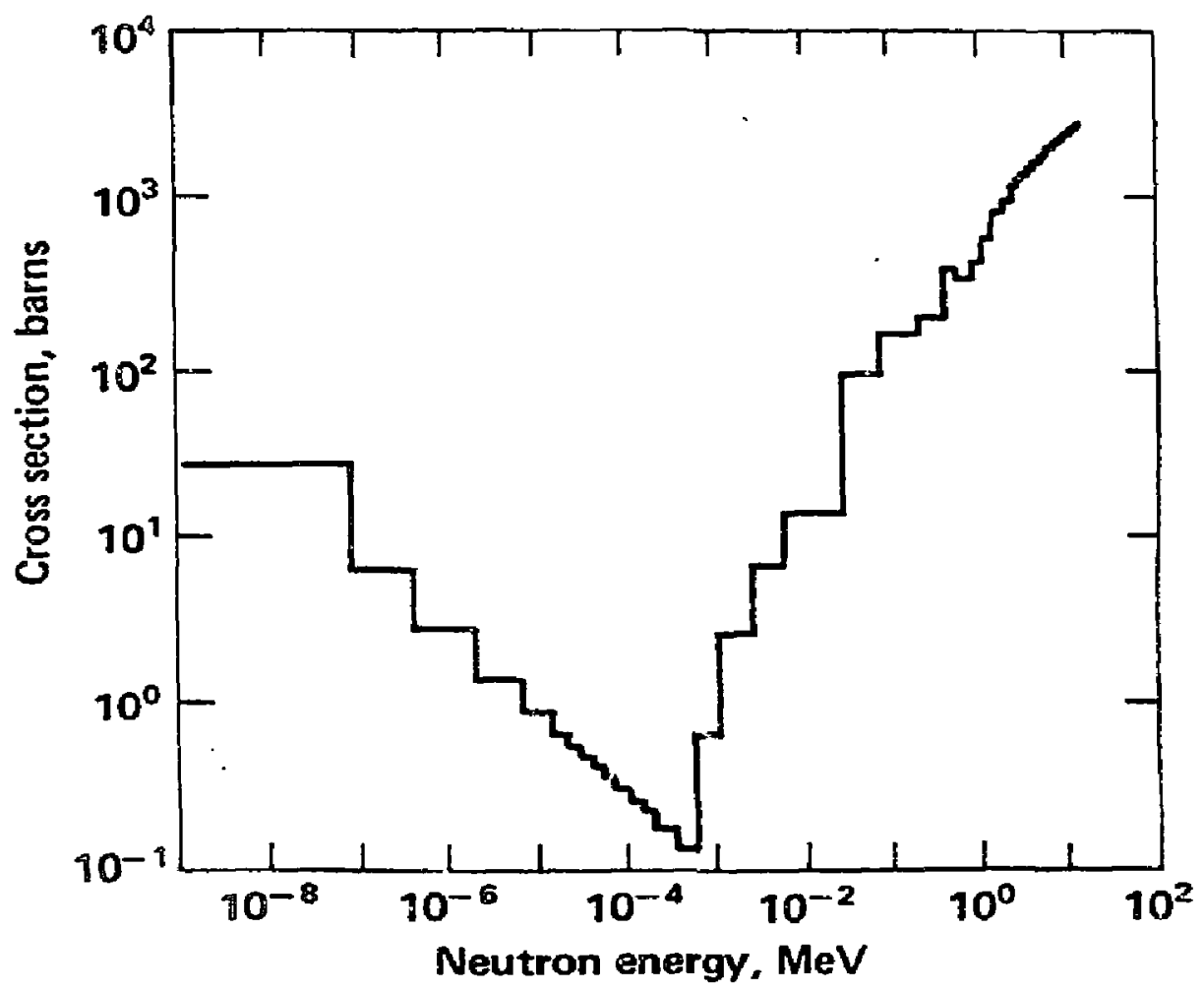


$31 \mathrm{~cm}$ of Flibe or $78 \mathrm{~cm}$ of ! ithium is needed to give a wall lifetime of 30 years

Fusion power $=2700 \mathrm{MW}$ Wall radius $=5.0 \mathrm{~m}$

Capacity factor $=70 \%$

$\Xi \quad$ Lifetime $=21 \mathrm{fpy}$

Dpa limit $=200 \mathrm{dpa}$

Limiting rate $=9.5 \mathrm{dpa} / \mathrm{fpy}$
Opa/fpy vs protective thickness of FlfBe

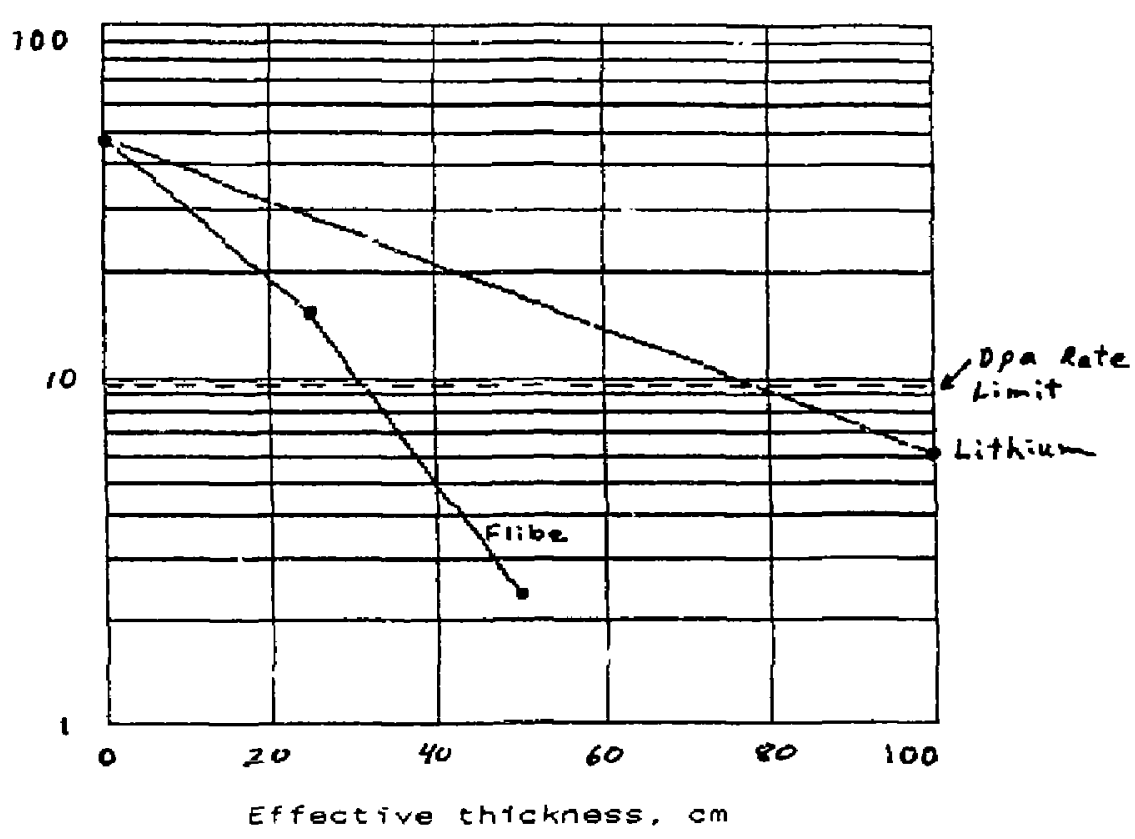




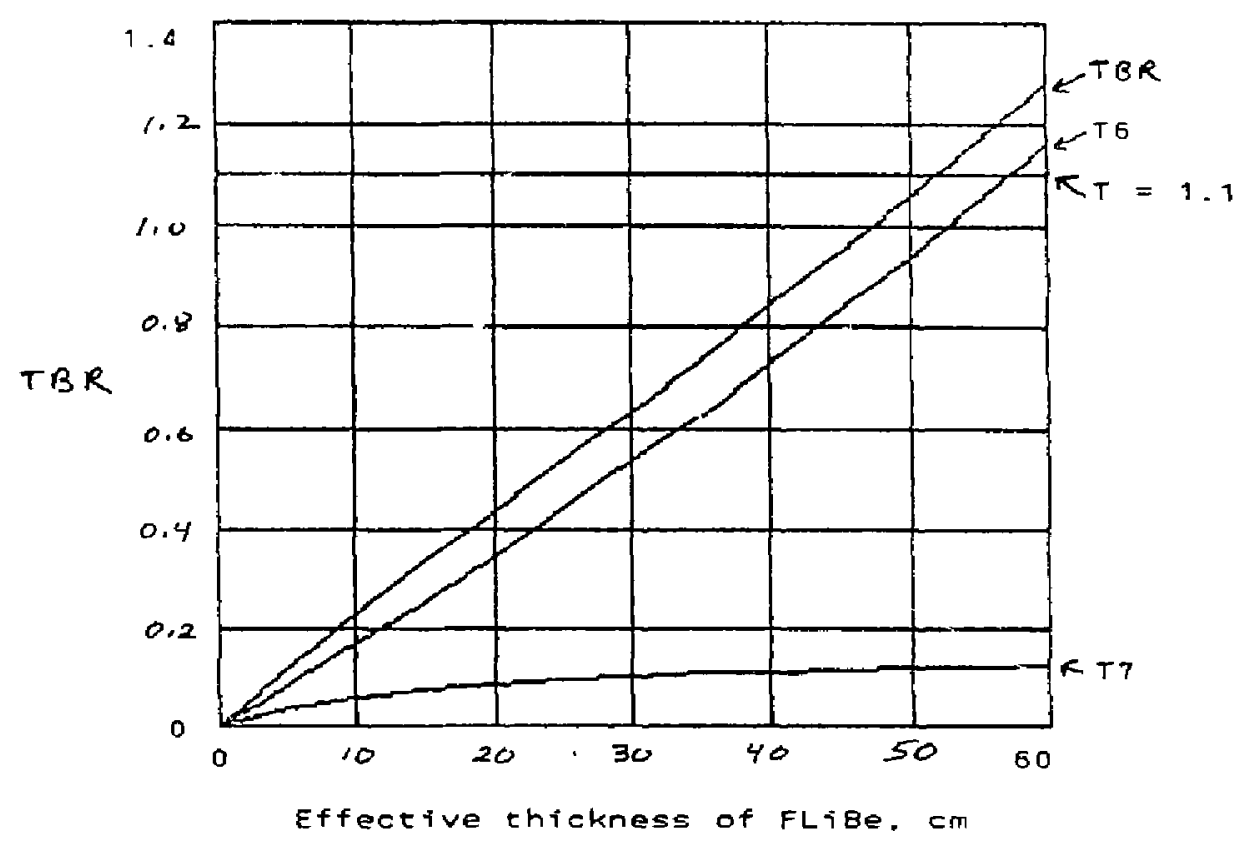


About $50 \mathrm{~cm}$ of Flibe is needed for an adequate tritium breeding ratio

$\begin{array}{cccc}\text { Zone } & \text { T6 } & \text { T7 } & \text { TBR } \\ 3 & 0.191 & 0.066 & 0.257 \\ 4 & 0.307 & 0.033 & 0.340 \\ 5 & 0.264 & 0.014 & 0.278 \\ 6 & \underline{0.176} & \underline{0.005} & \underline{0.181} \\ \text { TOTAL } & 0.938 & 0.118 & 1.056\end{array}$


1) Add Flibe coolant to graphite region

- reduced neutron leakage (0.092)

- reduced capture in $\mathrm{Fe}(0.079)$ and graphite (0.006)

- $\quad$ total potential increase in TBR $=0.177$

2) 2-D calculation should increase TBR

- longer average line-of-sight through Flibe blanket - increase will not exceed the previous 0.177

3) Including beam ports would reduce the TBR by 1 to 4 times the solid angle fraction of the ports 
Inner radius fixed

$0.5 \mathrm{~m}$

Packing fraction fixed

$50 \%$

Volume flow rate proportional to flow area

Mass flow rate proportional to density times flow area

Thickness, $m$ Flow area, $\mathrm{m}^{2}$ Density*area, $\mathrm{kg} / \mathrm{m}$

Lithium

Flibe

Flibe
0.78

0.31

0.50
12.55

3.16

6.28
6085

6374

12692 
- About $50 \mathrm{~cm}$ of flibe (equivalent full density thickness) will be needed to get an adequate tritium breeding ratio if all breeding is done in inner blanket

- About $30 \mathrm{~cm}$ of Flibe is needed to reduce the dpa rate to the point where a 5 -m-radius steel wall will last about 30 years

- It may be possible to get a TBR > 1 with a $30-40 \mathrm{~cm}$ thick blanket if Flibe is added to the graphite reflector region and reactor is modeled in cylindrical geometry.

- For the same radiation damage protection, the Flibe mass flow rate is about the same as with lithium while the volume flow rate is about a factor of 4 less. 


\section{HYFLIER NEUTRONICS UPDATE}

Sept. 6, 1988

\section{QUESTION}

What is the effect of adding FliBe coolant to the graphite reflector zone?

\section{MODEL}

Same as previously reported with following changes:

Inner blanket: FLiBe, $40 \mathrm{~cm}$ effective thickness

Reflector zone: 80 vol\% graphite, 20 vol\% FliBe

\section{RESLLTS}

Tritium breeding ratio:

T6

T7

0.055

Inner blanket

$\begin{array}{ll}0.125 & 0.055 \\ 0.217 & 0.033 \\ 0.228 & 0.018 \\ 0.191 & 0.009\end{array}$

Subtotal

Reflector

TBR
0.761

0.114

0.239

1.000

0.114

1.114

Dpa rate $=5.2 \mathrm{dpa} / \mathrm{fpy}$

(Recall $9.5 \mathrm{dpa} / \mathrm{fpy}$ was used as limit for 21 fpy of operation) 